\title{
Gelegentliche Gedanken über Universitäten in deutschem Sinn
}

Nebst einem Anhang über eine neu zu errichtende

\section{Vorrede}

Nur ein kleines Vorwort für die kleine Schrift. Schon durch die Art, wie sie sich bezeichnet, will sie gern diejenigen abweisen, welche hier etwa aus irgendeinem Mißverstand eine wissenschaftliche erschöpfende Behandlung des Gegenstandes suchen möchten. Es wäre falsche Bescheidenheit, wenn, was so gemeint ist, sich nur für etwas Gelegentliches ausgeben wollte; wie es Anmaßung wäre und leere Prahlerei, wenn, was nur gelegentlich entstanden ist und nur so wirken soll, sich wissenschaftlich gebärden wollte. Die Sache verträgt allerdings eine strenge und gründliche Behandlung; das wissenschaftliche Feld, wohin sie gehört, mag auch dem Verfasser nicht ganz fremd sein, und er hofft, daß die hier vorgetragenen Gedanken selbst größtenteils auch dort eine Stelle würden finden müssen. Nur hier macht er gar nicht Anspruch auf wissenschaftliche Reife oder strenge Darstellung. Er trägt seine Ansicht ohne diesen Grad der Vollendung vor, gelegentlich und soviel möglich leicht hingeworfen als ein verständliches Wort, zur Beherzigung für eine Zeit, welche während der Zerstörung so vieles Alten auch so manche neue Keime entwickelt.

Wer bei Pflanzung oder Erneuerung wissenschaftlicher Anstalten mitzuwirken hat, kann sich doch nicht genug vorsehn, ob er auch den Gegenstand, über den er zu ratschlagen hat, und seine einzelnen Teile in ihrer wahren Beziehung aufgefaßt habe. Schon seit langer Zeit werden die entgegengesetztesten Ansichten über diese 
Sache aufgestellt. Jede enthält unstreitig etwas Wahres und ist beherzigungswert; aber wenn es doch nur eine Seite ist, die sie nach Neigung oder nach Umständen heraushebt, so muß doch die Vorstellung des Ganzen, die sich bloß hieraus bildet, unsicher, störrig und verschroben ausfallen; denn einzelne Beziehungen können nie das Maß der Sache selbst sein, ja auch ihr eignes Maß nicht in sich haben. Und leider, wie schwer ist es nicht zu vermeiden, daß Neigung, daß besondere Verhältnisse, daß oft sogar ein fremdartiges Bedürfnis nicht Einfluß erhalte auf die Überlegungen derer, die eben zu handeln haben!

Drum soll auch derjenige nicht unwillkommen seine Stimme vernehmen lassen, der Muße hat, sich vor dem Gegenstand niederzulassen, und ihn, wie er sich seit langer Zeit verschiedentlich unter uns gestaltet hat, von allen Seiten zu betrachten. Denn auch, wo Neues gebaut werden soll, ist es von der größten Wichtigkeit $\mathrm{zu}$ wissen, was von dem Bisherigen wesentlich oder zufällig, und was vielleicht gar in Irrtum und Mißverständnis gegründet gewesen, und also verwerflich ist, wie sich dessen in allen Zweigen des menschlichen Tuns und Wirkens immer finden muß.

Eine solche Betrachtung eignet sich am meisten zur öffentlichsten Mitteilung, weil sie nicht nur für die wenigen angestellt wird, welche auf diesem Gebiet schaffen, umbilden, regieren sollen, sondern für alle, die einen lebhaften Anteil an der Sache nehmen. Diese alle daher möchte sich der Verfasser einladen, ihm bei seiner Beschauung zuzuschauen, und dadurch aufgeregt zu werden, den Gegenstand, es sei nun so wie er oder besser als er, auf jeden Fall aber gründlicher als zuvor zu erkennen. 


\section{Vom Verhältnis des wissenschaftlichen Vereins zum Staate}

Man kann annehmen, daß fast allgemein die Voraussetzung gemacht wird, es solle unter den Menschen nicht nur Kenntnisse aller Art geben, sondern auch eine Wissenschaft. Die Ahndung von ihr, das Verlangen nach ihr regt sich überall. Selbst die, welche ihr Geschäft am allermeisten nach hergebrachter Gewohnheit behandeln, berufen sich auf die Voreltern; was gar keinen Sinn hat, wenn nicht das dunkle Gefühl darin liegt, diese müßten bei dem gleichen Verfahren nicht bloß das Recht der Gewohnheit für sich gehabt haben, sondern vielmehr einen höheren Grund. Ebenso die, welche in menschlichen Dingen irgend etwas durch die Kraft des bloßen Instinkts weiter fördern, berufen sich darauf, daß andern obliegen müsse, ihr Tun zu erklären und verständig zu rechtfertigen. Dies alles weiset auf die Wissenschaft hin.

Daß aber diese durchaus nicht Sache des einzelnen sein, nicht von einem allein zur Vollendung gebracht und vollständig besessen werden kann, sondern ein gemeinschaftliches Werk sein muß, wozu jeder seinen Beitrag liefert, so daß jeder in Absicht ihrer von allen übrigen abhängig ist, und nur einen herausgerissenen Teil sehr unvollkommen allein besitzen kann, auch das muß gewiß allgemein einleuchten. Wie genau hängt doch alles zusammen und greifet ineinander auf dem Gebiete des Wissens, so daß man sagen kann, je mehr etwas für sich allein dargestellt wird, um desto mehr erscheine es unverständlich und verworren, indem streng genommen jedes einzelne nur in der Verbindung mit allem übrigen ganz kann durchschaut werden, und daher auch die Ausbildung jedes Teiles von der aller übrigen abhängig ist. Diese notwendige und innere Einheit aller Wissenschaft wird auch gefühlt überall, wo sich bestimmte Bestrebungen dieser Art zeigen. Alle wissenschaftlichen Bemühungen ziehen einander an und wollen in eines zusammengehen, und schwerlich gibt es auch 
auf irgendeinem andern Gebiete des menschlichen Tuns eine so ausgebreitete Gemeinschaft, eine so ununterbrochen fortlaufende Überlieferung von den ersten Anfängen an, als auf dem der Wissenschaft. Freilich nicht, als ob nicht auch hier die Bemühungen der Menschen gesondert und mannigfaltig geteilt, ja hie und da sogar gewaltsam und willkürlich auseinander gerissen wären. Was verschiedene Völker gleicher Zeit wissenschaftlich betreiben, hängt oft äußerlich gar wenig zusammen; und noch mehr erscheinen ganze Zeitmassen voneinander gesondert. Allein wer die Sache etwas im Großen ansieht, dem kann auch hier in dem fortschreitenden Bestreben, alles Getrennte allmählich zusammenzubringen, die vorherrschende Gewalt einer inneren Einheit nicht entgehen.

Bei diesem Zusammenhange nun kann es nur ein leerer Schein sein, als ob irgendein wissenschaftlicher Mensch abgeschlossen für sich in einsamen Arbeiten und Unternehmungen lebe. Vielmehr ist das erste Gesetz jedes auf Erkenntnis gerichteten Bestrebens: Mitteilung; und in der Unmöglichkeit, wissenschaftlich irgend etwas auch nur für sich allein ohne Sprache hervorzubringen, hat die Natur selbst dieses Gesetz ganz deutlich ausgesprochen. Daher müssen sich rein aus dem Triebe nach Erkenntnis, wo er nur wirklich erwacht ist, auch alle zu seiner zweckmäßigen Befriedigung nötigen Verbindungen, die verschiedensten Arten der Mitteilung und der Gemeinschaft aller Beschäftigungen von selbst gestalten; und es wäre irrig zu glauben, daß alle dergleichen Anstalten, wie es jetzt scheint, nur das Werk des Staats sein könnten. Niemand wird angeben können, wie dieser darauf gekommen sein sollte, das Wissen, wenn es ursprünglich ganz zerstreut gewesen wäre, auf solche Weise zu sammeln. Nur da werden alle Unterrichtsanstalten eigentlich vom Staate ausgehn müssen, wo über ein noch ganz rohes Volk eine kleine Anzahl eines gebildeten bildend herrscht, und den Trieb des Wissens erst in jenem erwecken will. Man sehe nur, wie schon im Schoße der 
Familie die Elemente zum Unterricht und zur Gemeinschaft der Kenntnisse sich selbst bilden; wie zweifelhaft es im allgemeinen bleibt auch von den größeren Vorkehrungen, ob sie von selbst entstanden, oder vom Staat, oder von der Kirche gegründet sind. Ergibt sich nicht aus allem, daß wir, um der Natur der Sache getreu zu bleiben, alle solche Veranstaltungen als etwas Ursprüngliches, aus freier Neigung, aus innerem Triebe Entstandenes ansehen müssen?

Aber freilich je mehr sie sich ausbilden, um desto mehr erfordern sie Hilfsmittel, Werkzeuge mancher Art, Befugnis der Verbundenen, auch als solche mit andern auf eine rechtsbeständige Art zu verkehren. Dies alles kann freilich nur durch den Staat erlangt werden, und daher ergeht an ihn die Anmutung, diejenigen, die sich zum Behuf der Wissenschaft miteinander verbunden haben, wie wir uns ausdrücken, als eine moralische Person anzuerkennen, zu dulden und zu schützen. Bei deutschen Völkerschaften und Verfassungen kann diese Zumutung am wenigsten befremdlich sein, da wir bei ihnen beständig eine Menge freier Vereinigungen zu allerlei Zwecken bestehen und entstehen sehen, die der Staat nicht nur duldet, so lange sie sich als unverdächtig ausweisen, so daß man ihnen, um Verfolgung gegen sie zu erregen, immer etwas Unbürgerliches, Staatzerstörendes erweisen muß, sondern denen er auch Vorrechte mancher Art einräumet, wie sie zusammengesetzten Personen, die ja doch größer sind als einzelne, wohl geziemen mögen.

Wie es aber auch mit andern Vereinigungen vielfältig geschieht, daß, wenn der Staat von ihrer Nützlichkeit überzeugt ist, er sie sich allmählich so aneignet und sie in sich aufnimmt, daß man hernach nicht mehr unterscheiden kann, ob sie frei für sich entstanden oder von der verwaltenden Macht gestiftet worden sind, dasselbige ist auch, wie wir sehen, sogar mit den wissenschaftlichen Verbindungen geschehen; wiewohl, wenn die Erfahrung 
nicht so klar vor Augen stände, jeder zweifeln möchte, ob wirklich, bei dem genauen Zusammenhang aller wissenschaftlichen Bestrebungen derselben gebildeten Zeit, diejenigen, die innerhalb eines gewissen Staates entstanden sind, sich gutwillig von den übrigen trennen, und dagegen dem Staat, der ihnen eigentlich fremd ist, sich so genau würden anschließen wollen. Und freilich fehlt es auch nicht an einer ebenso in die Augen fallenden Widersetzlichkeit des wissenschaftlichen Vereins gegen diese zu genaue Verbindung. Das Wahre und Natürliche von der Sache scheint aber dieses zu sein.

Alle wissenschaftlichen Tätigkeiten, welche sich in dem Gebiet einer Sprache bilden, haben eine natürliche genaue Verwandtschaft, vermöge deren sie näher unter sich, als mit irgend anderen zusammenhängen, und daher ein eignes gewissermaßen abgeschlossenes Ganzes in dem größeren Ganzen bilden. Denn was in einer Sprache wissenschaftlich erzeugt und dargestellt ist, hat teil an der besonderen Natur dieser Sprache; wenn es sich nicht ganz unmittelbar auf Erfahrungen und Verrichtungen bezieht, die überall notwendig dieselben sein müssen, wie im Gebiete der Mathematik und der experimentalen Naturlehre, so läßt es sich nicht genau ebenso in eine andere Sprache übertragen, und bildet daher unter sich vermöge des Zusammenhanges mit der Sprache ein gleichartiges Ganzes. Für die Wissenden bleibt es allerdings eine notwendige Aufgabe, auch die Trennung zwischen diesen verschiedenen Gebieten wieder aufzuheben, die Schranken der Sprache zu durchbrechen, und, was durch sie geschieden zu sein scheint, vergleichend aufeinander zurückzuführen; eine Aufgabe, in welcher vielleicht die wissenschaftliche Beschäftigung mit den Sprachen ihr höchstes Ziel findet. Allein diese Aufgabe ist offenbar für die Gemeinschaft des Wissens die höchste, vielleicht nie aufzulösende, und eben dadurch bewährt sich nur desto mehr jene Absonderung als eine unumgängliche. Denken wir uns also auf allen Punkten aus freiem Triebe nach Erkenntnis wissenschaftliche 
Verbindungen entstehend, so werden sich diese zunächst so weit zu vereinigen streben, als das Gebiet einer und derselben Sprache reicht. Dies wird der engste Bund sein, und jede darüber hinausgehende Gemeinschaft nur eine weitere.

Dem Staat aber leuchtet auch ein, daß Kenntnisse und sogar Wissenschaften etwas Heilsames und Treffliches sind. Wie groß oder klein er auch sei, wie recht oder unrecht er daran tue, ein eigner sein zu wollen: er kann als solcher nur durch eine Masse von Kenntnissen bestehn, die sich möglichst der Totalität nähert, so wenigstens, daß von allen Zweigen des Wissens einige Spur, einiges Bewußtsein in ihm vorkomme durch lebendigen Sinn, durch Nachfrage, durch williges Aufnehmen, wenn denn auch $\mathrm{zu}$ einer eigentümlichen Art der Vollendung nur einiges in ihm gedeiht. Wenigstens ein anständiges und edles Leben gibt es für den Staat ebensowenig als für den einzelnen, ohne mit der immer beschränkten Fertigkeit auf dem Gebiete des Wissens doch einen allgemeinen Sinn zu verbinden. Für alle diese Kenntnisse nun macht der Staat natürlich und notwendig eben die Voraussetzung wie der einzelne, daß sie in der Wissenschaft müssen begründet sein, und nur durch sie recht können fortgepflanzt und vervollkommnet werden. Er sucht sich daher in einen lebendigen Zusammenhang zu setzen mit allen Bestrebungen, die zu dieser Vervollkommnung führen; er nimmt sich der Anstalten an, die er selbst müßte gestiftet haben, wenn er sie nicht gefunden hätte; und da auch der wissenschaftliche Verein ein Bedürfnis hat, vom Staate geschützt und begünstiget $\mathrm{zu}$ werden, so werden beide ein Bestreben haben, sich miteinander zu verständigen und zu einigen. Der Staat aber arbeitet nur für sich, er ist, wie er geschichtlich erscheint, durchaus zunächst selbstsüchtig, und will also auch die Unterstützung, die er der Wissenschaft bietet, nicht über seine Grenzen hinaus wirksam sein lassen. Wenn nun der Staat das Gebiet seiner Sprache ganz erfüllt, so strebt auch die wissenschaftliche nähere Vereinigung nicht über seine Grenzen hinaus; und 
so geht die Verbindung zwischen beiden ohne allen Zwiespalt vor sich, schneller oder langsamer, je nachdem beide Teile lebendiger überzeugt sind, oder nur mangelhafter einsehen, wie sie einer des andern bedürfen, und was sie einander leisten können. Wenn aber der Staat dieses Gebiet nicht ausfüllt: so haben er und der wissenschaftliche Verein bei ihrer abzuschließenden Verbindung ein verschiedenes Interesse. Die wissenschaftlichen Männer wollen den Staat und seine Unterstützungen nur gebrauchen, um in dem größeren Gebiet der Sprache recht kräftig wirken zu können zu ihrem Zwecke; die engeren Grenzen des Staates wollen sie nicht für die ihrigen anerkennen; und müssen sie ihm für seine Unterstützungen Dienste leisten, so sehen sie diese nur als etwas Untergeordnetes an. Die Regierungen hingegen sind nur um so mehr eifersüchtig aufeinander, als sie einander näher stehen, und fürchten von der weiterstrebenden wissenschaftlichen Verbindung Gleichgültigkeit für den Staat, oder gar Vorliebe für fremde Einrichtungen, und andere nachteilige Einflüsse auf den Geist der Untertanen; sie tun daher das Mögliche, um den näheren Verein auch der Gelehrten in den Grenzen des Staates eingeschränkt zu halten. Umgekehrt, wenn ein Staat das Gebiet mehrerer Sprachen umfaßte: so würde er alle Gelehrten in seinem Umfange einladen, sich gleich nahe $\mathrm{zu}$ vereinigen und auch als solche ein Ganzes zu bilden. Diese aber würden offenbar zwei Parteien darstellen, jede Zunge würde die Begünstigung des Gewalthabers der anderen abzuringen suchen, und aufrichtige Verbrüderung würde nur unter denen stattfinden, die eine Sprache reden. Daß es unnatürlich ist, wenn ein Staat sich über die Grenzen der Sprache hinaus vergrößern will, hat neuerlich ein großer Herrscher selbst behauptet, so daß man sich nur wundem muß, was doch für eine dringende Notwendigkeit selbst ein so klares Bewußtsein wie das seinige beherrschen konnte. Ob es ebenso unnatürlich ist, wenn das Gebiet einer und derselben Sprache sich in so viele kleine Staaten zerteilt, als Deutschland erleidet, das sei dahingestellt. Wenigstens scheint es ratsam, wenn sie in einer genauen Verbindung bleiben, und 
töricht, wenn jeder von ihnen seine wissenschaftlichen Einrichtungen abgeschlossen für sich besitzen will. Denn nur äußerlich und erzwungen können diese ein Ganzes bilden, welches, je kleiner der Staat, desto lächerlicher werden wird, wenn es sich vollständig gestalten will; der Natur der Sache nach können sie immer nur Teile des weitergreifenden Vereins sein, und müssen sich, je mehr sie sich absondern wollen, um so mehr des wohltätigen Einflusses der übrigen Teile und damit zugleich ihrer Nahrung und Gesundheit berauben. In der Tat wunderlicher und von dem, was das gemeine Wohl erfordert, entfernter kann wohl nichts sein, als wenn ein deutscher Staat sich mit seinen wissenschaftlichen Bildungsanstalten einschließt. Vielmehr inniger sollte sich die Gemeinschaft, in welcher solche Staaten stehen müssen, nirgends aussprechen als in wissenschaftlichen Dingen; und wenn gar die natürliche Richtung dahin gehen sollte, daß sie ebenso ein s würden, wie die Sprache immer mehr eine wird, wo gäbe es wohl ein leichteres sichreres und natürlicheres Vorbereitungsmittel hiezu, als wenn auf dem wissenschaftlichen Gebiet, welches in so genauer Wechselwirkung sowohl mit dem Staate als mit der Sprache steht, die vielseitigste, treueste, eifersuchtsloseste Gemeinschaft gestiftet würde, durch welche die innere Einheit des äußerlich Getrennten recht klar zutage käme? Und wodurch soll denn endlich klar und leidenschaftslos entschieden werden, wie lange diese Absonderung dauern, und wie weit sie gehen soll, als durch die möglichst weit verbreitete wissenschaftliche Bildung, welche die Besonnenheit erhält, von keinem einzelnen Interesse geblendet wird, und die kleinlichen Leidenschaften und Vorurteile allmählich ausrottet?

Dennoch haben sich wenige von unsern vaterländischen Regierungen von allen Fehlern in dieser Hinsicht frei gehalten; sondern anstatt daß jede bei sich sollte gepflegt haben, was sie konnte, und überall Regierung und Volk mitgenießend und benutzend froh und stolz gewesen sein über alles, was sich irgendwo im Umfang 
des deutschen Vaterlandes bildete, haben je länger je mehr zwei ganz entgegengesetzte Maßregeln überhand genommen. Einige Regierungen nämlich wetteiferten miteinander darin, die ihnen untergebenen Bildungsanstalten zum Mittelpunkt alles wissenschaftlichen Verkehrs für ganz Deutschland zu machen, indem sie darauf bedacht waren, von weit umher alles, was sich wissenschaftlich auszeichnet, an sich zu ziehen, sollten auch andere Staaten dadurch in Dürftigkeit versetzt werden. Wenn hiebei nur ein wahrer Wetteifer zum Grunde gelegen hätte, ja nicht hinter dem zurückbleiben zu wollen, was man tun konnte; wenn dabei die gute Meinung gewesen wäre, für die kleinern Staaten, die hierauf nicht zu viel verwenden konnten, mit zu arbeiten, Anstalten für sie mit zu unterhalten, und Talente für sie mit zu belohnen: so wäre nicht viel dagegen zu sagen gewesen. Die Absicht war aber eigentlich zuerst, daß jeder Staat in Befriedigung seiner wissenschaftlichen Bedürfnisse sich unabhängig machen wollte von jedem andern, da doch die wahre Unabhängigkeit hierin nur die sein kann, wenn zu des gemeinschaftlichen Gutes Erhaltung und Vermehrung jeder nach Verhältnis reichlich beiträgt, jenes aber nur eine hochmütige, verderbliche Prahlerei ist. Dann wollte man auch durch geistiges Übergewicht dem Staate Macht und Ansehn verschaffen über sein eigentliches Gebiet hinaus. Dies ist freilich die friedlichste und schönste Art der Eroberung; aber der Wissenschaft kann es leicht gefährlich werden, wenn das bloße Geld den Gelehrten zur Lockspeise gemacht wird. Und werden diese Eroberungen im Mißverhältnis mit der natürlichen Wichtigkeit des Staates oder in einem kleinlichen Stile betrieben: so ist das überhaupt lächerlich oder krankhaft. Die andere Maßregel ist die wissenschaftliche Sperre, wenn nämlich die Regierungen das wissenschaftliche Verkehr mit dem Auslande beschränken oder aufheben, und ihre Bürger hindern, auf jede Art, wie sie es wünschen, an den wissenschaftlichen Bemühungen benachbarter Staaten teilzunehmen. Geschieht dies, wo die Kirche den Staat beherrscht, wie bis neuerlich größtenteils im katholischen Deutschland: so ist 
das ein bedauernswürdiger Beweis eines finstern Zustandes. Versucht diese Sperre ein mäßiger Staat, der von größeren umgeben ist, und fühlt, daß er sich auf alle Weise anstrengen und alle Mittel zu Hilfe nehmen muß, um seine Selbständigkeit so lange als möglich gegen sie zu behaupten: so ist zu beklagen, daß man sich so gewaltig verrechnen kann bei so löblicher Absicht, indem doch geistige Beschränktheit, die aus solcher Absonderung entstehen muß, niemals die Selbständigkeit sichern oder vermehren kann. Wenn aber gar ein selbst mächtiger Staat, und der auch jenes Erobern mit Erfolg betreibt, wenig zufrieden mit dem, was er in diesem Fache schon geleistet hat, bis er das Fehlende ersetzen kann, auch noch die Sperre verordnet: so ist das offenbar ein Hochmut, eine Illiberalität, eine niedrige und geldsüchtige Ökonomie, die auch auf die Absicht jener Eroberungen ein noch nachteiligeres Licht wirft, und mehr als irgend etwas eine solche Regierung bei allen Gebildeten der Nation verhaßt machen muß.

Allein in einem noch wesentlicheren Punkte pflegt der Staat, indem er sich der wissenschaftlichen Anstalten annimmt, von der Art, wie sie müssen geleitet und geordnet werden, eine ganz andere Ansicht zu haben, als die Gelehrten, welche zum Behuf der Wissenschaft selbst näher unter sich verbunden sind. Beide Teile würden gewiß sehr einig sein, wenn der Staat von den Forderungen eines alten Weisen, wenn auch nicht die erste, daß die Wissenden herrschen sollen, doch die zweite, daß die Herrschenden wissen sollen, recht wollte gelten lassen in ihrem vollen Sinne. Die Staatsmänner, auch diejenigen, welche das gemeine Wesen am meisten fortbilden, erscheinen sich und anderen mehr den Künstlern ähnlich, als daß sie wissenschaftlich zu Werke gingen, indem sie den Staat handhaben. Glücklich ahndend, das Rechte herausfühlend, bringen sie unbewußt hervor, und gestalten mit geschickter Hand nach einem ihnen einwohnenden Urbilde, wie jeder Künstler nach dem seinigen. Das ist leicht zu erkennen und aufrichtig zu loben, und so herrschen sie allerdings nicht als Wis- 
sende. Aber daß dieser künstlerische Sinn doch bei denen am gebildetsten und richtigsten sein wird, welche entweder selbst die Tatsachen und Erfahrungen wissenschaftlich anzusehn verstehn, oder wenigstens Darstellungen derselben, die diesen Endzweck haben, zu benutzen; daß der Staatsmann, wie jeder, der künstlerisch etwas hervorbringt, aus dem Schatze der Wissenschaft mittelbar oder unmittelbar für seine Kunst schöpfen muß, wie gewiß auch er ihn seinerseits durch seine Werke wiederum bereichert; daß wahre Verbesserungen in allen Zweigen der Staatsverwaltung nur um so sicherer eingeleitet werden und gedeihen können, als die Herrschenden und soviel möglich auch die Beherrschten die wahre Idee des Staates überhaupt sowohl, als auch dieses bestimmten richtig aufgefaßt haben, und mit dem Bewußtsein derselben Beispiele aus dem ganzen Gebiet der Geschichte zu benutzen wissen, und daß also auf jede Weise wahrhaft gewußt werden muß, wenn gut geherrscht werden soll: dies sollte wenigstens um so mehr anerkannt werden, da schon die Erfahrung zeigt, daß, wenn man sich auf irgend einem Gebiet von dieser Einsicht entfernt, in demselben entweder ein tumultuarischer, anarchischer Zustand sich bildet, wie im ehemaligen Polen und in manchem anderen Reiche, welches bei vielen Kenntnissen nur gar wenig Wissenschaft besitzt, oder auch ein Kastenwesen entsteht, eine ärmliche Empirie, die sich streng und ängstlich an die Tradition anschließt, im offenbaren Mißverhältnis mit andern besser geleiteten und daher fortschreitenden Zweigen. Allein eben dies wird doch oft gar nicht anerkannt, sondern vielmehr der Einfluß, den die Wissenschaft auf den Staat zu gewinnen sucht, gehaßt und gefürchtet. Der Staat ist alsdann natürlich nur von dem unmittelbaren Nutzen der Kenntnisse überzeugt und ergriffen. Ausgebreitete Bekanntschaft mit Tatsachen, Erscheinungen und Erfolgen aller Art sucht er zu begünstigen, und wenn er sich der wissenschaftlichen Anstalten annimmt, sie vorzüglich hierauf zu lenken. Denjenigen hingegen, welche sich zum Behuf der Wissenschaft freiwillig vereinigen, kommt es auf ganz etwas anderes an, als 
allein auf die Masse der Kenntnisse. Was sie vereiniget, ist das Bewußtsein von der notwendigen Einheit alles Wissens, von den Gesetzen und Bedingungen seines Entstehens, von der Form und dem Gepräge, wodurch eigentlich jede Wahrnehmung, jeder Gedanke, ein eigentliches Wissen ist. Und eben dieses Bewußtsein suchen sie vornehmlich $\mathrm{zu}$ erwecken und $\mathrm{zu}$ verbreiten, durch welches allein auch in allen Kenntnissen und in jeder Erweiterung derselben die Wahrheit und die Sicherheit kann erhalten werden. Darum arbeiten sie überall schon bei einer mäßigen Summe von Kenntnissen darauf hin, ihnen diesen wissenschaftlichen Charakter zu geben. Wo nur erst das Notdürftigste über einen Gegenstand in Erfahrung gebracht ist, ziehn sie ihn in das Gebiet der Wissenschaft, suchen die Einheit darin auf, aus welcher alles Mannigfaltige begreiflich wird, trachten das Ganze in jedem Einzelnen zu sehen, und wiederum jedes Einzelne nur im Ganzen. So auch jeden Menschen, den sie sich ähnlich bilden wollen, führen sie, auch nur mäßig ausgerüstet, gleich auf diesen Hauptpunkt wissenschaftlicher Einheit und Form, üben ihn in dieser Art zu sehen, und lassen ihn nur, nachdem er sich so festgesetzt hat, noch tiefer in das Einzelne hineingehn, weil er alles wirklich wissen soll im strengeren Sinn, und sonst alles Anhäufen einzelner Kenntnisse nur ein unsicheres Umhertappen wäre, was immer nur in bezug auf eine bessere Behandlung einen vorläufigen Wert haben könnte. Der Staat hingegen verkennt nur zu leicht den Wert dieses Bestrebens, und je lauter sich die Spekulation - so wollen wir immer nennen, was sich von wissenschaftlichen Beschäftigungen überwiegend nur auf die Einheit und die gemeinschaftliche Form alles Wissens bezieht - je lauter sich diese gebärdet, desto mehr sucht der Staat sie zu beschränken, und allen seinen Einfluß, den aufmunternden und den einengenden, dazu zu gebrauchen, daß die realen Kenntnisse, die Massen des wirklich Ausgemittelten, auch ohne Hinsicht darauf, ob jenes Gepräge der Wissenschaft ihnen aufgedrückt ist oder nicht, allein gefördert werden, und als die einzig echten Früchte alles auf Erkenntnis gehenden Bestrebens 
erscheinen. Dieser Richtung nun muß der wissenschaftliche Verein notwendig entgegenstreben, und die edleren Mitglieder desselben werden daher immer darnach trachten, sich möglichst zur Unabhängigkeit vom Staat heraufzuarbeiten, indem sie teils ihre Vereinigung der Gewalt und Anordnung des Staates zu entziehen, teils ihren eigenen Einfluß auf denselben zu erhöhen suchen. Wo möglich flößen sie dem Staate eine würdigere und wissenschaftlichere Denkungsart ein; wo aber nicht, so suchen sie wenigstens sich selbst je länger je mehr Glauben und Ansehn zu verschaffen. Je mehr aber die wissenschaftlich Gebildeten so in den Staat verflochten sind, daß das Wissenschaftliche bei ihnen vom Politischen überwogen wird und nicht zum klaren Bewußtsein kommt, desto eher werden sie sich diesen Eingriffen des Staates fügen; und je genauer sich in diesem Sinn beide Teile verbinden, um desto mehr isoliert sich ein solcher Teil des größeren wissenschaftlichen Nationalvereins von allen übrigen, die ihre eigentümlichen Prinzipien fester halten, und sinkt zu einer bloßen Veranstaltung für den Gebrauch des Staates herab. Vorzüglich wo der Staat schon das gesamte Gebiet der Sprache zu einem Ganzen verbunden hat, und also sehr mächtig und glänzend ist, schlägt dieser Kampf gewöhnlich zum Nachteil der Wissenschaft aus. Und wenn man dem entgegengesetzten Zustand einige Vorzüge zugestehen will, so ist gewiß dies keiner der geringsten, daß alsdann der Staat wenigstens in dieser Hinsicht die Wissenschaft freier gewähren läßt, wäre es auch nur um sich mit ihr zu schmücken.

Auf dasjenige, was in dieser Darstellung flüchtig hingeworfen ist, werden wir öfters zurückweisen müssen; denn ohne die vornehmsten Momente dieser Gegenwirkungen zwischen Staat und Wissenschaft im Auge zu haben, ist es nicht möglich, die äußeren Schicksale der letzteren zu begreifen, oder wenn eine bestimmte Aufgabe gelöset werden soll, einen, dem jedesmaligen Verhältnis zwischen Staat und Wissenschaft angemessenen Gang einzuschlagen. Am wenigsten aber kann man sonst verstehen, warum 
der Staat die Universitäten gerade so, wie wir sehen, zu behandeln pflegt, und warum diese so sehr nach der Unabhängigkeit von ihm trachten, und es als die vorteilhafteste Lage ansehn, wenn sich der Staat in ihre Verwaltung wenigst möglich einmischt. Doch wir müssen zuerst sehen, welchen Platz eigentlich die Universitäten einnehmen in dem wissenschaftlichen Verein, und welches ihr vorzüglichstes Geschäfte ist.

\section{Von Schulen, Universitäten und Akademien}

Unter Akademien werden hier, was man gelehrte Gesellschaften nennt, von aller Art verstanden, und die Verbindung, in welcher sie untereinander stehen sollten, und innerlich gewiß auch stehen. Von Schulen aber denken wir hier nur an diejenigen, die man wenigstens ansehn kann, als wären sie unmittelbar aus dem Bedürfnis und Trieb nach Erkenntnis entstanden, also nur die gelehrten, deren Vorsteher notwendig vollkommen wissenschaftlich gebildete Männer sein müssen, und in denen Kenntnisse mitgeteilt werden, die unmittelbar in das Gebiet der Wissenschaft fallen.

Alsdann sind dieses die drei Hauptformen, in welche sich jetzt alle Vereinigungen zum Betrieb der Wissenschaften gestalten. Sie kommen zwar überall im neueren Europa vor; aber auch deshalb könnte man wohl Deutschland als den Mittelpunkt der Bildung ansehn, weil in anderen Ländern zwar einzelne dieser Formen, Schulen besonders und Akademien, in einem größeren Stil vorkommen, alle drei nebeneinander aber nirgends so rein heraustreten als bei uns. Auch könnte man wohl sagen, der ganze Typus, der sich darin zeigt, sei ursprünglich deutsch, und schließe sich genau der Bildung anderer auch aus Deutschland hervorgegangener Verhältnisse an. Die Schule als das Zusammensein der Meister mit den Lehrburschen, die Universität mit den Gesellen, und die Akademie als Versammlung der Meister unter sich. 
Doch für die meisten, die von einer tiefen Verachtung für alles Zunftwesen durchdrungen sind, heißt dies wohl wenigstens das, was erst beschrieben werden soll, durch Dunkleres erläutern, wo nicht gar die wissenschaftlichen Anstalten herabwürdigen durch Gleichsetzung mit diesen verschrienen Formen, denen aber doch auch gar viel Schönes zum Grunde liegt. Betrachten wir also diese drei Verbindungen, Schule, Universität und Akademie, lieber für sich und fragen, was doch jede bedeutet, und wie sie unter sich zusammenhängen. Denn ohne sie alle drei verstanden zu haben, möchte es uns schwerlich gelingen, über das Wesen und die zweckmäßige Einrichtung der einen, auf die es uns ankommt, einig zu werden.

Die Wissenschaft, wie sie in der Gesamtheit der gebildeten Völker als ihr gemeinschaftliches Werk und Besitztum vorhanden ist, soll den Einzelnen zur Erkenntnis hinanbilden, und der Einzelne soll auch wiederum an seinem Teil die Wissenschaft weiter bilden. Dies sind die beiden Verrichtungen, auf welche alles gemeinschaftliche Tun auf diesem Gebiet hinausläuft. Man sieht leicht, wie die erste von ihnen in der Schule ganz die Oberhand hat, und in der Akademie dagegen die andere. Die Schulen sind durchaus gymnastisch, die Kräfte übend, und besitzen ihren fremden Namen mit Recht. Den Knaben von besserer Natur und hervorstechenden Gaben, welche die Vermutung erregen, er könne für die Wissenschaft empfänglich sein, oder wenigstens eine Masse von Kenntnissen vorteilhaft verarbeiten, diesen übernehmen sie, und versuchen auf alle Weise, ob dem wirklich also sei. Zweierlei aber ist, woran sich zeigen muß, ob ein Mensch für diese höhere Bildung sich eigne, auf der einen Seite ein bestimmtes Talent, welches ihn an ein einzelnes Feld der Erkenntnis fesselt, auf der andern der allgemeine Sinn für die Einheit und den durchgängigen Zusammenhang alles Wissens, der systematisch philosophische Geist. Zusammentreffen muß beides, wenn der Mensch sich zu etwas Ausgezeichnetem bilden soll. Auch das entschiedenste Talent wird 
ohne diesen Geist keine Selbständigkeit haben, und nicht weiter gedeihen können, als daß es ein tüchtiges Organ wird für andere, die das wissenschaftliche Prinzip in sich haben. Und der systematische Geist ohne ein bestimmtes Talent wird sich mit seinen Produktionen in einem sehr engen Kreise herumdrehen, und sich in wunderlichen Auswüchsen, Wiederholungen und Umbildungen immer des nämlichen höchst Allgemeinen erschöpfen, weil er eben keines Stoffes recht Meister ist.

Dies hindert aber nicht, daß nicht auch, bei der Vereinigung beider, bei einigen das Talent hervorherrsche, bei andern der allgemeine wissenschaftliche Geist. Beides aber bedarf, wo es nicht in einem ganz ausgezeichneten Grade vorhanden ist, um erweckt und ans Licht gebracht zu werden, bald mehr bald minder eines absichtlich angebrachten Reizes, einer kunstmäßigen Behandlung. Und so muß die Schule auf beides wirken. Sie muß elementarisch auf der einen Seite den gesamten Inhalt des Wissens in bedeutenden Umrissen vorführen, so daß jedes schlummernde Talent zu seinem Gegenstande sich kann angelockt fühlen, und muß auf der andern dasjenige besonders herausheben und mit vorzüglichem Fleiß behandeln, worin die wissenschaftliche Form der Einheit und des Zusammenhanges am frühsten kann deutlich angeschaut werden, und was aus demselben Grunde zugleich das allgemeine Hilfsmittel alles andern Wissens ist. Aus dieser Ursache sind mit Recht Grammatik und Mathematik die Hauptgegenstände auf Schulen, ich möchte sagen: die einzigen, die mit einem Anklang von Wissenschaftlichkeit können vorgetragen werden. Zugleich muß aber auch die Schule methodisch alle geistigen Kräfte so üben, daß sie bestimmt auseinander treten und ihre verschiedenen Funktionen klar eingesehen werden, und sie so stärken, daß jede sich eines gegebenen Gegenstandes mit Leichtigkeit ganz bemächtigen kann. Dies vereinigt durch die einfachsten und sichersten Operationen zu bewirken, ist das Ziel der Schulen. Gewiß wird keine auch bei der besten Einrichtung und 
Leitung dies alles in gleicher Vollkommenheit leisten, sondern die eine mehr in diesem, die andere mehr in jenem Teile sich Vorzüge erwerben. Aber nur um desto nötiger wird es sein, daß man überall den Gesamtzweck vor Augen behalte, damit jede auf dem Wege zu der ihr angemessenen Virtuosität sich vor verderblicher Einseitigkeit bewahren könne; und desto mehr ist eine höchste allgemeine Leitung zu wünschen, um von jeder solchen Anstalt ganz den Nutzen für das wissenschaftliche Gebiet zu ziehen, den sie gewähren kann.

In der Akademie hingegen finden sich die Meister der Wissenschaft vereinigt; und wenn nicht alle auf gleiche Weise Mitglieder derselben sein können, so sollen wenigstens alle durch sie repräsentiert werden, und zwischen den Mitgliedern und den übrigen des Namens würdigen Gelehrten ein solcher lebendiger Zusammenhang stattfinden, daß die Arbeiten der Akademie wirklich als das Gesamtwerk ihrer aller können angesehen werden. Jeder muß darnach streben, dieser Verbindung anzugehören, weil das Talent, was einer in sich ausgebildet hat, ohne die Ergänzung der übrigen doch nichts wäre für die Wissenschaft. Darum bilden alle ein Ganzes, weil sie sich Eins fühlen durch den lebendigen Sinn und Eifer für die Sache des Erkennens überhaupt, und durch die Einsicht in den notwendigen Zusammenhang aller Teile des Wissens; eben darum aber sondern sie sich auch wieder in verschiedene Abteilungen, weil jeder Zweig des Wissens einer noch engern Vereinigung bedarf, um gründlich und zweckmäßig bearbeitet zu werden. Je feiner diese Verzweigung sich vervielfältiget und je lebendiger dabei die Einheit des Ganzen bleibt, ohne sich in eine leere Form zu verlieren, so daß in jedem Einzelnen die Teilnahme an den Fortschritten des Ganzen und der Eifer für sein besonderes Fach einander gegenseitig beleben, und also die engste Gemeinschaft zwischen den verschiedenen Teilen der Wissenschaft in dem Schoß der Akademie auf das leichteste unterhalten wird: um desto vollkommner ist die Einrichtung des Ganzen. 
Wie viele Akademien nach dieser Idee Deutschland wohl haben sollte? Eine höchstens oder zwei, eine nördliche und eine südliche, die aber auch in der innigsten Verbindung stehn, und überall, teils wo ein natürlicher Zusammenfluß von Gelehrten aller Art entstünde, teils wo ein Ort für ein besonderes wissenschaftliches Gebiet sich vorzüglich eignete, ihre Töchter haben müßten. So lange eine solche Vereinigung, nach welcher der Natur der Sache wegen alles strebt, noch nicht erfolgt ist, können sich also unsere zerstreuten gelehrten Gesellschaften nur als Bruchstücke ansehn, und nur durch das lebhafteste Verkehr untereinander sich ihr Dasein bis zu diesem Zeitpunkt, der vielleicht nicht mehr fern ist, erhalten.

Mit dieser Ansicht von Schulen und Akademien stimmt auch das ganze Verfahren dieser Anstalten zusammen. Die Schulen geben in den öffentlichen Prüfungen eine Ausstellung, die ganz gymnastisch ist, und nur zeigen kann, wie weit die intellektuellen Kräfte für das Wissen geübt sind. Literarische Produktionen aber kommen ihnen als solchen gar nicht zu, weil nichts öffentlich erscheinen soll, was nicht die Wissenschaft weiter fördert. Darum sieht man auch immer den Programmen oder Einladungsschriften der Vorsteher das Mißverhältnis an, indem sie entweder gar nicht verdienen aufgestellt $\mathrm{zu}$ werden, oder wenn das, sich für das Publikum nicht eignen, welches sie doch zunächst in Anspruch nehmen. Daher in vieler Hinsicht ein vortreffliches Zeichen für eine Schule ist, wenn dergleichen gar nicht von ihr gefertiget werden. Dagegen fordert man von jeder Akademie, daß sie Werke hervorbringt, nämlich nicht große, das Ganze umfassende oder gar revolutionäre Bücher, sondern Sammlungen von Aufsätzen, welche einzelne noch unerforschte Gegenstände beleuchten, eigene Entdeckungen darlegen, neuerfundene Methoden ans Licht bringen oder prüfen. Denn so durch viele kleine Beiträge die Wissenschaften, welche schon Umfang und Sicherheit in gewissem Maß gewonnen haben, zu fördern, das ist die Sache der Akademie; 
und je mehr Gehalt und Zusammenstimmung sich in ihren Werken zeigt, um desto mehr Verdienst wird man ihr zuschreiben. In demselbigen Sinne läßt auch die Akademie Aufgaben zur Auflösung ergehen, teils um sich für einzelne Fälle, wo der Versuche nicht genug gemacht werden können, oder wo Untersuchungen erforderlich sind, die sich nicht an jedem Ort anstellen lassen, auch außerhalb ihrer Mitte Hilfe zu verschaffen - daher mit Recht die eigentlichen Mitglieder ausgeschlossen sind von der Preisbewerbung - teils auch um auszuspüren, wer, noch nicht $\mathrm{zu}$ ihr gehörend, sich mit wissenschaftlichen Gegenständen aus einzelnen Gebieten ernsthaft und erfolgreich beschäftiget, damit sie sich aus diesen von Zeit zu Zeit würdige Genossen aneignen könne.

Was ist nun aber die Universität zwischen beiden, der Schule und der Akademie? Man könnte denken, daß diese beiden sich in alle wissenschaftlichen Verrichtungen teilten, und jene ganz überflüssig wäre zwischen ihnen. So urteilen auch gewiß manche unter uns, schwerlich mit echt deutschem Sinn; denn diese Ansicht ist ja die herrschende eines anderen Volkes, welchem, je mehr es sich in sich selbst konsolidierte, um so mehr alles ausgegangen ist, was einer Universität ähnlich sieht, und nichts übrig geblieben, als Schulen und Akademien in unzähliger Menge und in den mannigfaltigsten Formen. Allein man übersieht hiebei offenbar einen sehr wesentlichen Punkt. Die Schulen beschäftigten sich nur mit Kenntnissen als solchen; die Einsicht in die Natur der Erkenntnis überhaupt, den wissenschaftlichen Geist, das Vermögen der Erfindung und der eigenen Kombination suchen sie nur vorbereitend anzuregen, ausgebildet aber wird dies alles nicht in ihnen. Die Akademien aber müssen dies alles bei ihren Mitgliedern voraussetzen; nur von einem gemeinschaftlichen Mittelpunkt aus, und durch das Bewußtsein desselben - das spricht ihre ganze Organisation aus, wenn sie auch keine Veranlassung finden, es ausdrücklich zu erklären - wollen sie die Wissenschaften fördern; auch kann dies nur so auf eine übereinstimmende Weise geschehen. 
Wie leer müßten die Werke einer Akademie sein, wenn sie überall bloße Empirie triebe, und an keine Prinzipien in jeder Wissenschaft glaubte! Wie leer wäre der ganze Gedanke einer gemeinschaftlichen Beförderung aller Wissenschaften, wenn diese Prinzipien nicht wiederum zusammenstimmten und ein Ganzes bildeten! Und wie jämmerlich die Ausführung, wenn etwa die Mitglieder über alle diese Prinzipien uneins wären! Offenbar also wird vorausgesetzt, jedes Mitglied einer Akademie sei über die philosophischen Prinzipien seiner Wissenschaft mit sich selbst und den übrigen verstanden, jedes behandle sein Fach mit philosophischem Geist, und eben dieser in allen sich ähnliche Geist in seiner Vermählung mit dem jedem Einzelnen eigentümlichen Talent mache nur jeden zu einem wahren Gliede der Vereinigung. Soll dieser Geist dem Menschen von ohngefähr kommen im Schlaf? Soll nur das wissenschaftliche Leben aus dem Nichts entstehen, nicht wie jedes andere durch Erzeugung? Soll nur dieses in seinen ersten zarten Äußerungen keiner Pflege bedürfen, und keiner Erziehung? Hier also liegt das Wesen der Universität. Diese Erzeugung und Erziehung liegt ihr ob, und damit bildet sie den Übergangspunkt zwischen der Zeit, wo durch eine Grundlage von Kenntnissen, durch eigentliches Lernen die Jugend erst bearbeitet wird für die Wissenschaft, und der, wo der Mann in der vollen Kraft und Fülle des wissenschaftlichen Lebens nun selbst forschend das Gebiet der Erkenntnis erweitert oder schöner anbaut. Die Universität hat es also vorzüglich mit der Einleitung eines Prozesses, mit der Aufsicht über seine ersten Entwicklungen zu tun. Aber nichts Geringeres ist dies als ein ganz neuer geistiger Lebensprozeß. Die Idee der Wissenschaft in den edleren, mit Kenntnissen mancher Art schon ausgerüsteten Jünglingen zu erwecken, ihr zur Herrschaft über sie zu verhelfen auf demjenigen Gebiet der Erkenntnis, dem jeder sich besonders widmen will, so daß es ihnen zur Natur werde, alles aus dem Gesichtspunkt der Wissenschaft zu betrachten, alles Einzelne nicht für sich, sondern in seinen nächsten wissenschaftlichen Verbindungen anzuschau- 
en, und in einen großen Zusammenhang einzutragen in beständiger Beziehung auf die Einheit und Allheit der Erkenntnis, daß sie lernen, in jedem Denken sich der Grundgesetze der Wissenschaft bewußt zu werden, und eben dadurch das Vermögen selbst $\mathrm{zu}$ forschen, zu erfinden und darzustellen, allmählich in sich herausarbeiten, dies ist das Geschäft der Universität. Hierauf deutet auch dieser ihr eigentlicher Name, weil eben hier nicht nur mehrere, wären es auch andere und höhere, Kenntnisse sollen eingesammelt, sondern die Gesamtheit der Erkenntnis soll dargestellt werden, indem man die Prinzipien und gleichsam den Grundriß alles Wissens auf solche Art zur Anschauung bringt, daß daraus die Fähigkeit entsteht, sich in jedes Gebiet des Wissens hineinzuarbeiten. Hieraus erklärt sich die kürzere Zeit, welche jeder auf der Universität zubringt als auf der Schule; nicht als ob nicht um alles zu lernen mehr Zeit erfordert würde, sondern weil man das Lernen des Lernens wohl abmachen kann in kürzerer; weil eigentlich, was auf der Universität verlebt wird, nur ein Moment ist, nur ein Akt vollbracht wird, daß nämlich die Idee des Erkennens, das höchste Bewußtsein der Vernunft, als ein leitendes Prinzip in dem Menschen aufwacht. Hierauf weisen alle Eigentümlichkeiten hin, welche die Universität von der Schule auf der einen, von der Akademie auf der andern Seite unterscheiden. Auf der Schule geht man nach den Gesetzen des leichtesten Fortschrittes von einem einzelnen zum andern über, und ist wenig bekümmert darum, ob jeder überall etwas Ganzes vollende. Auf der Universität dagegen ist man hierauf so sehr bedacht, daß man in jedem Gebiet das Enzyklopädische, die allgemeine Übersicht des Umfanges und des Zusammenhanges als das Notwendigste voranschickt, und zur Grundlage des gesamten Unterrichts macht. Und die Hauptwerke der Universität als solcher sind Lehrbücher, Kompendien, deren Endzweck nicht ist, die Wissenschaft im einzelnen zu erschöpfen oder zu bereichern, wo auch weder das Leichteste noch das Schwerste noch das Seltenste den Vorzug genießt bei der Auswahl, sondern deren Verdienst in der höhern Ansicht, in der syste- 
matischen Darstellung besteht, und welche dasjenige am meisten herausheben, worin sich am faßlichsten die Idee des Ganzen darstellt, und wodurch Umfang und innere Verbindung desselben am anschaulichsten wird. Ferner in den Akademien kommt alles darauf an, daß das einzelne vollkommen richtig und genau herausgearbeitet werde im Gebiet aller realen Wissenschaften; dagegen die reine Philosophie, die Spekulation, die Beschäftigung mit der Einheit und dem Zusammenhang aller Erkenntnisse und mit der Natur des Erkennens selbst durchaus zurücktritt. Gewiß nicht als etwas für das reale Wissen Geringfügiges, oder gar an sich Verwerfliches und Nichtiges. Denn, wie man sich auch anstelle, alles einzelne Wissen ruht doch immer auf jenem Allgemeinen; es gibt kein wissenschaftlich hervorbringendes Vermögen ohne spekulativen Geist, und beides hängt so zusammen, daß, wer keine bestimmte philosophische Denkungsart sich gebildet hat, auch nichts Tüchtiges und Merkwürdiges wissenschaftlich selbständig hervorbringen wird, sondern er wird immer, bewußt oder unbewußt, auch da, wo er durch einen wunderbaren Instinkt erfindet, von einer spekulativen Richtung der Vernunft abhängen, die sich vielleicht nur in andern deutlich offenbart. Auch wird eines jeden philosophische Denkungsart sich in der Sprache, in der Methode, in der Darstellung, bei jedem wissenschaftlichen Werke aussprechen. Sondern deswegen tritt die Philosophie hier zurück, weil, wenn auf akademische Weise die Wissenschaften gemeinschaftlich sollen gefördert werden, alles rein Philosophische schon so muß in Richtigkeit gebracht sein, daß fast nichts mehr darüber zu sagen ist. Diese Voraussetzung scheint freilich bisher nirgends unter uns vollkommen begründet gewesen zu sein, und man würde vielleicht nicht $\mathrm{zu}$ viel einräumen, wenn man gestände, eine solche völlige Einigung und Befriedigung in Sachen der Philosophie könne sogar unter einem Volk, wenn es ihm wirklich ernst ist mit der Sache, nie als wirklich vollendet gegeben sein, sondern nur durch eine immer fortschreitende Annäherung und Verständigung. Allein jede Akademie macht dennoch diese Vorausset- 
zung notwendig, wenigstens insofern, daß es ihr natürlich ist, dasjenige, was in dieser Hinsicht schon geschehen ist, als die Hauptsache anzusehn, und was noch übrig ist, als das Kleinere. Eine spekulative Abteilung kann sie eigentlich nur in dem Sinne haben, daß sie, voraussetzend, es gebe unter einem Volke nur eine philosophische Denkungsart, die Einerleiheit dessen, was zu verschiedenen Zeiten verschieden ausgedrückt worden ist, darstellt, die in einer und derselben Zeit gegeneinander tretenden Differenzen beleuchtet, was sich philosophisch gebärdet und doch nur Polemik gegen die Philosophie ist, in seiner Blöße zeigt, kurz durch historische und kritische Behandlung des auf diesem Gebiete Vorhandenen jene Annäherung und Selbstverständigung der Nation befördert. Selbst hervorzubringen aber und neue Wege einzuschlagen auf dem Gebiete der eigentlichen Philosophie, dies scheint der Akademie weniger zuzukommen. Dagegen ist für die Universität allgemein anerkannt der philosophische Unterricht die Grundlage von allem, was dort getrieben wird; und weil eben diese höchsten Ansichten vorzüglich mitgeteilt werden sollen, und zwar auf die individuellste Weise, so müssen sie auch in ihrer Differenz von allem, was Gleichartiges neben ihnen besteht, dargestellt werden, daher auf und zwischen Universitäten vorzüglich die philosophischen Streitigkeiten ihren Platz haben, und auf ihnen vornehmlich die philosophischen Schulen sich bilden.

So ist die Universität in Absicht ihres Hauptzweckes etwas ganz Eigentümliches, von Schule und Akademie gleich wesentlich Verschiedenes; allein äußerlich, das will nicht sagen zufällig, sondern so wie es für jedes Innere notwendig ein Äußeres gibt, äußerlich hat sie ebenso notwendig etwas Ähnliches von beiden; sonst würde es auch wunderliche Sprünge geben in dem wissenschaftlichen Leben der einzelnen Menschen. Der wissenschaftliche Geist als das höchste Prinzip, die unmittelbare Einheit aller Erkenntnis kann nicht etwa für sich allein hingestellt und aufgezeigt werden in bloßer Transzendentalphilosophie, gespensterartig, wie leider 
manche versucht und Spuk und unheimliches Wesen damit getrieben haben. Leerer läßt sich wohl nichts denken, als eine Philosophie, die sich so rein auszieht, und wartet, daß das reale Wissen, als ein niederes, ganz anders woher soll gegeben oder genommen werden; und vergeblicher für die Wissenschaft würde wohl nichts die Jünglinge in den schönsten Jahren vorzüglich beschäftigen, als eine Philosophie, die keine bestimmte Leitung für das künftige wissenschaftliche Leben in allen Fächern gäbe, sondern höchstens diente, den Kopf aufzuräumen, was man ja schon an der gemeinen Mathematik rühmt. Sondern nur in ihrem lebendigen Einfluß auf alles Wissen läßt sich die Philosophie, nur mit seinem Leibe, dem realen Wissen zugleich läßt dieser Geist sich darstellen und auffassen. Daher werden auf der Universität auch Kenntnisse mitgeteilt, höhere zum Teil und andere, die in dem Plan der Schule gar nicht lagen. Insofern entsteht also Zulernen, und die Universität ist zugleich Nachschule. Ebenso ist sie auch Vorakademie. Der wissenschaftliche Geist, der durch den philosophischen Unterricht geweckt ist, und durch Wiederanschauung des vorher schon Erlernten aus einem höheren Standpunkt sich befestiget und zur Klarheit kommt, muß seiner Natur nach auch gleich seine Kräfte versuchen und üben, indem er von dem Mittelpunkt aus sich tiefer in das einzelne hineinbegibt, um $\mathrm{zu}$ forschen, $\mathrm{zu}$ verbinden, Eignes hervorzubringen und durch dessen Richtigkeit die erlangte Einsicht in die Natur und den Zusammenhang alles Wissens zu bewähren. Dies ist der Sinn der wissenschaftlichen Seminarien und der praktischen Anstalten auf der Universität, welche alle durchaus akademischer Natur sind. Daher auch beide Benennungen wieder in die Universität hineinspielen, und sie oft hohe Schule genannt wird, und dann wieder Akademie. Daher es Unverstand ist, zu behaupten, Universitäten dürften solche Anstalten nicht haben, weil sie nur für Akademien gehörten.

Dies scheint im wesentlichen, wie aus der Betrachtung ihrer Hauptzüge hervorgeht, das Verhältnis jener drei verschiedenen 
Anstalten zu dem gemeinschaftlichen Zwecke zu sein; und in der Tat, wenn sie wohl eingerichtet sind und recht ineinandergreifen, so scheint gar nichts zu fehlen, sondern dieser Zweck vollständig durch sie erreicht werden zu müssen. Um desto verderblicher aber muß es auch sein, wenn sie ihr Gebiet und ihre Grenzen verkennen. Verderblich, wenn die Schulen sich hinauf versteigen wollen und spielen mit philosophischem Unterricht, um vorzuspiegeln, als sei es nur ein leerer Schein mit dem wesentlichen Unterschiede zwischen ihnen und den Universitäten. Denn nicht sicherer können die Zöglinge verdorben werden für letztere, und für das wissenschaftliche Leben überhaupt, als wenn man sie anleitet, auch die höchste Wissenschaft, die nur Geist und Leben sein kann, und sich sehr wenig äußerlich gestaltet, nur so anzusehen wie eine Summe einzelner Sätze und Angaben, die man ebenso erwerben und besitzen kann wie andere Schulkenntnisse. Verderblich, wenn die Universitäten ihrerseits jenes Vorgeben wahr machen und in der Tat nur fortgesetzte Schulen werden, indem sie zwar voreiligerweise Akademien vorstellen und vollendete Gelehrte treibhäuslich bei sich ausbilden wollen durch immer tieferes Hineinführen in das Detail der Wissenschaften, dabei aber, was ihnen eigentlich obliegt, nämlich den allgemeinen wissenschaftlichen Geist zu wecken und ihm eine bestimmte Richtung zu geben, darüber vernachlässigen. Verderblich, wenn die Akademien von Parteigeist ergriffen sich in spekulative Streitigkeiten einlassen, oder ebenso verderblich, wenn sie, in ein nicht allzuwohl begründetes reales Wissen eingehüllt, hochmütig herabsehend auf jene Zwistigkeiten, denen etwa die Lebhaftigkeit der mitteilenden Begeisterung den Anschein des Leidenschaftlichen gibt, sich wenig darum kümmern, ob diejenigen, die sie zur Bereicherung der Wissenschaften unter sich aufnehmen, durch diese spekulativen Untersuchungen hindurchgegangen sind oder nicht.

Woher aber diese Mißverständnisse so häufig? Gewiß großenteils aus Mangel an inniger Einheit in allem, was für die Wissenschaft 
und durch sie unter uns da ist. Wer nur in einer dieser Formen des wissenschaftlichen Vereins lebt, dem kann es gar leicht begegnen, daß er, durch Vorurteile verleitet, vergessend was ihm die andern früher gewesen sind, sie für nichts hält, und die seinige zu allem machen will. Diese Vorurteile finden sich auch überall. Was ist gewöhnlicher, als daß akademische Gelehrte auf den Schulmann als auf einen Unglücklichen, in hartes Joch Verdammten herabsehn, der, um nur seine Pflicht zu erfüllen, sich unvermeidlich gewöhnen müsse, pedantisch an Kleinigkeiten zu haften, und der in den Vorhof der Wissenschaften eingezwängt, die höchsten Genüsse derselben für immer entbehre? Was gewöhnlicher, als daß sie den Universitätslehrer als einen sich vornehmer dünkenden Schulmann betrachten, der gleichsam nur ihr Diener sei, bestimmt, die Wissenschaften, wie sie sie ihm übergeben, fortzupflanzen, und ihrem Gange demütig zu folgen als der Unsterblichen Fußtritte? So verschreit wiederum der Schulmann die Akademiker als Müßiggänger, weil sie wenig täten im Vergleich mit ihm zur Ausbreitung des Reiches der Wissenschaften, und klagt über die Universitätslehrer, als über anmaßende Undankbare, die oft die bessere Hälfte von dem wieder verdürben, was er gebaut hat. Diese wiederum beweisen den Schulmännern Geringschätzung, als solchen, die nur am Buchstaben kleben, und denen der Geist ihrer eignen Wissenschaft größtenteils fremd bleibt, und schildern die Akademien als Versorgungs- oder Mitleidsanstalten für zudringliche, falschberühmte oder abgelebte Gelehrte. Wie verkehrt ist dieses alles! Der tüchtige Vorsteher einer gelehrten Schule muß als Gegengewicht gegen das, was er beständig auszuüben hat, und selbst als Leitung dafür, eine Umsicht des Ganzen besitzen, durch die er in seiner Person die Akademie repräsentiert; er bedarf derselben wissenschaftlichen Besonnenheit, desselben reinen Beobachtungsgeistes, wie einer, der die Wissenschaft weiter fördert, und die Entwicklung der Jugend, die er leitet, ist wohl schwieriger als irgend eine einzelne Untersuchung. Wie der Akademiker in einsamer Meditation alle vorhandenen Resultate erwägen, alle 
Andeutungen benutzen, und so neue Entdeckungen fördern, und wie der Universitätslehrer immer in demselben Kreise sich umdrehend mit der erkenntnislustigen Jugend leben und sie auf alle Weise erregen, dies sind freilich zwei sehr verschiedene Beschäftigungen: aber von der einen aus über die andere als über etwas weit Geringeres hinwegsehen, das kann doch nur der, welcher gar nicht beide miteinander verbindet. Und es ist unmöglich, daß dies dem ausgezeichnetern Gelehrten begegne. Denn auch der stillste emsigste Forscher muß eben in seinen glücklichsten Augenblicken, in denen der Entdeckung, welche doch allemal auch zu einer neuen lebendigern Ansicht des Ganzen führt, sich $\mathrm{zu}$ der belebendsten begeisterten Mitteilung aufgelegt fühlen, und wünschen, sich im Geiste der Jünglinge ausgießen zu können. Und kein bedeutender Universitätslehrer kann wohl eine Zeitlang seinen Lehrstuhl würdig ausgefüllt haben, ohne auf Untersuchungen und Aufgaben gestoßen zu sein, die ihm den großen Wert einer Vereinigung fühlbar machen, in der jeder bei allen Unterstützung und Hilfe findet auf seinem wissenschaftlichen Wege. Um aber diese gegründete gegenseitige Wertschätzung bei allen immer zu erhalten, müßte eine genauere Gemeinschaft gestiftet sein zwischen den öffentlichen Bildungsanstalten; die vortrefflichsten Schulmänner, Universitätslehrer und Akademiker müßten gemeinschaftlich an der Spitze der wissenschaftlichen Angelegenheiten stehen, dann würde sich wahrer Gemeinsinn für ihre ganze Sache von ihnen aus unter allen Gelehrten immer weiter verbreiten.

Geschieht das nicht? wird man fragen; vereinigt nicht der Staat Gelehrte aus allen diesen verschiedenen Klassen in den Verwaltungsräten, durch welche er die Sache des öffentlichen Unterrichtes leitet? Wohl; aber als Staatsdiener vereiniget er sie da mit andern Geschäftsmännern, unter ihm eigentümlichen, ihnen aber fremden Formen, zu einer Aufsicht, die alles immer vorzüglich in Beziehung auf den Staat betrachtet. Von hier aus gibt es für 
die Verhältnisse dieser Anstalten eine ganz andere Ansicht; und jemehr bei so beamteten Gelehrten ihr Verhältnis als Staatsdiener überwiegt, was so natürlich erfolgen muß, um desto leichter tragen sie dann auch diese Ansicht auf ihren eigentlich wissenschaftlichen Wirkungskreis über, alles schätzend und behandelnd nach seinem unmittelbaren Einfluß auf den Staat, und, wie auch die Erfahrung lehrt, gewiß nicht zum Vorteil der geistigen Verbesserung. Es ist dem ganzen Gang neueuropäischer Bildung angemessen, daß die Regierungen auch der Wissenschaften sich aufmunternd annehmen und die Anstalten zu ihrer Verbreitung in Gang bringen mußten, wie es mit Künsten und Fertigkeiten aller Art der Fall zu sein pflegt. Allein hier wie überall kommt eine Zeit, wo diese Vormundschaft aufhören muß. Sollte diese nicht für Deutschland allmählich eintreten, und wenigstens in dem protestantischen Teile desselben bald ratsam sein, daß der Staat die Wissenschaften sich selbst überlasse, alle innern Einrichtungen gänzlich den Gelehrten als solchen anheimstelle, und sich nur die ökonomische Verwaltung, die polizeiliche Oberaufsicht und die Beobachtung des unmittelbaren Einflusses dieser Anstalten auf den Staatsdienst vorbehalte? Die Akademien, denen die Regierungen immer nur einen mittelbaren Einfluß auf ihre Zwecke zutrauten, sind von jeher freier gewesen, und haben sich wohl dabei befunden. Aber Schulen und Universitäten leiden je länger je mehr darunter, daß der Staat sie als Anstalten ansieht, in welchen die Wissenschaften nicht um ihret-, sondern um seinetwillen betrieben werden, daß er das natürliche Bestreben derselben, sich ganz nach den Gesetzen, welche die Wissenschaft fordert, $\mathrm{zu}$ gestalten, mißversteht und hindert, und sich fürchtet, wenn er sie sich selbst überließe, würde sich bald alles in dem Kreise eines unfruchtbaren, vom Leben und von der Anwendung weit entfernten Lernens und Lehrens herumdrehen, vor lauter reiner Wißbegierde würde die Lust zum Handeln vergehn, und niemand würde in die bürgerlichen Geschäfte hinein wollen. Dies scheint seit langer Zeit die Hauptursache zu sein, weshalb der Staat sich 
zu sehr auf seine Weise dieser Dinge annimmt. Und allerdings kann man nicht leugnen, daß, wenn den Reden zu glauben wäre, die bisweilen einige Philosophen führen, so würden diese alle ihre Schüler, und sie wissen die Jugend sehr zu fesseln, von aller bürgerlichen Tätigkeit zurückhalten. Allein warum sollte man das, und warum dem vorübergehenden Reiz einen so dauernden Einfluß zuschreiben? So ist von jeher gesprochen worden, und von jeher sind die jungen Männer aus den Schulen der Weisen unmittelbar in die Säle der Gerichtshöfe und die Verwaltungskammern geströmt, um die Menschen beherrschen zu helfen. Schauen und Tun, wenn sie auch gegeneinander reden, arbeiten einander immer in die Hände; das Verhältnis zwischen denen, welche sich der bloßen Wissenschaft widmen, und den übrigen bestimmt die Natur selbst immer richtig und sehr ebenmäßig. Man vergleiche nur den großen Haufen derer, welche durch die Schulen und Universitäten hindurchgehn, mit der kleinen Anzahl derer, welche endlich die Akademie eines Volkes bilden, und betrachte, wie viele auch von den letzteren noch zugleich angesehene Staatsdiener sind, um sich hierüber für immer zu beruhigen, und zu gestehen, daß der Staat Vorsprung genug hat durch die vielen Vorteile, die er allein bieten kann, und durch die Gewalt, mit welcher politisches Talent, wo es sich irgend findet, immer durchzubrechen weiß. Nährt aber der Staat durch falsche Besorgnisse und darauf gegründete Anordnungen jene Mißverständnisse der mit der Verbreitung der Wissenschaften beschäftigten Gelehrten unter sich: so werden die Schulen ungründlich; auf den Universitäten wird die Hauptsache unter einer Menge von Nebendingen erstickt; die Akademien werden verächtlich, wenn sie sich je länger je mehr mit lauter unmittelbar nützlichen Dingen beschäftigen, und der Staat beraubt sich selbst auf die Länge der wesentlichsten Vorteile, welche ihm die Wissenschaften gewähren, indem es ihm je länger je mehr an solchen fehlen muß, die Großes auffassen und durchführen, und mit scharfem Blick die Wurzel und den Zusammenhang aller Irrtümer aufdecken können. 


\section{Nähere Betrachtung der Universität im allgemeinen}

Die Vergleichung der Universität mit den Schulen und Akademien hat uns ihren wesentlichen Charakter gezeigt, vermöge dessen sie notwendig in die Mitte tritt zwischen beide, daß nämlich durch sie der wissenschaftliche Geist in den Jünglingen soll geweckt und zu einem klaren Bewußtsein gesteigert werden. Und dies haben wir fast ohne Beweis, wie es denn höchst anschaulich ist für sich, hinzugenommen, daß hiezu die formelle Spekulation allein nicht hinreiche, sondern diese gleich verkörpert werden müsse in dem realen Wissen. Auch genügt hiezu nicht etwan eine beliebige Auswahl von Kenntnissen, wie auf Schulen zur gymnastischen Übung. Denn der wissenschaftliche Geist ist seiner Natur nach systematisch, und so kann er unmöglich in einem einzelnen zum klaren Bewußtsein gedeihen, wenn ihm nicht auch das Gesamtgebiet des Wissens wenigstens in seinen Grundzügen zur Anschauung kommt. Noch weniger können sich in den Einzelnen der allgemeine Sinn und das besondere Talent vereint zu einem eigentümlichen intellektuellen Leben ausbilden, wenn nicht auf der Universität jeder dasjenige findet, was sein besonderes Talent anregen kann. Die Universität muß also alles Wissen umfassen, und in der Art, wie sie für jeden einzelnen Zweig sorget, sein natürliches inneres Verhältnis zu der Gesamtheit des Wissens, seine nähere oder enferntere Beziehung auf den gemeinschaftlichen Mittelpunkt ausdrücken. Nur eine Abweichung hievon, scheint es, kann man gestatten, daß nämlich dasjenige überwiegend hervorgezogen werde, wohin sich überhaupt das Talent der Nation vorzüglich neigt; eine $\mathrm{Ab}$ weichung, die sich auch nur in den der Akademie sich nähernden Veranstaltungen der Universität zeigen dürfte.

So müßte es sein, wenn ohne fremden Einfluß der wissenschaftliche Trieb allein die Universitäten errichtete und ordnete. Sehen wir aber, wie sie sind, so finden wir alles ganz anders. Wissenschaftlich angesehen erscheint das meiste höchst unverhältnismä- 
ßig, dem Unbedeutenden ein großer Raum vergönnt, vieles, was an sich gar nicht zusammenzugehören scheint, äußerlich verbunden, Wichtiges dagegen verkürzt, oder noch ganz neu aussehend, als ob es erst hinzugekommen wäre, vieles auch so behandelt, als wäre es gar nicht für die bestimmt, in denen wissenschaftlicher Geist sich entwickeln will, sondern für die, denen er ewig fremd bleiben muß.

Offenbar geht dieser Geist nicht in jedem, auch nicht in allen denen auf, die wohl fähig und geneigt sind, eine schöne Masse von Kenntnissen zu sammeln und in gewissem Sinne zu verarbeiten. Deshalb soll schon die gelehrte Schule nur eine Auswahl junger Naturen in sich fassen, und aus diesen selbst wiederum nur eine Auswahl zur Universität senden; allein weil sie nur vorbereitend ist, und nicht bestimmt, diese Gesinnung selbst schon ans Licht zu bringen, so kann sie auch über den Grad der wissenschaftlichen Fähigkeit nicht zuverlässig und definitiv entscheiden. Sie schließt aus der Lust und Leichtigkeit, mit welcher die von ihr dargebotenen Kenntnisse aufgefaßt werden, aus der mehr oder minder aufkeimenden Vorliebe für den wissenschaftlichen Gehalt in denselben. Aber das alles ist ziemlich trüglich, und das Sicherste davon grade am wenigsten in eine äußerlich gültige Form zu bringen. Wie oft findet man erstaunlichen Fleiß und große Lust und Liebe, die sich nur für den Kenner durch etwas gar unbewußtes Tierisches unterscheidet, bei gar wenig Geist und Talent. Ja bei manchen öffnet sich grade in dieser entscheidenden Zeit eine taube Blüte, die nur zu leicht für fruchtbar gehalten wird. Und wiederum, wenn die Schule sich in ihrem Urteil die größte Strenge zum Gesetz machen wollte: wie manche, die sich erst später entwickelt hätten, würden dann voreilig der ferneren Pflege beraubt! Kurz, es ist unvermeidlich, daß viele zur Universität kommen, die eigentlich untauglich sind für die Wissenschaft im höchsten Sinne, ja daß diese den größeren Haufen bilden, weil in der Tat dies weit weniger nachteilig sein kann, als wenn ein 
einziges großes und entschiedenes Talent die wohltätigen Einflüsse dieser Anstalt ganz entbehren müßte. Der Gedanke, schon auf der Schule oder beim Abgehn von derselben eine Trennung festzusetzen zwischen denen, welche der höchsten wissenschaftlichen Bildung fähig, und denen, die für eine untergeordnete Stufe bestimmt sind, und für letztere eigene Anstalten zu stiften, wo sie ohne die philosophischen Anleitungen der Universität gleich für ihr bestimmtes Fach der Erkenntnis mehr handwerksmäßig und traditionell weitergebildet würden, dieser Gedanke ist jedem furchtbar und schrecklich, der an der Bildung der Jugend einen lebendigen Anteil nimmt. Nicht in eine Zeit gehört er, wo jede Aristokratie der Natur der Sache nach untergehen muß, sondern in eine solche, wo man sie erst recht pflegen und erweitern will. Oder meint man, angehende Jünglinge, welche sich auf gelehrten Schulen auch nur mit einigem Erfolge gebildet haben, sollten sich selbst zu einer Zeit, wo sie unmöglich schon sich selbst zu erkennen vermögen, das Urteil einer solchen Herabsetzung sprechen, und nicht vielmehr nach aller Herrlichkeit der Wissenschaft ihre Hand ausstrecken wollen? Solche verdienten wirklich, ganz verstoßen und verunehrt zu werden! Nein, man lasse zusammen die trefflicheren und die minderen Köpfe erst die entscheidenden Versuche durchgehen, welche auf der Universität angestellt werden, um ein eignes wissenschaftliches Leben in den Jünglingen zu erzeugen, und erst, wenn diese alle ihres höchsten Zweckes verfehlt haben, werden sich von selbst die meisten auf die untergeordnete Stufe treuer und tüchtiger Arbeiter stellen. Solcher bedarf der wissenschaftliche Verein gar sehr; denn die wenigen wahrhaft herrschenden und bildenden Geister können gar viele Organe in Tätigkeit setzen. Darum müssen die Universitäten so eingerichtet sein, daß sie zugleich höhere Schulen sind, um diejenigen weiter $\mathrm{zu}$ fördern, deren Talente, wenn sie auch selbst auf die höchste Würde der Wissenschaft Verzicht leisten, doch sehr gut für dieselbe gebraucht werden können. Und zwar darf sich dies nicht als eine besondere Veranstaltung äußerlich unterscheiden lassen, weil ja 
auch beide Klassen von Lernenden nicht äußerlich unterschieden sind, sondern sich erst durch die Tat selbst voneinander trennen sollen. Noch mehr aber bedarf der Staat von diesen Köpfen der zweiten Klasse. Er kann sehr wohl einsehen, daß die obersten Geschäfte in jedem Zweige nur denen mit Vorteil anvertraut werden, welche von wissenschaftlichem Geiste durchdrungen sind, und wird doch danach streben müssen, daß ihm auch der größte Teil von jenen untergeordneten Talenten anheimfalle, welche auch ohne diesen höheren Geist ihm durch wissenschaftliche Bildung und eine Masse von Kenntnissen brauchbar sind. Daher muß er nun aus demselben Grunde dafür sorgen, daß die Universitäten zugleich höhere Spezialschulen seien für alles dasjenige, was von den in seinem Dienst nutzbaren Kenntnissen zunächst mit der eigentlichen wissenschaftlichen Bildung zusammenhängt; und wenn es auch auf diesem Gebiete nicht ebenso notwendig ist, ist es doch natürlich genug, auch hier die äußere Unterscheidung zu vermeiden.

So weit ist also alles gut, und auch dies letztere nicht als ein Mißbrauch, oder als eine Verunreinigung rein wissenschaftlicher Anstalten anzusehen; sondern vielmehr vortrefflich, weil auf diese Weise doch auch in der größeren Masse der Gebildeten so viel, als jedem möglich ist, aufgeregt werden kann, wenigstens vom Sinn für wahre Erkenntnis, weil denen, die eine solche Schule gemacht haben, wenigstens eingeprägt bleiben muß das Gefühl der Abhängigkeit der Kenntnisse, die sie dort einsammelten von den höheren wissenschaftlichen Bestrebungen, und weil die Bildungsanstalten für den Dienst des Staates durch ihre Verbindung mit den rein wissenschaftlichen empfänglicher bleiben müssen für jede Verbesserung, und in sich selbst lebendiger. Und dieses ist unstreitig das Wesen der deutschen Universitäten, wie sie seit langer Zeit wirklich sind. Wenn aber hie und da die Regierungen anfangen, den politischen Teil dieser Anstalten für die Hauptsache anzusehen, hinter welcher das eigentlich Wissenschaftliche in je- 
dem streitigen Falle zurückstehen müsse: so ist das schon ein sehr verderblicher Mißverstand; und wenn sie gar wünschen, der Form der Universität ganz überhoben zu sein, und an die allgemeinen gelehrten Schulen gleich die Spezialschulen für die verschiedenen Fächer des Staatsdienstes anknüpfen zu können, so ist dies ein trauriges Zeichen davon, daß man den Wert der höchsten Bildung für den Staat verkennt, und daß man den bloßen Mechanismus dem Leben vorzieht. Ja, wo ein Staat die Universitäten, den Mittelpunkt, die Pflanzschule aller Erkenntnis zerstörte, und alle dann nur noch gleichsam wissenschaftlichen Bestrebungen zu vereinzeln und aus ihrem lebendigen Zusammenhang herauszureißen suchte: da darf man nicht zweifeln: die Absicht oder wenigstens die unbewußte Wirkung eines solchen Verfahrens ist Unterdrückung der höchsten freiesten Bildung und alles wissenschaftlichen Geistes, und die unfehlbare Folge das Überhandnehmen eines handwerksmäßigen Wesens und einer kläglichen Beschränktheit in allen Fächern. Unüberlegt handeln diejenigen, oder sind von einem undeutschen verderblichen Geiste angesteckt, die uns eine Umbildung und Zerstreuung der Universitäten in Spezialschulen vorschlagen; so wie in jedem Lande, wo jene Form von selbst ausstürbe, oder wo, auch wenn die Regierung es nicht hinderte, doch nie eine wahre Universität zustande käme, sondern alles immer schulmäßig bliebe, die Wissenschaft gewiß im Rückgang und der Geist im Einschlafen begriffen sein müßte.

Wie nun, so lange der Staat die Grenzen des rechtmäßigen Einflusses, den ihm die Wissenschaft gestatten kann, nicht überschreitet, der Unterricht auf der Universität sich gestalten muß, das läßt sich an jeder nur noch mittelmäßig eingerichteten leicht erkennen. Das Allgemeinste nämlich ist allen gemein, und alle beginnen damit, und trennen sich erst späterhin auf dem Gebiete des Besondern, nachdem in jedem sein eigentümliches Talent und mit demselben die Liebe zu dem Geschäft erwacht ist, in welchem er es vorzüglich kann geltend machen. Alles also beginnt 
mit der Philosophie, mit der reinen Spekulation, und was etwa noch propädeutisch als Übergang von Schule zu Universität dazu gehört. Nur beruht das Leben der ganzen Universität, das Gedeihen des ganzen Geschäftes darauf, daß es nicht die leere Form der Spekulation sei, womit allein die Jünglinge gesättigt werden, sondern daß sich aus der unmittelbaren Anschauung der Vernunft und ihrer Tätigkeit die Einsicht entwickele in die Notwendigkeit und den Umfang alles realen Wissens, damit von Anfang an der vermeinte Gegensatz zwischen Vernunft und Erfahrung, zwischen Spekulation und Empirie vernichtet, und so das wahre Wissen nicht nur möglich gemacht, sondern seinem Wesen nach wenigstens eingehüllt gleich mit hervorgebracht werde. Denn ohne hier über den Wert der verschiedenen philosophischen Systeme zu entscheiden, ist doch klar, daß sonst gar kein Band sein würde zwischen dem philosophischen Unterricht und dem übrigen, und gar nichts bei demselben herauskommen, als etwa die Kenntnis der logischen Regeln und ein in seiner Bedeutung und Abstammung nicht verstandener Apparat von Begriffen und Formeln. Die Aussicht also muß eröffnet werden schon durch die Philosophie in die beiden großen Gebiete der Natur und der Geschichte, und das Allgemeinste in beiden muß nicht minder allen gemein sein. Von der höhern Philologie, sofern in der Sprache niedergelegt sind alle Schätze des Wissens und auch die Formen desselben sich in ihr ausprägen, von der Sittenlehre, sofern sie die Natur alles menschlichen Seins und Wirkens darlegt, müssen die Hauptideen jedem einwohnen, wenn er auch seine besondere Ausbildung mehr auf der Seite der Naturwissenschaft sucht; so wie sich kein wissenschaftliches Leben denken läßt für den, dem jede Idee von der Natur fremd bliebe, die Kenntnis ihrer allgemeinsten Prozesse und wesentlichsten Formen, der Gegensatz und Zusammenhang in dem Gebiete des Organischen und Unorganischen. Daher das Wesen der Mathematik, der Erdkenntnis, der Naturlehre und Naturbeschreibung jeder innehaben muß. Je mehr aber ins Besondere hinein, in Geschichtsforschung, Staats- 
und Menschenbildungskunst, in Geologie und Physiologie, desto mehr auch beschränkt sich jeder auf das Einzelne, wozu er berufen ist; und an diese Beschränkung wendet sich hernach der Staat mit seinen besondern Instituten für die, welche an der politischen und religiösen Fortbildung, sowie an der physischen Erhaltung und Vervollkommnung der Bürger arbeiten sollen; Institute, welche, wenn sie der Universität nicht ganz fremd und verderbliche Auswüchse auf ihr sein sollen, sich selbst abhängig erklären und erhalten müssen von der wissenschaftlichen Behandlung der Natur und der Geschichte, und mithin von der Philosophie.

Weil aber selbst hierin, und ohnerachtet an diesem Unterricht viele teilnehmen, denen der philosophische die wahre Weihe nicht gegeben hat, dennoch der äußere Unterschied, um auch von dieser Seite die Einheit des Ganzen nicht zu stören, möglichst vermieden wird, weil in jedem Unterricht, wenn er noch einigermaßen dem Charakter der Universität treu bleibt, die wissenschaftliche Darstellung die Hauptsache ist, und das Detail nur Wert hat als Belag, als Handhabe, als roher Stoff für die Versuche in eigner Kombination und Darstellung: so ist auch die Lehrweise mit geringen Abstufungen überall dieselbe.

Wenige verstehen die Bedeutung des Kathedervortrages; aber zum Wunder hat er sich, ohnerachtet immer von dem größten Teile der Lehrer sehr schlecht durchgeführt, doch immer erhalten, zum deutlichen Beweise, wie sehr er zum Wesen einer Universität gehört, und wie sehr es der Mühe lohnt, diese Form immer aufzusparen für die wenigen, die sie von Zeit zu Zeit recht zu handhaben wissen. Ja man könnte sagen, der wahre eigentümliche Nutzen, den ein Universitätslehrer stiftet, stehe immer in gradem Verhältnis mit seiner Fertigkeit in dieser Kunst.

Jede Gesinnung, die wissenschaftliche wie die religiöse, bildet und vervollkommnet sich nur im Leben, in der Gemeinschaft mehre- 
rer. Durch Ausströmung aus den Gebildetern, Vollkommenern, wird sie zuerst aufgeregt und aus ihrem Schlummer erweckt in den Neulingen; durch gegenseitige Mitteilung wächst sie und stärkt sich in denen, die einander gleich sind. Wie nun die ganze Universität ein solches wissenschaftliches Zusammenleben ist, so sind die Vorlesungen insbesondere das Heiligtum desselben. Man sollte meinen, das Gespräch könne am besten das schlummernde Leben wecken und seine ersten Regungen hervorlocken, wie denn die bewundernswürdige Kunst des Altertums in dieser Gattung noch jetzt dieselben Wirkungen äußert. Es mag auch so sein zwischen zweien, oder wo aus einer ganzen Menge einer als Repräsentant derselben mit Sicherheit kann aufgestellt werden, oder wenn einzelne die niedergeschriebenen trefflichen Werke dieser Art genießen, und gleichsam das Dargestellte an sich wiederholend durchleben. Allein es muß wohl nicht so sein unter vielen und in der neueren Zeit, weil doch ohnerachtet so mancher erneuerten Versuche das Gespräch nie als allgemeine Lehrform auf dem wissenschaftlichen Gebiet aufgekommen ist, sondern die zusammenhangende Rede sich immer erhalten hat. Es ist auch leicht einzusehen warum. Unsere Bildung ist weit individueller als die alte, das Gespräch wird daher gleich weit persönlicher, so daß kein einzelner im Namen aller als Mitunterredner aufgestellt werden kann, und das Gespräch eine viel zu äußerliche, nur verwirrende und störende Form sein würde. Aber der Kathedervortrag der Universität muß allerdings, weil er Ideen zuerst zum Bewußtsein bringen soll, doch in dieser Hinsicht die Natur des alten Dialogs haben, wenn auch nicht seine äußere Form; er muß darnach streben, einerseits das gemeinschaftliche Innere der Zuhörer, ihr Nichthaben sowohl als ihr unbewußtes Haben dessen, was sie erwerben sollen, andererseits das Innere des Lehrers, sein Haben dieser Idee und ihre Tätigkeit in ihm recht klar ans Licht zu bringen. Zwei Elemente sind daher in dieser Art des Vortrages unentbehrlich und bilden sein eigentliches Wesen. Das eine möchte ich das populäre nennen: die Darlegung des mut- 
maßlichen Zustandes, in welchem sich die Zuhörer befinden, die Kunst, sie auf das Dürftige in demselben hinzuweisen und auf den letzten Grund alles Nichtigen im Nichtwissen. Dies ist die wahre dialektische Kunst, und je strenger dialektisch, desto populärer. Das andere möchte ich das produktive nennen. Der Lehrer muß alles, was er sagt, vor den Zuhörern entstehen lassen; er muß nicht erzählen, was er weiß, sondern sein eignes Erkennen, die Tat selbst, reproduzieren, damit sie beständig nicht etwa nur Kenntnisse sammeln, sondern die Tätigkeit der Vernunft im Hervorbringen der Erkenntnis unmittelbar anschauen und anschauend nachbilden. Der Hauptsitz dieser Kunst des Vortrags ist freilich die Philosophie, das eigentlich Spekulative; aber alles Lehren auf der Universität soll ja auch hievon durchdrungen sein, also ist doch dies überall die eigentliche Kunst des Universitätslehrers. Zwei Tugenden müssen sich in ihr vereinigen: Lebendigkeit und Begeisterung auf der einen Seite. Sein Reproduzieren muß kein bloßes Spiel sein, sondern Wahrheit; so oft er seine Erkenntnis in ihrem Ursprung, in ihrem Sein und Gewordensein vortragend anschaut, so oft er den Weg vom Mittelpunkt zum Umkreise der Wissenschaft beschreibt, muß er ihn auch wirklich machen. Bei keinem wahren Meister der Wissenschaft wird das auch anders sein; ihm wird keine Wiederholung möglich sein, ohne daß eine neue Kombination ihn belebt, eine neue Entdeckung ihn an sich zieht; er wird lehrend immer lernen, und immer lebendig und wahrhaft hervorbringend dastehn vor seinen Zuhörern. Ebenso notwendig ist ihm aber auch Besonnenheit und Klarheit, um, was die Begeisterung wirkt, verständlich und gedeihlich $\mathrm{zu}$ machen, um das Bewußtsein seines Zusammenseins mit den Neulingen immer lebendig zu erhalten, daß er nicht etwa nur für sich, sondern wirklich für sie rede, und seine Ideen und Kombinationen ihnen wirklich zum Verständnis bringe und darin befestige, damit nicht etwa nur dunkle Ahndungen von der Herrlichkeit des Wissens in ihnen entstehen, statt des Wissens selbst. Kein Universitätslehrer kann wahren Nutzen stiften, wenn er von einer dieser 
Trefflichkeiten ganz entblößt ist; und die rechte gesunde Fülle der Anstalt besteht darin, daß, was etwa einem Lehrer, der von der einen Seite sich vorzüglich auszeichnet, an der andern menschlicherweise abgeht, durch einen andern ersetzt werde. Diese beiden Tugenden des Vortrags sind die wahre Gründlichkeit desselben, nicht eine Anhäufung von Literatur, welche dem Anfänger nichts hilft, und vielmehr in Schriften muß niedergelegt als mündlich mitgeteilt werden; aus ihnen fließt die echte Klarheit, nicht besteht sie in unermüdetem Wiederkäuen, in preiswürdiger Dünne und Dürre des Gesagten; aus ihnen die wahre Lebendigkeit, nicht aus dem Reichtum gleichbedeutender Beispiele und, gleichviel ob guter oder schlechter, nebenherlaufender Einfälle und polemischer Ausfälle. Wunderbar genug ist die Gelehrsamkeit eines Professors zum Sprichwort geworden. Je mehr er besitzt, desto besser freilich; aber auch die größte ist unnütz ohne die Kunst des Vortrages. Übet der Lehrer diese an seinen Schülern gehörig aus, so kann es wenig schaden, wenn sie ihn auch bisweilen darauf ertappen, etwas Einzelnes auf dem Gebiet seiner Wissenschaft nicht $\mathrm{zu}$ wissen; sie werden dennoch wissen, daß er die Wissenschaft als solche vollkommen besitzt. Ja man kann immer hoffen, daß einem jungen Universitätslehrer die Gelehrsamkeit noch komme: wenn er aber jenes Talent der Mitteilung nicht in den Jahren hat, wo er seinen Zuhörern am nächsten steht, so wird er es späterhin schwerlich erlangen. Was hilft alle Gelehrsamkeit, wenn statt des echten Kathedervortrags nur der falsche Schein, die leere Form davon vorhanden ist! Nichts Jämmerlicheres zu denken als dieses. Ein Professor, der ein ein für allemal geschriebenes Heft immer wieder abliest und abschreiben läßt, mahnt uns sehr ungelegen an jene Zeit, wo es noch keine Druckerei gab, und es schon viel wert war, wenn ein Gelehrter seine Handschrift vielen auf einmal diktierte, und wo der mündliche Vortrag zugleich statt der Bücher dienen mußte. Jetzt aber kann niemand einsehn, warum der Staat einige Männer lediglich dazu besoldet, damit sie sich des Privilegiums erfreuen sollen, die Wohltat der Druckerei ignorieren zu 
dürfen, oder weshalb wohl sonst ein solcher Mann die Leute zu sich bemüht, und ihnen nicht lieber seine ohnehin mit stehenbleibenden Schriften abgefaßte Weisheit auf dem gewöhnlichen Wege schwarz auf weiß verkauft. Denn bei solchem Werk und Wesen von dem wunderbaren Eindruck der lebendigen Stimme zu reden, möchte wohl lächerlich sein.

Soll aber der Vortrag den geforderten Charakter haben: so dürfen freilich die eigentlichen Vorlesungen nicht das einzige Verkehr des Lehrers mit seinen Schülern sein. Steife Zurückgezogenheit und Unfähigkeit, auch außerhalb des Katheders noch etwas für die studierende Jugend zu sein, hängen auch gewöhnlich mit den schon gerügten Untugenden des Vortrages zusammen. Wenn der Lehrer mit Nutzen anknüpfen soll an den Erkenntniszustand der Zuhörer; wenn er ihnen helfen soll, die Abweichungen zu vermeiden, zu welchen sie hinneigen; wenn er sich glücklich hindurcharbeiten soll durch die unter ihnen herrschenden Unfähigkeiten im Auffassen: so müssen noch andere Arten und Stufen des Zusammenlebens mit ihnen ihm zustatten kommen, um ihn in der nötigen Bekanntschaft mit den immer abwechselnden Generationen zu erhalten. Man sage nicht, daß dies der Zahl wegen unmöglich sei. Es schließt sich an die Vorlesungen eine Kette von Verhältnissen, an denen, je vertrauter sie werden, schon von selbst desto wenigere teilnehmen, Konversatorien, Wiederholungs- und Prüfungsstunden, solche, in denen eigne Arbeiten mitgeteilt und besprochen werden, bis zum Privatumgang des Lehrers mit seinen Zuhörern, wo das eigentliche Gespräch dann herrscht, und wo er, wenn er sich Vertrauen zu erwerben weiß, durch die Äußerungen der erlesensten und gebildetsten Jünglinge von allem Kenntnis erlangt, was irgend auf eine merkwürdige Weise in die Masse eindringt und sie bewegt. Nur indem er allmählich diese Verhältnisse knüpft und benutzt, kann der Lehrer die herrliche Sicherheit der Alten, welche immer den rechten Fleck trafen in ihren Unterredungen, verbinden mit der edeln Bescheidenheit der 
Neueren, welche eine schon angefangene und selbständig fortgehende individuelle Bildung jedes einzelnen immer voraussetzen müssen.

Man sieht, diese Gabe der Mitteilung läßt noch die mannigfaltigsten Verschiedenheiten zu. Dem einen wird besser gelingen, das Scheinwissen zu demütigen und das Bedürfnis wahrer Wissenschaft zu erregen, dem andern, die Grundzüge derselben anschaulich darzustellen; der eine wird mehreren durch Begeisterung die erste Weihe geben, der andere mehr sie durch Besonnenheit befestigen; der eine wird geschickter sein, indem er nur scheint es mit dem Einzelnen und Mannigfaltigen zu tun $\mathrm{zu}$ haben, doch immer zu der innersten und höchsten Einheit die Betrachtung zurückzuführen; ein anderer wird mit seinem Talent mehr dem Einzelnen angehören, und es auch da vorwalten lassen, wo er an das Allgemeinste und Höchste geheftet zu sein scheint. Jeder aber wird ein vortrefflicher Lehrer sein, bei welchem sich, wie auch das eine oder das andere überwiege, doch alles Notwendige lebendig vereint findet; und die Universität muß auch darin Universität sein, daß sie alle diese Verschiedenheiten in sich zu vereinigen strebt, damit jeder Zögling imstande sei, einen solchen Lehrer zu finden, wie ihn unter den gegebenen Umständen und bei den gemachten Fortschritten seine Natur begehrt.

Allein wie lebendig und glücklich auch dieses Bestreben sei, ein völliges Gleichgewicht, so daß für jedes Bedürfnis auf gleich vollkommene Art gesorgt sei, wird doch auf einer solchen Anstalt wohl nie erreicht werden. Jede wird sich zu jeder Zeit auf irgend eine Seite hinneigen. Die eine wird sich auszeichnen durch lebendigere Erregung des wissenschaftlichen Geistes im allgemeinen, aber in den meisten Fächern vielleicht zurückbleiben in gründlicher Ausführung des Einzelnen, die andere umgekehrt dieses mehr leisten als jenes; die eine wird vorzüglicher sein in rein philosophischer Hinsicht, die andere als Vorakademie oder als Ag- 
gregat von Spezialschulen; die eine mehr ihren Zöglingen vorarbeiten, und dagegen die freiere, höhere Kombination ihnen selbst überlassen, die andere sie mehr zu dieser anleiten, aber alles, was irgend Sache des Fleißes ist, ihnen selbst zumuten. Ja ziemlich lange behaupten oft Universitäten denselben Charakter, daß die eine mehr spekulative Köpfe bildet, die aber wohltun werden, die realen Wissenschaften anderwärts $\mathrm{zu}$ suchen, und eine andere lange Zeit fast nur Rotüriers erzieht, weil schon ein entschiedenes Talent dazu gehört, um auf ihr einen höheren wissenschaftlichen Geist zu entwickeln, welches dann die beiden schon gefährlichen Extreme der Einseitigkeit sind, zwischen welchen die übrigen besser schwanken. Dies deutet darauf, daß notwendig auch innerhalb des Gebietes einer und derselben Nationalbildung eine Mehrheit von Universitäten sich finden muß, und daß das möglichst freie Verkehr und der unbeschränkteste Gebrauch von jeder nach eines jeden Bedürfnis nicht zu entbehren ist. Wie natürlich diese Wahrheit ist, geht freilich schon daraus hervor, daß die Universitäten in der Mitte stehen zwischen den gelehrten Schulen und der Akademie. Achtunddreißig davon zu besitzen, wie die deutsche Nation bis jetzt geduldet hat, mag freilich ein großes Unglück sein, und die Ursache, warum so wenige zu etwas Tüchtigem gediehen sind: aber wie soll nun das rechte Maß gefunden werden? Man finde nur zuerst das rechte Maß der gelehrten Schulen, man bringe dann mehr Einigungsgeist unter die Deutschen, daß nicht jeder Gau auch hierin etwas Besonderes für sich haben wolle, und dann lasse man mehr die Sache selbst gewähren, künstle nicht, und wolle nicht Leichen frisch erhalten, so wird sich allmählich das Rechte finden. Doch immer noch besser hier das Maß überschritten, als den Gedanken an eine deutsche Zentraluniversität aufkommen lassen, oder den an eine gänzliche Umschmelzung der alten Form, zwei Extreme, von denen jedes das größte Unglück wäre, welches nach allen bisherigen den Deutschen noch begegnen könnte. 


\section{Von den Fakultäten}

Man hat schon oft und viel gesagt, unsere vier Fakultäten, die theologische, juridische, medizinische und philosophische, und noch in dieser Ordnung obenein, gäben den Universitäten ein gar groteskes Ansehn. Und das ist auch gewiß unleugbar. Wenn man es aber dennoch als einen großen Vorteil ansieht, den Umschaffungen oder bedeutende Veränderungen solcher Anstalten gewähren können, daß man dabei zugleich dieser Formen sich entledigen und bessere dafür einführen werde: so übereile man sich doch ja nicht, damit man nicht etwas ganz Willkürliches an die Stelle dessen setze, was sich auf eine natürliche Art gebildet, und eben seiner Natürlichkeit wegen so lange erhalten hat; sondern suche doch erst die Bedeutung dieser bisherigen Formen recht zu verstehen.

Durch das bisher Gesagte sollte dies Verständnis schon sehr erleichtert und vollständig eingeleitet sein. Es kann wohl von unserm Gesichtspunkt aus niemanden entgehen, daß diese Formen, wie grotesk sie auch sein mögen, wenigstens sehr repräsentativ sind, und sich ganz genau auf das Gewordensein und den jetzigen Zustand der Universitäten beziehen. Offenbar nämlich ist die eigentliche Universität, wie sie der wissenschaftliche Verein bilden würde, lediglich in der philosophischen Fakultät enthalten, und die drei anderen dagegen sind die Spezialschulen, welche der Staat entweder gestiftet, oder wenigstens, weil sie sich unmittelbar auf seine wesentlichen Bedürfnisse beziehen, früher und vorzüglicher in seinen Schutz genommen hat. Die philosophische hingegen ist für ihn ursprünglich ein bloßes Privatunternehmen, wie der wissenschaftliche Verein überhaupt ihm eine Privatperson ist, und nur durch die innere Notwendigkeit und durch den rein wissenschaftlichen Sinn der in jenen Fakultäten Angestellten subsidiarisch herbeigeholt worden, weshalb sie denn die letzte ist von allen. In der ganzen Form also spiegelt sich die Geschichte 
der Universitäten in ihren Grundzügen ab. Die positiven Fakultäten sind einzeln entstanden durch das Bedürfnis, eine unentbehrliche Praxis durch Theorie, durch Tradition von Kenntnissen sicher $\mathrm{zu}$ fundieren. Die juridische gründet sich unmittelbar in dem staatbildenden Instinkt, in dem Bedürfnis, aus einem anarchischen Zustande - anarchisch, weil die Gesetzgebung nicht gleichmäßig fortgeschritten war mit der Kultur - einen rechtlichen hervorgehen zu lassen, in dem Gefühl, daß dies nur geschehen könne, indem man zu dem Besitz eines Systems vollständiger, unter sich übereinstimmender Gesetze zu gelangen suchte, und zu höheren Prinzipien, nach welchen in zweideutigen Fällen die Gesetze auszulegen wären. Die theologische hat sich in der Kirche gebildet, um die Weisheit der Väter zu erhalten, um, was schon früher geschehen war, Wahrheit und Irrtum zu sondern, nicht für die Zukunft verloren gehen zu lassen, um der weiteren Fortbildung der Lehre und der Kirche eine geschichtliche Basis, eine sichere, bestimmte Richtung und einen gemeinsamen Geist zu geben; und wie der Staat sich näher mit der Kirche verband, mußte er auch diese Anstalten sanktionieren und unter seine Obhut nehmen. Die medizinischen Schulen haben sich seit uralten Zeiten gegründet auf das Bedürfnis, teils den Zustand des Leibes $\mathrm{zu}$ erkennen und zu modifizieren, teils auf eine mehr oder minder dunkle, geheimnisvolle Ahndung von den innigen Verhältnissen der gesamten übrigen Natur zu dem menschlichen Leibe. Daher waren sie von Anfang an teils überwiegend gymnastisch, teils magisch und mystisch. Durch Vereinigung beider Zweige gewannen diese Bemühungen allmählich ein mehr kunstmäßiges Ansehn, und in dem Maß, als sie anfingen, durch Beobachtungen und Versuche in die verschiedenen Zweige der Naturwissenschaft sich hineinzuarbeiten, und also großer äußerer Unterstützungen zu bedürfen, mußte der Staat sich ihrer ebenfalls annehmen. So sind diese Anstalten entstanden; der tiefe, richtige Sinn, der sich immer mehr über das Schlechte hervorarbeitet, hat die Neigung zu dem bloß Handwerksmäßigen und Empirischen besiegt, und 
der wissenschaftliche Geist, wir dürfen sagen vorzüglich der deutschen Nation, das immer klarer werdende Gefühl von dem innern Zusammenhange alles Wissens, hat sie in einen Körper endlich vereinigt, wobei natürlich, wenn dies nicht als ein bloß zufälliges und äußeres Nebeneinandersein erscheinen sollte, auch jener $\mathrm{Zu}$ sammenhang, jene gemeinschaftliche Begründung sich äußerlich darstellen mußte, was denn durch die philosophische Fakultät geschieht. In dieser einen ist daher allein die ganze natürliche Organisation der Wissenschaft enthalten, die reine transzendentale Philosophie und die ganze naturwissenschaftliche und geschichtliche Seite, beide vorzüglich mit denen Disziplinen, welche sich am meisten jenem Mittelpunkt der Erkenntnis nähern; aber doch auch die mehr ins Besondere gehenden schließen sich so lange an die philosophische Fakultät an, als sie nicht zum Behuf eines bestimmten Zweckes pragmatisch behandelt werden. Jene drei Fakultäten hingegen haben ihre Einheit nicht in der Erkenntnis unmittelbar, sondern in einem äußeren Geschäft, und verbinden, was zu diesem erfordert wird, aus den verschiedenen Disziplinen. Diese eine also stellt allein dar, was der wissenschaftliche Verein für sich als Universität würde gestiftet haben, jene drei aber, was durch anderweitiges Bedürfnis entstanden, und wobei die reinwissenschaftliche Richtung äußerlich untergeordnet ist. Die Ordnung, welche sie unter sich beobachten, beweiset offenbar das dominierende Verhältnis des Staats auch in den öffentlichen wissenschaftlichen Anstalten; und genauer angesehen zeigt sich darin teils das geschichtliche Vorantreten der Kirche vor den Staat, teils die alte löbliche Weise, die Seele dem Leibe voranzustellen.

Was sich unstreitig sehr bald, gewiß sobald als wahrer Nutzen dadurch wird gestiftet werden können, von selbst machen wird, das ist eine Umbildung der juridischen Fakultät. Die bloße Kenntnis eines positiven Gesetzbuches als solchen, welches doch immer mit Unrecht ein feststehendes und unveränderliches ist, und von den wissenschaftlichen Männern soll fortgebildet werden, nicht 
sie sich unterwerfen, hat zu wenig wissenschaftlichen Charakter. Hier müssen also die Politik, die Staatswirtschaft, die philosophische und historische Kenntnis der Gesetzgebung selbst mehr heraustreten. Was sollen aber andere Veränderungen, wie man sie hie und da entwerfen und ausführen sieht? Was man damit meint, ist Willkür, Spielerei; und was man damit bewirkt, ist wohl etwas Übleres; und es ist zu fürchten, daß man nicht ungestraft Einrichtungen vertilgen kann, die für sich schon geschichtliche Denkmäler sind, und die, wenn gleich von vielen nicht verstanden, den Geist der Nation aussprechen. Entsteht je eine Universität durch eine freie Vereinigung von Gelehrten, dann wird von selbst das, was jetzt in der philosophischen Fakultät vereiniget ist, die erste Stelle finden, und die Institute, welche Staat und Kirche bitten werden damit zu verknüpfen, werden ihre untergeordneten Stellen einnehmen. Solange dies nicht geschieht, sondert sie sich am besten dadurch von den übrigen ab, daß sie die letzte ist, besser als wenn sie sich zwischen die andern stellt und sich dadurch mit ihnen vermischt, oder wohl gar als wenn sie - damit das nicht als eins und also weniger erscheine als die übrigen drei, was doch weit mehr ist als sie - sich spalten wollte in mehrere Abteilungen. Gewiß würden dann die einzelnen Disziplinen den wissenschaftlichen Charakter immer mehr verlieren, und sich den pragmatischen Instituten nähern. Und für die reine Philosophie ist in dieser Vereinigung mit den realen Wissenschaften zu einem äußerlichen Ganzen so schön ausgesprochen die Freiheit, bald mehr einzeln für sich herauszutreten, bald mehr an den realen Wissenschaften, als außer ihnen, sich darzustellen, eine Freiheit, ohne welche sie nicht gedeihen und sich in ihrem wahren Wesen zeigen kann, und die nicht mehr bestehen könnte, wenn ein äußeres Zeichen der Trennung festgestellt wäre.

Erhalte sich also nur die philosophische Fakultät dabei, daß sie alles zusammenfaßt, was sich natürlich und von selbst als Wissenschaft gestaltet, so mag sie immerhin die letzte sein. Was ist auch 
hier an dem Range gelegen? Sie ist doch die erste deshalb, weil jedermann ihre Selbständigkeit einsehen und gestehen muß, daß sie nicht wie die übrigen, sobald man von einer bestimmten äußeren Beziehung hinwegsieht, in ein ungleichartiges Mannigfaltiges zerfällt und aufgelöst werden kann. Sie ist auch deshalb die erste und in der Tat Herrin aller übrigen, weil alle Mitglieder der Universität, zu welcher Fakultät sie auch gehören, in ihr müssen eingewurzelt sein. Dies Recht übt sie fast überall aus über die ankommenden Studierenden; von ihr werden zunächst alle geprüft und aufgenommen, und dies ist eine sehr löbliche und bedeutende Sitte. Nur scheint sie noch erweitert werden zu müssen, um ihre Bedeutung ganz zu erfüllen. Es ist gewiß verderblich, daß die Studierenden gleich anfänglich sich können irgend einer andern Fakultät einverleiben. Alle müssen zuerst sein und sind auch der Philosophie Beflissene; aber alle sollten eigentlich auch in dem ersten Jahre ihres akademischen Aufenthaltes nichts anderes sein dürfen. Das alte Unwesen, die Knaben in der Wiege für ein gewisses Geschäft zu bestimmen, ist immer noch nicht ausgerottet; denn für das wissenschaftliche Leben ist die gelehrte Schule nur die Wiege. Was für Vorstellungen von seinem künftigen Beruf, von dem Verhältnis desselben zu dem ganzen großen Gebiet der Wissenschaften und des durch sie unmittelbar befruchteten Lebens kann der angehende Jüngling wohl von dort her mitbringen? Die allgemeinen Übersichten, theologische, juridische, mit welchen man die Abgehenden hie und da zu versenden pflegt, sind nur Huldigungen, welche man verkehrterweise jener Verkehrtheit der voreiligen Bestimmung darbringt, und ein Raub, der schwerlich ungestraft an den Universitäten begangen wird. Gewiß sind die Fälle selten, wo sich eine bestimmte Richtung des Talentes schon auf der Schule offenbart, und mit Recht kann man sagen, daß in jedem solchen Falle nur desto notwendiger sei, den Jüngling, wenn er für die Wissenschaft gedeihen soll, eine Zeitlang im Allgemeinen derselben aufzuhalten, damit sein allgemeiner Sinn nicht ganz unterdrückt werde von der vorherrschenden Gewalt 
des besonderen Talents. Möchte man doch bald dahin kommen, die Jünglinge nur zum Studieren überhaupt der Universität zuzuschicken. Wenn sie sich ein Jahr nehmen dürfen, um sich in den Prinzipien festzusetzen und sich von allen wahrhaft wissenschaftlichen Disziplinen eine Übersicht zu verschaffen: so wird diese Zeit nicht verloren sein; während derselben wird am sichersten ihre Gesinnung, ihre Liebe, ihr Talent sich entwickeln; sie werden untrüglicher ihren rechten Beruf entdecken, und des großen Vorteils genießen, ihn selbständig gefunden zu haben.

Nicht anders aber sollten auch alle Universitätslehrer in der philosophischen Fakultät eingewurzelt sein. Besonders kann man bei der juridischen und theologischen Fakultät nie sicher sein, daß nicht das Studium allmählich immer mehr einer handwerksmäßigen Tradition sich nähere, oder in ganz unwissenschaftlicher Oberflächlichkeit verderbe, wenn nicht alle Lehrer zugleich auf dem Felde der reinen Wissenschaft eignen Wert und Namen haben, und eine Stelle als Lehrer verdienen. Man sollte daher nicht nur ausschließend solche wählen, sondern es müßte gesetzmäßig sein, daß jeder Lehrer dieser Fakultäten, wenn auch nicht zugleich Mitglied der philosophischen, doch als außerordentlicher Lehrer bei irgend einem Zweige derselben verpflichtet wäre, und von Zeit zu Zeit Vorträge aus dem reinen wissenschaftlichen Gebiete hielte, die in gar keiner unmittelbaren Beziehung auf seine Fakultät ständen. Nur dadurch könnte man auch äußerlich sicher sein, die lebendige Verbindung dieser Doktrinen mit der wahren Wissenschaft, ohne welche jene gar nicht auf die Universität gehören könnten, zu erhalten. Und in der Tat verdient ja wohl jeder Lehrer des Rechts oder der Theologie ausgelacht und von der Universität ausgeschlossen zu werden, der nicht Kraft und Lust in sich fühlte, auf dem Gebiet, es sei nun der reinen Philosophie oder der Sittenlehre oder der philosophischen Geschichtsbetrachtung oder der Philologie, etwas Eignes mit ausgezeichnetem Erfolg zu leisten. 
Wenn übrigens schon die philosophische Fakultät am besten tut, eine zu bleiben, und wenn sie sich zum Behuf gewisser Geschäfte in Unterabteilungen spalten müßte, dies ja nicht auf eine zu bestimmte und bleibende Art, kurz ja nicht so zu tun, daß die Einheit als das Wesentlichere darüber verloren gehe: so ist ja wohl deutlich, daß auch das allgemeine Streben der Universität darauf gehn muß, sich nicht zu sehr ins Einzelne hinein bestimmt zu teilen, jeden Lehrer etwa streng in den Grenzen seiner Fakultät zu halten, oder gar in dieser ihn ganz bestimmt auf ein gewisses Fach einzuschränken. Vieles fällt freilich von selbst weg, wenn jeder Lehrer einer Fakultät zugleich, wenn auch nicht ebenso genau, der philosophischen angehört und in dieser selbst die Sektionen nicht streng geschieden sind. Aber warum sollte auch ein Lehrer gehindert werden, einmal das Gebiet einer andern Fakultät zu betreten? Grenzen doch alle aneinander und berühren sich in mehreren Punkten, so daß es an Veranlassungen nicht fehlt, aus einer in die andern hinüberzuschweifen. Ergreift diese ein Gelehrter recht, und begnügt er sich nicht damit, nur für sein eignes Studium zu leihen, was er von dort her braucht: so muß er gewiß etwas recht Eigentümliches und Geistreiches hervorgebracht haben auf dem fremden Gebiet, wenn er sich entschließt, es öffentlich vorzutragen. Die Eifersucht der Fakultäten aufeinander wegen ihres Gebietes ist etwas mit Recht Veraltetes und Lächerliches. Wem einmal öffentlich die Würde eines wissenschaftlichen Lehrers gegeben und sein Talent dazu anerkannt ist, der muß es auch üben können, auf welchem Gebiet er will. Die Zeit, während der einem Gelehrten diese Gabe der Mitteilung zu Gebote steht, ist zu beschränkt; die Gabe selbst ist zu zart und zu schwer ganz in die Gewalt zu bekommen, als daß man nicht jede gute Stunde und alles, was sie eingibt, vollständig genießen und auch benutzen sollte.

Eben deshalb ist auch der wahre Geist der Universität der, auch innerhalb jeder Fakultät die größte Freiheit herrschen zu lassen. Ordnungen vorschreiben, wie die Vorlesungen aufeinander folgen 
müssen, das ganze Gebiet unter die einzelnen bestimmt verteilen, das sind Torheiten; nicht einmal ein solches Privatabkommen der Lehrer unter sich wäre wünschenswert. Es wäre immer eine Beförderung der Stagnation, dahingegen neues Leben in einen jeden Zweig der Wissenschaften kommt, wenn er wieder von andern, und vorzüglich von solchen, die sich mit andern Zweigen mehr abgegeben haben, aufs neue bearbeitet wird. Darum lasse keiner sein Talent so bestimmt und äußerlich binden, oder binde es selbst. Männer von Geist und Fleiß, und denen das Geschäft wert und lieb ist, welches sie auf der Universität treiben, können unmöglich in dieser Hinsicht eines äußerlichen Gesetzes bedürfen; sie haben in sich, was sie treibt, so viel zu tun als sie können, und sie müssen sich selbst ihr Gesetz sein. Auch ist dies natürlich viel zu eigentümlich, um von einem andern oder im allgemeinen gegeben zu werden, da es so genau von dem Verhältnis des Lehrers zu seinen Schülern abhängt. Je fester diese ihm anhangen, je mehr sie sich in ihrem wissenschaftlichen Streben allgemein von ihm gefördert fühlen, durch ein desto größeres Gebiet werden sie von ihm wollen geführt sein; je mehr sie dagegen in ihm nur eine besondere Virtuosität bewundern, um desto weniger werden sie wünschen, daß er sich aus deren Gebiet hinaus versteige, sondern so etwas vielmehr mit einer leisen Schadenfreude ansehn.

Daher ist es auch gewiß mehr schulmäßig als im wahren Geiste der Universität, wenn die Nominalprofessuren zu stark hervortreten. Einem Lehrer vorschreiben, daß er in einem bestimmten Zeitraume dasselbe wieder vortrage, heißt ihm sein Geschäft zuwider machen, und also schuld sein, daß sein Talent nur desto schneller ablaufe. Auch ist es natürlich, daß, wer noch auf andere Weise als auf dem Katheder für die Wissenschaft arbeitet, sich einrichten muß, damit seine Arbeiten sich nicht allzusehr hindern, wenn er anders mit Lust und Interesse vortragen soll, und sich also solchen Geboten unmöglich fügen kann. Freilich sagt man, es müsse doch dafür gesorgt werden, daß in einem solchen Zeitraum, als man für 
einen gewöhnlichen Aufenthalt auf der Universität rechnen kann, alles Wesentliche eines jeden Gebietes wirklich vorkomme. Gewiß richtig! aber ist nur eine gehörige Fülle von Lehrern rechter Art vorhanden, so hat es damit keine Not. Und sollte es ja: nun wohl, so weise man jedem sein besonderes Fach an, aber nur insofern, daß, wenn innerhalb des bestimmten Zeitraumes keiner sich gefunden habe, der es in dem gehörigen Umfang vorgetragen hätte, dieser alsdann dazu verpflichtet sei. Und diese Anweisung sei so wenig rechtlich verklausuliert und so lose als möglich, so daß ohne alle Weitläufigkeit zwei Lehrer die Gewährleistung, welche sie übernommen haben, gegeneinander vertauschen können. So wird jeder seine Freiheit behalten, und das Ganze dadurch nicht vernachlässiget werden, sondern nur gewinnen.

Je mehr nun jeder Lehrer auf diese Art seinen Kreis selbst bestimmen und nach Belieben bald erweitern bald verengern kann, um desto mehr söhnt man sich auch aus mit dem so sehr verschrieenen Honorar. Auch dies muß doch wunderbar genug mit dem Geist und Wesen unserer Universitäten zusammenhängen, weil es sich so beständig, trotz mancher spöttischen Ausfälle der neuesten Verfeinerung, erhalten hat, und man kann wohl sagen, daß das die schlechtesten Universitäten und die schlechtesten Partien jeder Universität sind, wo am meisten das Honorar umgangen wird. Zuerst gehört es zu den wenigen Einrichtungen, worin sich die Universität als aus einer ganz freien Privatvereinigung von Gelehrten entstanden darstellt. Weil dies nun ihre natürlichste und schönste Seite ist, so hat auch gewiß das Verhältnis, sich seinen Unterricht bezahlen zu lassen, nie einem Lehrer, der es nicht selbst durch niedrige Gesinnung entweihte, in der Achtung der Jünglinge geschadet, noch kann es ihm selbst erniedrigend erschienen sein, da es zugleich das Gefühl seiner Abhängigkeit vom Staat verringert. Daher soll sich auch der Staat in dies Verhältnis gar nicht mischen; er soll das Betragen gegen die Ärmeren dem guten Ton der Lehrer überlassen. Will er vorschreiben, was 
oder wie oft jeder auch unentgeltlich vortragen soll: so mahnt dies an die schlechtesten Einrichtungen kleiner Schulen, wo das Gemeinere öffentlich und das Seltnere und Höhere in Privatstunden zu lernen ist. Viel besser werden die Lehrer selbst finden, was sich von Zeit zu Zeit dazu eignet, ein solches Gastmahl für eine auserlesene Anzahl zu sein.

Hierher gehören denn auch die Seminarien, welche mit den meisten Fakultäten, der medizinischen, der theologischen, und der philologischen Sektion der philosophischen verbunden $\mathrm{zu}$ sein pflegen, und fast überall als eigene Anstalten erscheinen, welche ganz besonders vom Staate gestiftet und begünstiget sind. Die Lehrer, welche ihnen vorstehen, werden dafür noch besonders besoldet, und größtenteils (nur in den klinischen Anstalten der Mediziner ist es nicht üblich) genießen auch die Jünglinge, welche daran teilnehmen, namhafte Vorteile. Es ist schon oben erwähnt, daß diese Seminarien dasjenige sind, wodurch sich die Universität der Akademie nähert, und daß die eignen darstellenden Versuche, die ins einzelne gehenden Studien und Untersuchungen der Jünglinge darin sollen geleitet werden. Daher der innerste Kreis der reinen Philosophie auch nichts von dieser Art aufzuzeigen hat, sondern für ihn die Stelle jener Anstalten eigentlich die Disputierübungen vertreten sollten, welche den Zweck haben, sich in den philosophischen Prinzipien und in den allgemeinen Ansichten recht festzusetzen. Die Seminarien aber schließen sich an die Disziplinen an, welche mehr in das Besondere gehen, und sind dasjenige $\mathrm{Zu}$ sammensein der Lehrer und Schüler, worin die letzteren schon als produzierend auftreten, und die Lehrer nicht sowohl unmittelbar mitteilen, als nur diese Produktion leiten, unterstützen und beurteilen. Daß in den Seminarien Höheres, als im gewöhnlichen Laufe der Vorlesungen vorkommt, unmittelbar gelehrt werden soll, ist notwendig eine ganz falsche Ansicht. Denn auf alles unmittelbare Lehren haben auf der Universität alle ein gleiches Recht; die Seminarien sind aber ihrer Natur nach immer nur für einen Ausschuß 
bestimmt. Zwischen ihnen und den Vorlesungen liegen noch die Konversatorien, in welchen die Reaktion des Jünglings zuerst dem Lehrer sichtbar wird; er unterscheidet das minder faßlich Vorgetragene, und gibt es dem Lehrer zur Umarbeitung und Erläuterung zurück; er bringt Zweifel und Einwendungen vor, um sie sich lösen zu lassen. Diese fast wesentliche Form fehlt freilich häufig genug, aber die Lücke muß gewiß sehr fühlbar werden, wo sich nicht etwa eine solche freiere Vereinigung mit in den Seminarien versteckt. Schon bei dieser mehr gegenseitigen Mitteilung erscheinen gewiß nur diejenigen, in welchen der wissenschaftliche Geist sich wirklich regt. Natürlich ergibt sich hier Gelegenheit genug, den Jünglingen Arbeiten anzuweisen, und sie zu Untersuchungen aufzufordern, wodurch sie mehr Licht in einzelne Gegenden ihres Wissens bringen, und die Nebel, von denen sie umfangen sind, zerstreuen, oder die Unbeholfenheit in ihren geistigen Tätigkeiten, welche sie drückt, überwinden können. Nur die ernsteren, hinlänglicher Kräfte sich bewußten, werden den anstrengungsvollen Weg nicht scheuen; und wenn sie das Bedürfnis fühlen, auch auf diesem die Gemeinschaft mit dem Lehrer fortzusetzen, so ist das Seminarium gemacht. Eigentlich also muß jedem Lehrer, welchem es gelingt, eine Anzahl der Jünglinge seines Faches näher an sich zu ziehn, diese Leitung ihrer eignen Arbeiten von ihnen selbst übertragen werden, jeder muß sich sein Seminarium selbst bilden. Diesem natürlichen Gange tritt der Staat in den Weg, wenn er für jede Fakultät ein Seminarium stiftet, und dieses mit besonderen Begünstigungen einem Lehrer überträgt. Daran, daß der Staat gewöhnlich auf Lebenszeit verleiht, und daß, auch wenn er eine solche Anstalt zuerst stiftet, doch die in Deutschland so sehr herrschende Achtung für das Alter sie dem Ältesten übertragen wird, der $\mathrm{zu}$ einem solchen näheren persönlichen Verkehr mit der Jugend, wenn alles Übrige gleich gesetzt wird, der Regel nach der minder geschickte ist, daran wollen wir nicht einmal denken; das größte und sichtbarste Übel ist, daß, wenn ein Lehrer mit solchen Begünstigungen versehen ist, der Anteil 
an den eignen Arbeiten der Jünglinge dadurch ein Monopol wird, und die andern außer Stand gesetzt werden, ihr Verhältnis zu den Jünglingen zur Vollendung zu bringen, und so viel zu nutzen, als sie könnten. Ebenso wenn der Staat eine bestimmte Anzahl von Studierenden, oft schon bald nach ihrer Ankunft auf der Universität, als Seminaristen begünstiget: so zieht er nicht nur die Jünglinge auf eine unreine Art zu dem Lehrer ausschließend hin, der diese Begünstigungen zu verteilen hat; sondern er verfällt auch in den so allgemein dafür anerkannten Fehler, reine Aufmunterungen, die nur selten wirklich aufmuntern, Belohnungen, ehe noch etwas geschehen ist, zu verteilen. Auf diese Art sollte es wohl keine Seminarien geben, sondern der Staat sollte die Unterstützungen, welche er jeder Fakultät zu diesem Behuf bestimmt hat, gemeinsam niederlegen, und jeder Lehrer, welcher einen Kreis von engeren Schülern zu eignen, wahrhaft wissenschaftlichen Arbeiten unter sich vereinigen will und kann, müßte den tüchtigsten unter ihnen einen Teil davon können zufließen lassen. Nur wenn der traurige Fall eintreten sollte, daß kein Lehrer von selbst, und ohne eine besondere Belohnung, Beruf hierzu fühlte, müßte die gesamte Anstalt oder der Staat zutreten. Vielleicht sind die bestehenden Seminarien zum Teil auf diese Art, zum Teil aus dieser Voraussetzung entstanden; auf jeden Fall aber müßte das Monopol in demselben Augenblick aufgehoben werden, wo sich ein anderer Konkurrent zu diesem Geschäft findet.

Nach ähnlichen Grundsätzen, daß nämlich der Staat nie Aufmunterungen und Wohltaten verteilen soll, sondern nur Belohnungen und Ehrenzeichen, muß auch das ganze Stipendienwesen beurteilt und auf seinen ursprünglichen Zweck zurückgeführt werden, da es nur durch die allmählich eingerissene Weichlichkeit in ein Benefizienwesen ist verwandelt worden. Der Student müsse keine anderen Stipendien mitbringen, als die er auf der Schule schon verdient hat, und diese müssen nur so lange dauern, bis er sich auf der Universität neue verdienen kann, damit er nicht, ohne daß 
es bemerkt und geahndet werde, aus einem trefflichen Schüler ein schlechter Student werde. Alle Unterstützungen müssen nur dem Geprüften, und für ausgezeichnet Erkannten, erteilt werden, und ein Ehrenzeichen begleite sie, so daß sich der Reiche ebensowohl darum bewerbe als der Arme, und nur den Vorteil davon einem andern gern überlasse. Nur so wird der ursprüngliche Zweck erreicht, und Demütigungen und Unterscheidungen vermieden, welche nirgend weniger an ihrer Stelle sind als auf der Universität.

Alles dies setzt freilich voraus, daß die Lehrer der Universität sind, wie sie sein sollen. Allein wie könnte man auch eine andere Voraussetzung als diese bei den wesentlichsten Einrichtungen zum Grunde legen? Es mag vielleicht andere Dinge geben, welche gedeihen können, wenn auch diejenigen, die daran arbeiten, nur durch einen äußern Zwang gehalten und getrieben werden; dieses Werk aber nicht, sondern es kann nur durch Lust und Liebe bestehen, und was ohne diese auch die vortrefflichsten äußeren Gebote und Statuten tun können, kann immer nur ein leerer Schein werden. Wer sich die Aufgabe setzt, eine Universität so einzurichten, daß sie gehen und Dienste leisten müßte, wenn auch die Lehrer kaum mittelmäßig wären, und nicht vom besten Willen, der unternimmt ein töricht Ding. Denn was für den Geist sein und ihn kräftigen soll, das muß auch aus der Kraft des Geistes hervorgehen.

Darum ist nun freilich die erste Sorge die: wie bekommt man Lehrer, welche den rechten Sinn haben, und welchen alle die nötigen Kräfte mit großem Geschick zu Gebote stehen? Wir haben die wesentlichsten Zweige der Universität betrachtet; aber wie erneuern sie sich nun in jedem vorkommenden Fall am besten? Die Erfahrung scheint $\mathrm{zu}$ verraten, daß gerade dieser wichtige Punkt noch nicht auf eine der Idee und dem Wesen des Ganzen angemessene Art ist eingerichtet gewesen. Es finden sich überall der Mißgriffe $\mathrm{zu}$ viele, als daß man dies glauben könnte; und man darf nicht annehmen, daß die Anzahl tauglicher Männer zu diesem Geschäft 
so gering wäre, als die Anzahl trefflicher Lehrer wirklich ist; ja es lassen sich ganze Perioden unterscheiden, wo eine Universität mit fast lauter ausgezeichneten, und andere, wo sie mit minder als mittelmäßigen Männern besetzt ist. Dies scheint seinen Grund darin $\mathrm{zu}$ haben, daß die Regierung die Sorge für die Besetzung dieser Ämter gewöhnlich einem bedeutenden Staatsmanne überläßt. Hat dieser das rechte Talent und den wahren Eifer für die Sache, so wird es ihm nicht fehlen, vortreffliche Männer zusammenzubringen; folgt ihm ein anderer Übelgewählter, so werden auch dessen schlechte Wahlen allmählich statt jener trefflichen eine Reihe von unbedeutenden Männern aufstellen. Ja es ist zu besorgen, daß nur in einem kleinen Staate, der unmöglich die Universität als für seine Bedürfnisse daseiend ansehen kann, der Aufsicht führende Staatsmann lediglich auf die wissenschaftliche Qualität sehen wird; je größer aber der Staat, desto mehr wird er sich verleiten lassen durch die so allgemeine herrschende Ansicht, und den talentvollsten Gelehrten, denen es aber um die Wissenschaft selbst zu tun ist, solche Männer vorziehn, welche sich als Freunde und Meister in der Kunst gezeigt haben, die Wißbegierde der Jünglinge nur zum vermeinten Besten des Staats zu bearbeiten. Sollte man also nicht dieser so schwer zu vermeidenden falschen Richtung, und jener für das Gedeihen der Universität so üblen Veränderlichkeit derselben zuvorzukommen suchen, indem man die Besetzung der Lehrstellen weniger von einer Person abhängig machte? Spricht nicht die Natur der Sache dafür, daß, wenn die Wissenschaft nicht untergehn soll, an der Wahl ihrer eigentlichsten Erhalter und Fortpflanzer auch der wissenschaftliche Verein einen bedeutenden Anteil nehmen müsse?

Man sagt freilich, der Kurator der Universitäten sei ja notwendig immer ein wissenschaftlich gebildeter Mann, und nicht minder diejenigen, welche ihm zunächst an die Hand gehen, Mitglieder gewöhnlich des höchsten Kirchenrats oder Schulrates; allein hier tritt nun die Besorgnis ein, daß diese alle je länger je mehr sich 
vorzüglich als Staatsdiener betrachten werden, und der Wunsch, daß der Anteil des wissenschaftlichen Vereins an dieser Angelegenheit bestimmter und abgesonderter von dem des Staates hervortreten möge. Auch darauf kann man freilich erwidern, es stehe jeder Universität frei, diese Wahl dem Wesentlichen nach ganz in ihre eignen Hände zu bringen und sich aus sich selbst zu erneuern. Denn sie könne aus ihren eigenen Zöglingen Privatdozenten bilden, und wenn diese eine Zeitlang mit Erfolg aufgetreten wären und sich Verdienste erworben hätten, würde der Staat sie gewiß nicht übergehen; und wenn er es auch täte, würden sie doch wirksamer sein auf der Universität als die von ihm angestellten Lehrer. Das heißt aber zu wenig aus der Natur der Sache gesprochen. Ein Privatdozent als solcher wird es nie über einen öffentlich sanktionierten Lehrer, auch nicht über einen solchen, der ihm wissenschaftlich weit nachsteht, davontragen; bleibt er immer ausgeschlossen von der Teilnahme an der innern Leitung des Ganzen, so muß ihm Mut und Lust vergehen, und er wird sich entweder hinwegbegeben, oder sein Talent wird ungenutzt verwelken. Ist also der Staat nicht daran gebunden, solche Männer aufsteigen und einrücken zu lassen, so ist mit dieser Freiheit des Lehrens wenig gewonnen für die Sache der Wissenschaft. Auf der andern Seite aber wäre es wahrlich nicht gut, wenn eine Universität sich so ganz aus sich selbst erneuerte, wie es auch sonst keine gedeihlichen Früchte gibt, wenn in einem Boden immer nur der Same ausgestreut wird, den er selbst hervorgebracht hat; oder wie in Familien, die immer nur unter sich verkehren und heiraten, die Manieren sich versteinern und der Geist verschwindet, so würde auch eine solche Universität immer einseitiger werden und trockener. Eine jede muß vielmehr auf jede Weise auch von den andern auf sich einwirken lassen, und es müsse keiner je an Lehrern fehlen, welche in mehreren wissenschaftlichen Gemeinheiten gelebt haben, um das fremde Gute und die Früchte eines vielseitigen Verkehrs auch den nur daheim Erzogenen mitzuteilen. 
Die Universität selbst muß freilich am besten wissen, was sie bedarf, so oft ihr eine Lücke entsteht, oder sie Gelegenheit bekommt, sich zu erweitern; und da man bei ihren Mitgliedern Bekanntschaft voraussetzen darf mit allem, was sich Merkwürdiges auf dem vaterländischen Gebiete der Wissenschaften regt, so muß sie auch wissen, wo sie ihren Bedarf finden kann. Allein leider möchte wohl niemand dafür stimmen, ihr jede Wahl allein zu überlassen; die Universitäten sind im ganzen so berüchtiget wegen eines Geistes kleinlicher Intrigue, daß wohl jeder bei einer solchen Einrichtung von der Parteisucht, von den in literarischen Fehden gereizten Leidenschaften, von den persönlichen Verbindungen die nachteiligsten Folgen befürchten wird. Der Regierung und ihren Repräsentanten, denen freilich diese Versuchungen ganz fremd sind, fehlt dagegen als solchen gar vieles, was zur richtigen Beurteilung gehört, und auch wenn sie schon erworbenen Ruhm zum Maßstab nehmen, werden sie sich oft irren.

Am meisten Schwierigkeit scheinen in beider Hinsicht zu verursachen die Lehrstellen der reinen Philosophie. Denn dieses Gebiet liegt dem Staate am entferntesten, und am wunderlichsten müßte es ihm selbst vorkommen, wenn er entscheiden sollte, wer nun der echteste Philosoph sei, der am meisten begünstiget und hervorgezogen zu werden verdiene. Auch gibt es nichts Verhaßteres auf diesem Gebiete, nichts, was gutes Vernehmen und gegenseitiges Vertrauen so sehr schwächen muß, als wenn eine Regierung Partei nimmt in Sachen der Philosophie, indem sie eines oder das andere der streitenden Systeme ausschließt oder zurücksetzt. Auf der andern Seite aber sind die Universitäten selbst immer der Kampfplatz, wo am heftigsten, und bisweilen bis zur Vernichtung, dieser Streit der Systeme geführt wird, so daß man, wenn ihnen selbst die Entscheidung überlassen wäre, die heftigsten Bewegungen fürchten müßte. Hier scheint kaum eine andere Hilfe zu sein, als eben in jener Freiheit des Lehrens. Wer sich Bahn macht, dem vergönne man Raum; wem es gelingt, 
nachdem er sich in der gehörigen Form auf einer Universität niedergelassen, den größten Beifall zu erwerben und $\mathrm{zu}$ bewahren, und das Talent zur Spekulation aufzuregen, den bekleide man mit dem Charakter des öffentlichen Lehrers ohne Rücksicht auf sein System, ja selbst ohne Scheu vor den Streitigkeiten, die unter gewissen Umständen auf diesem Gebiet einmal nicht zu vermeiden sind. Nur hafte kein öffentlicher Fleck auf seinem sittlichen Ruf, nur sei zugleich von ihm bekannt, daß er auch irgend ein Feld des realen Wissens bearbeitet. Vielleicht ist dies das einzige Gebiet, wo ein Melden, ein Ansuchen um die öffentliche Lehrerstelle von seiten der Konkurrenten stattfinden dürfte, und die Entscheidung zwischen mehreren fast gleich qualifizierten überließe vielleicht der Kurator am besten derjenigen Klasse der Nationalakademie, welche am wenigsten in die Streitigkeiten der Parteien verflochten zu sein und den reinsten Sinn für jedes Talent an sich zu haben pflegt, nämlich der philologischen.

Auf jedem andern Gebiet scheint es weniger schwierig zu sein, wie sich am besten der Staat und der wissenschaftliche Verein in das Geschäft der Besetzung zu teilen haben. Für Stellen, an denen das Interesse des Staates als solchen sich unmittelbar ausspricht, möge der Kurator vorschlagen, mit Zuziehung derjenigen Mitglieder des ihm zugeordneten höchsten Studienrates, welche auf diesem Gebiet die höchsten gelehrten Würden erworben haben - denn andere sollten nie eine Stimme haben in Sachen der Universitäten - und wählen sollte die Fakultät, in welche der Anzustellende eintreten wird, mit Zuziehung derjenigen Sektion der philosophischen, an welcher ihre Mitglieder teilhaben, oder in welche der Anzustellende auch eintreten will. Für solche Lehrstellen aber, welche den wissenschaftlichen Charakter am strengsten beibehalten, schlage die Universität selbst vor etwa drei, wie sie in der Stimmenmehrheit aufeinander gefolgt sind, und unter diesen wähle mit ähnlicher Zuziehung der Kurator. Durch eine Einrichtung dieser Art, wie sie sich auch für jede Universität eigen mo- 
difiziere, scheint das Gleichgewicht am besten gesichert, und die meisten übeln Einflüsse abgehalten zu werden.

Aber wäre es nicht fast ebenso nötig zu fragen: wie kann man sich am besten zur rechten Zeit der trefflichen Lehrer wieder entledigen? Wahrlich, niemand spielt eine traurigere Rolle als ein Universitätslehrer, der sich als solcher überlebt hat, der dies fühlt, und doch noch genötigt ist, sein Geschäft fortzutreiben, um nicht in einen dürftigen Zustand zu geraten! Hier sieht man, wie wichtig es einem Staate ist, nur wenig Universitäten zu haben, weil so am besten ein Lehrer während seiner blühendsten Zeit für die spätere einigermaßen sorgen kann, und vor allem wohlbegabte, so daß die Anstalt jedem Verdienten eine ehrenvolle und bequeme Zurückziehung gewähren könne. Aber ebenso wichtig ist gewiß in dieser Hinsicht ein richtiges und freundliches Verhältnis zwischen den Universitäten und der Akademie. Die Gabe der Mitteilung, wie sie der Universitätslehrer haben muß, ist ein zartes Talent, das nur in dem schönsten Zeitpunkte des Lebens sich findet; und wenn sonst Philosophen den rechten natürlichen Anfang und das Ende der Zeugungskraft zu bestimmen sich nicht scheuten, so könnte man auch für dieses Talent wohl festsetzen, daß es in der Regel zwischen dem fünfundzwanzigsten und dreißigsten Jahre anfängt sich zu entwickeln, und rasch seiner schönsten Blüte zueilt, und daß, wer das funfzigste Jahr zurückgelegt hat, einer schnellen Abnahme desselben entgegensehen kann. Nicht sowohl der aus der Wiederholung entstehende Überdruß, wie man meint, bewirkt diese Abnahme; eine solche Wirkung hat der wahre geistvolle Lehrer auf einer wohl eingerichteten Universität erst sehr spät zu befürchten: sondern je mehr die Jugend schon einem ganz anderen Zeitalter angehört als der Lehrer, je weniger er sich ihr in Gedanken assimilieren und eine bestimmte Liebe und Freude mit ihr gemein haben kann, um desto mehr muß sich die Neigung und das Geschick verlieren, sich mit ihr in nähere Verhältnisse einzulassen, und um desto unerfreulicher und unfruchtbarer wird das 
Geschäft. Wird aber jemand sagen, wer dieses Talent nicht mehr besitze, der sei der Wissenschaft abgestorben? und die Akademie würdige sich herab zu einer Verpflegungsanstalt, wenn sie solche Männer unter sich aufnehme? Ist nicht auch in demselben Maß erst die in einzelnen schwierigen Untersuchungen so oft störende und übereilende Lebhaftigkeit der Phantasie verschwunden, und dagegen die Besonnenheit in ihrer vollen Kraft? Vollbringt nicht eben diese in solchen Jahren noch die herrlichsten Werke? Auch sehnt sich jeder wahrhaft wissenschaftliche Lehrer auf der Universität am meisten in späteren Jahren, je gründlicher er seine Wissenschaft gelehrt hat, um desto mehr nach der Muße des Akademikers, um seine Forschungen ruhiger verfolgen und die schönsten Früchte seiner Meditation zur Reife bringen zu können. Auch an solchen pflegt es nicht zu fehlen unter den Universitätslehrern, welche sich zum Geschäftsleben hinneigen, wenn ihre Lehrgabe anfängt zu verblühen. Für beide muß es einen ehrenvollen und verfassungsmäßigen Übergang geben, wenn die Universität nicht in dem Maß erkranken soll, als mehrere ihrer Mitglieder anfangen schwach zu werden für ihr Geschäft. Denn sollen sie gedeihen, so muß der Lehrer wie der Schüler eine, nur langsamer, vorübergehende Erscheinung sein.

Man sieht leicht, die natürliche Richtung der Universitäten geht dahin, den allmählich vorherrschend gewordenen Einfluß des Staates wieder in seine natürlichen Grenzen zurückzuweisen, und dagegen immer mehr den Charakter des wissenschaftlichen Vereins in diesen ihm zunächst angehörigen Anstalten hervortreten zu lassen. Dies muß also auch von ihren öffentlichen Handlungen gelten, und von den Formen, unter welchen die Universität oder ihre wesentlichen Glieder, die Fakultäten, als ein Ganzes auftreten. Es muß sich allmählich immer genauer trennen, was zum innern häuslichen Leben der Anstalt selbst gehört, von allem, wobei sie selbst oder ihre einzelnen Glieder nur als Mitglieder der bürgerlichen Gesellschaft anzusehen sind. In allem, was zu 
jenem Gebiet sicher gehört, muß die Universität sich frei und unabhängig ihr Hausrecht selbst bilden, und es nach Beschaffenheit der Umstände verändern können; der Staat kann sich dabei keiner Leitung anmaßen, sondern nur Mitwissenschaft fodern und Aufsicht führen, damit dieses Gebiet nicht überschritten werde. Nur von den Vorteilen und Besitztümern, welche er verliehen hat, mag er Rechenschaft fordern und verlangen, daß sie durch von ihm dafür anerkannte Sachverständige, aus deren Zahl aber doch die Universität muß auswählen können, verwaltet werden. Alles übrige ist Vormundschaft, welche nur in der Kindheit der Wissenschaft an ihrer Stelle sein kann, und gegen welche die natürliche Widersetzlichkeit um so stärker sein muß, je mehr die Universität ihre Mündigkeit fühlt und $\mathrm{zu}$ festen Ansichten und einem gründlichen Stil ihres Lebens gelangt ist. Was aber die Formen betrifft, unter welchen sie öffentlich auftritt und ihre Rechte und Ordnungen bildet: so ist die wissenschaftliche Gesinnung unserer Zeit ihrer Natur nach durchaus demokratisch, und das Bewußtsein lebendig, daß alle wissenschaftlichen Männer dem Geiste nach einander gleich sind, und die Geschäfte eines jeden gleich wesentlich dem Ganzen angehören. Je mehr also die Verfassung sich frei gestalten kann, um desto demokratischer wird sie sich bilden. Es sei nun, daß eine persönliche Repräsentation aller eigentlichen Mitglieder den öffentlichen Körper konstituiere, oder ein engerer Ausschuß: der Geist wird immer derselbe sein, und auch der Form nach wird ein Ausschuß immer nur entstehen können durch freie Wahl, um diejenigen in vorzügliche Tätigkeit zu setzen, welche man für die Geschicktesten hält, den gemeinsamen Willen aller zutage zu fördern und auszusprechen. Wo ein regierender Ausschuß durch bestimmtere Qualifikationen feststehend gebildet wird, da muß sich gewiß auch in andern Dingen die zum Grunde liegende aristokratische Gesinnung mit ihren vielfältigen Nachteilen offenbaren, vorzüglich durch Tyrannei gegen aufkeimende Verdienste, durch Haschen nach äußerem Ansehen, durch einen verschrobenen, unwissenschaftlich vornehmen Ton. 
Die innere demokratische Gesinnung hindert aber nicht, daß die Verfassung äußerlich eine monarchische Form habe, wie wir sie überall und gewiß zu großem Nutzen der Universitäten finden. Denn diejenigen, welche mit ihr verkehren, wenden sich natürlich zunächst an den, von dem die Ausfertigung ausgeht, sei es nun die mündliche oder die schriftliche. Ist dies nun nur ein untergeordneter Beamter, so wird dadurch nur zu sehr eine minder achtungsvolle Behandlung des ganzen Körpers erleichtert. Daher ist es sehr dienlich, daß einer, der übrigens innerhalb nur der erste ist unter Gleichen, außerhalb mit der Würde des ganzen Körpers bekleidet, diesen gegen die Staatsbehörden, gegen die einzelnen, und vorzüglich auch gegen die Jünglinge repräsentiere. Dies ist die wahre Idee eines Rektors der Universität, welcher, um dem demokratischen Charakter des Ganzen nichts zu vergeben, aus dem repräsentierenden Körper und von demselben nach bestimmten Formen und auf eine bestimmte Zeit muß wählbar sein. Wo ihn der Staat aber ernennt, vielleicht auf lange Zeit oder lebenslänglich, vielleicht gar auch innerlich ihn mit größern Vorrechten begabt, als nur der erste zu sein unter Gleichen, da ist schon die wahre wissenschaftliche Freiheit gefährdet, und ein verderbliches Übergewicht solcher Ansichten zu fürchten, welche die Wissenschaft zum bloßen Dienst des Staates herabwürdigen. Denselben demokratischen Charakter muß auch die Geschäftsführung einer jeden einzelnen Fakultät haben. Wo ein Präsidium ist, ist es wechselnd entweder durch Wahl, oder, was bei einer kleineren Anzahl natürlicher ist, durch Reihenfolge, und hebt innerhalb die Gleichheit aller nicht im mindesten auf. Wenn man irgend, sei es dem Lebensalter oder dem Geschäftsalter, oder aus sonst einem Grunde einem einzelnen einen inneren Vorzug einräumt: so muß das Ganze notwendig den Charakter der Schwächlichkeit bekommen, der dem Alter eigen ist, oder leiden durch die Abhängigkeit von der Beschränktheit eines Einzelnen. 


\section{Von den Sitten der Universität, und von der Aufsicht}

Dies ist die größte Klage, welche seit langer Zeit geführt wird über die deutschen Universitäten, daß im ganzen rohe und allen Umgebenden lästige Sitten, daß eine höchst unordentliche Lebensweise der den Wissenschaften obliegenden Jünglinge fast unzertrennlich scheint von ihrer ursprünglichen Gestalt und Verfassung, und daß aus dem in ihr gegründeten Mangel an Aufsicht über eine bis zum Übermut mutige Jugend nicht nur eine Menge kleinen Frevels und Störungen der Ruhe entstehen, sondern auch viele von den vortrefflichsten Einrichtungen dadurch vergeblich gemacht werden, und selbst das Beste auf der Universität ohne Nutzen bleibt: so daß man zweifeln müßte, meinen viele, ob nicht dennoch wegen dieses einen Punktes eine Umarbeitung der ganzen bisherigen Form zu wünschen wäre.

Alles durcheinander, was den Gegenstand dieser Beschuldigung ausmacht, ist unter dem Namen der akademischen Freiheit bekannt und verschrieen, von den meisten gefürchtet, wenn es in ihre Nähe kommen sollte, und der Beschreibung nach gehaßt von denen, die sie nicht kennen, oder die vergeßlich und undankbar sind gegen ihre Jugend, vielen aber eine erfreuliche und anmutige Erinnerung an die reichste und kräftigste Zeit des Lebens, und wenigen, welche in den Zusammenhang eingeweiht sind, ein interessanter Gegenstand, und die dabei vorkommenden Schwierigkeiten zu lösen eine wichtige Aufgabe.

Sie hat zwei Seiten, diese Freiheit der Studenten, welche wir abgesondert betrachten wollen. Die eine ist die Freiheit, welche sie in Vergleich mit der Schule, von der sie herkommen, auf der Universität genießen, in bezug vornehmlich auf ihre geistigen Beschäftigungen. Sie sind dabei keiner Art des Zwanges unterworfen; nirgends werden sie hingetrieben, und nichts ist ihnen verschlossen. Niemand befiehlt ihnen, diese oder jene Lehrstun- 
den zu besuchen; niemand kann ihnen Vorwürfe machen, wenn sie es nachlässig tun oder unterlassen. Über alle ihre Beschäftigungen gibt es keine Aufsicht, als nur so viel sie selbst einem Lehrer freiwillig übertragen. Sie wissen, was von ihnen gefordert wird, wenn sie die Universität verlassen, und was für Prüfungen ihnen dann bevorstehen; aber mit welchem Eifer sie nun diesem Ziel entgegenarbeiten wollen, und wie gleichförmig oder ungleich ihn verteilen, das bleibt ganz ihnen selbst anheimgestellt. Man sorgt dafür, daß es ihnen an Hilfsmitteln nicht fehle, um immer tiefer in ihr Studium einzudringen; wie gut oder schlecht sie sie aber benutzen, darüber zieht sie, wenn es auch bemerkt wird, wenigstens niemand unmittelbar zur Rechenschaft. So haben sie also volle Freiheit, sich der Trägheit zu überlassen und den nichtswürdigen Zerstreuungen, und können anstatt eines löblichen Fleißes die schönste Zeit ihres Lebens unverantwortlich verschwenden. Und was für ein großer Schade ist es nicht, meint man, wenn auf diese Art viele Jünglinge ohne bedeutenden Nutzen von der Universität zurückkehren, da sie allerdings viel würden gelernt haben, wenn sie in besserer Zucht und Ordnung wären gehalten worden, und einem heilsamen Zwang unterworfen gewesen.

Allerdings würden manche mehr lernen auf diese Art; allein man vergißt, daß das Lernen an und für sich, wie es auch sei, nicht der Zweck der Universität ist, sondern das Erkennen; daß dort nicht das Gedächtnis angefüllt, auch nicht bloß der Verstand soll bereichert werden, sondern daß ein ganz neues Leben, daß ein höherer, der wahrhaft wissenschaftliche Geist soll erregt werden, wenn er anders kann, in den Jünglingen. Dieses aber gelingt nun einmal nicht im Zwang; sondern der Versuch kann nur angestellt werden in der Temperatur einer völligen Freiheit des Geistes, schon an und für sich, vornehmlich aber unter Deutschen und mit Deutschen. So wie nur durch Liebe und Glauben, und dadurch, daß man ihn empfänglich annimmt für beides, der Mensch kann unter das Gesetz der Liebe und des Glaubens gebracht werden, 
nicht durch irgendeine Gewalt oder durch einen Zwang äußerer Übungen; so auch zur Wissenschaft und zum Erkennen, welches ihn befreit vom Dienst jeder Autorität, kann er nur kommen, indem man lediglich durch die Erkenntnis und durch kein anderes Mittel auf ihn wirkt, indem man schon die Kraft in ihm voraussetzt, welche ihn entbindet, irgendeiner Autorität zu dienen, als nur insofern sie sein eignes Erkennen wird, und also aufhört Autorität zu sein. Und nun wir Deutsche noch besonders, wir geschworenen Verehrer der Freiheit nicht nur, sondern der Eigentümlichkeit eines jeden, die wir nie etwas gehalten haben von einer allgemeinen Form und Norm des Wissens wie des Glaubens, noch von einer einzigen unfehlbaren Methode dazu zu gelangen für alle, wie können wir anders als annehmen, daß dieser höhere Geist des Erkennens in jedem auf eine eigene Weise hervorbreche? Wie können wir anders als annehmen und durch unsre Einrichtungen dartun, daß dieser Prozeß durchaus auf keine mechanische Weise könne gehandhabt werden, sondern einen ganz entgegengesetzten Charakter, nämlich den der Freiheit, in allen seinen Teilen an sich tragen müsse? Darum können wir alles, was dazu gehört, nicht anders als höchst zart behandeln; darum sind wir überzeugt, es müsse jedem von den Anleitungen, die dazu führen, eine große Mannigfaltigkeit dargeboten werden, und versetzen eben darum alle, denen wir zum Erkennen verhelfen wollen, in eine so große Gemeinschaft der geistigen Anregungen aller Art; darum setzen wir voraus, jeder müsse am besten wissen, wieviel von diesen Anregungen er vertragen und sich aneignen könne; darum wollen wir gern Raum lassen allem, was jedem von innen kommt, als den ersten Spuren und Andeutungen dessen, was wir zu erreichen streben, und wollen keinen darin beschränken, wie er beides miteinander mische und sich in jedes vertiefe; darum lassen wir jeden, soviel es in einer Gemeinschaft möglich ist, auswählen die schönsten und kräftigsten Stunden, und ihn die anderen nutzen, wie er will und kann. 
So hängt dieser Teil der studentischen Freiheit innig zusammen mit unserer nationalen Ansicht von der Würde der Wissenschaft, und es müßte uns unmöglich sein, diejenigen anders zu behandeln, welche wir für bestimmt halten, Wissende zu werden. Guter Rat darf nicht fehlen, und die Einrichtung der Universitäten gibt Veranlassung genug, ihn zu erteilen; aber auch die mindeste Spur von Zwang, jede noch so leise bewußte Einwirkung einer äußeren Autorität ist verderblich. Bei einer mechanischen, schulmäßigen Einrichtung würde es ein Wunder sein, gesetzt auch die Lehrer wären alle vortrefflich, und alles übrige ebenfalls, wenn diejenigen, die wirklich fähig sind zur Erkenntnis zu kommen, auf der Universität und durch sie dazu gelangten; denn je mehr sich der Geist der Wissenschaft regt, desto mehr wird sich auch der Geist der Freiheit regen, und sie werden sich nur in Opposition stellen gegen die ihnen zugemutete Dienstbarkeit. Und diejenigen, welche die Natur für die Wissenschaft bestimmt hat, sind doch die würdigsten, die eigentlichsten Glieder der Universität; alles ist um ihretwillen da, alles muß sich auf sie beziehen, und nichts darf gelitten werden, was ihnen schlechthin zuwider sein müßte.

Wir haben freilich gesehn, daß die größere Anzahl immer aus solchen bestehen wird, welche nicht bestimmt sind, in das Innerste der Wissenschaft einzudringen; aber ebenso auch, daß es in dem Geiste der Universität liegt, keinen äußeren Unterschied in der Behandlung beider festzusetzen, sondern von der Voraussetzung auszugehn, als würden alle sich zu jener Höhe erheben lassen. Darum müssen alle sich dieser Freiheit erfreuen, und hievon ist um so weniger etwas nachzulassen, da ja gar nicht folgt, daß diejenigen, die freilich nicht den rechten Nutzen aus ihr ziehen, sie deshalb mißbrauchen müssen als eine Lockung zur Trägheit und Zerstreuung. Ist doch auf jeder Universität bei weitem die größte die Anzahl der gar nicht genialischen oder sich eigentümlich und auszeichnend entwickelnden, aber doch treuen und fleißigen Jünglinge. Und das ist auch ganz natürlich. Denn diejenigen, in 
welchen sich keine höhere Kraft regt, und oft wild und verworren genug äußert, ehe sie aus der Gärung in die Klarheit des Bewußtseins übergeht, diese sind desto lenksamer durch alles, was ihnen edel erscheint. Auf sie ist zu wirken durch die Macht der Liebe und der Ehre, in ihnen ist lebendig zu erhalten die Anhänglichkeit an das Haus, an den Staat, an den Beruf, den sie sich vorgesetzt haben, an alles, was Gesetz und Ordnung heißt. Wenn also Eltern und Pfleger Jünglinge zur Universität senden, in denen sie den Genius vermissen, welcher die Freiheit schlechthin fodert; so mögen sie nur dafür sorgen, sie hinzusenden aufs festeste gebunden durch alle diese schönen Bande. Die Universität kommt ihnen ja auf alle Weise zu Hilfe. Sie bietet religiöse Anstalten dar, welche nicht etwa nur um dieser untergeordneten Glieder willen, sondern ebenso sehr auch für die edelsten und trefflichsten, um die Wissenschaft und die innerste Kraft des sittlichen Lebens auf das festeste zu binden, nirgends fehlen sollten; sie vergegenwärtiget in den Entlassungen derer, welche die öffentlichen Zeugnisse ihrer fortgeschrittenen Bildung ausstellen, die Zeit, wo jeder anfängt zu ernten, was er gesäet hat; sie besitzt eben in ihren Seminarien, ihren Preisaufgaben, ihren dargebotenen Belohnungen und Ehrenzeichen sehr kräftige Ermunterungen zum Fleiß und Erweckungen der Ehrliebe. Gibt es aber auf der Universität Jünglinge, welche weder durch diese Mittel zu einem regelmäßigen Studium zu bringen sind, noch kraft jener Freiheit selbst und der durch sie sich entwickelnden innern Lust und Liebe zur Wissenschaft unmittelbar den dargebotenen Unterricht nutzen: so sind dies unstreitig solche, welche gar nicht auf eine Universität, und gar nicht, auch nicht als treue Arbeiter in das Gebiet der Wissenschaft gehören, welche entweder ganz abgeneigt sind der Erkenntnis, oder gar auch einer niedrigen Denkungsart hingegeben. Daß sich dies eher zeigt in diesem Reiche der Freiheit und vielleicht schneller die Oberhand gewinnt, das ist weder für sie selbst, für ihre Sittlichkeit und ihren persönlichen Wert, noch auch für die Gesellschaft ein Verlust zu nennen, welche es lieber darauf wagen 
muß, daß solche, die schon einen unrichtigen Weg eingeschlagen hatten, die Zeit verlieren, oder eiliger in ihr Verderben gehn, als daß sie denen, auf welchen ihre schönsten Hoffnungen ruhen, das Mittel entziehen sollte, diese wirklich zu erfüllen. Mögen diejenigen zusehn, welche ihre Pflegebefohlenen in diesen reichen und üppigen Boden verpflanzen, wo freilich ganz umkommt, was seiner nicht bedurft hätte, um zu gedeihen! Die Freiheit aber, mit jedem den Versuch zu machen, wie er ihm zusagt, darf weder der Staat noch der wissenschaftliche Körper beschränken. Wenn der letzte schon auf den gelehrten Schulen über der angehenden Jünglinge geistigen Zustand Gutachten ausstellt, welche ihren Pflegern als Rat und Wink dienen können; wenn der erstere die gesetzliche Notwendigkeit, die Universität besucht zu haben, nicht über die Gebühr auch auf solche Geschäfte ausdehnt, die mit der Wissenschaft gar nicht zusammenhängen; wenn er das Vorurteil nicht beschützt, als seien die Universitäten das einzige Mittel, um zu einem gewissen, sehr mäßigen Grade einer ziemlich oberflächlichen geistigen Bildung zu gelangen: so ist alles geschehen, was geschehen konnte, um diejenigen vor der Universität zu bewahren, denen sie verderblich sein muß.

Doch betrachten wir nun auch die andere Seite der studentischen Freiheit. Diese nämlich ist Freiheit in Vergleich mit dem Zustande, welcher auf die Universität folgt, wenn jeder in die bürgerlichen und in die gewöhnlichen geselligen Verhältnisse eintritt. Das Wesentliche dieser Freiheit recht $\mathrm{zu}$ fassen, ist eigentlich nicht leicht. Der eigene Gerichtsstand ist wohl nur ein sehr weniges oder gar nichts davon. Auch kann man nicht sagen, daß den Studenten etwa Vergehungen gegen die Gesetze nachgesehen würden, welche in andern Verhältnissen der Strafe nicht entgehen könnten. Vielmehr genießen sie hierunter keiner andern Begünstigungen, als welcher sich die Jugend überhaupt erfreut, ja sie sind noch Strafen ausgesetzt, welche härter. sind als alle sonst gewöhnlichen, weil sie, wenigstens der Absicht des Gesetzes nach, einen entscheidenden 
Einfluß auf die künftige Lebenszeit haben. Ebensowenig ist die Sache in andern bestimmten Vorrechten zu suchen, welche die Studenten als ein eigen privilegierter Stand genössen. Genau genommen möchte das Wesen dieser Freiheit nur darin bestehen, daß die Studenten unter sich von fast alle dem sich frei halten, was sonst in der Gesellschaft Konvenienz ist, daß sie sich an die Sitten nicht binden, denen hernach jeder in dem Stande, welchen er wählet, sich fügen muß, sondern daß sich auf der Universität die verschiedensten Sitten und Lebensweisen auf das freieste entfalten können. Auf der Straße leben und wohnen auf antike Art; sie mit Musik und Gesang, oft ziemlich rohem, erfüllen, wie die Südländer; schlemmen, wie der Reichste so lange es gehen kann, oder einer Menge von gewohnten Bequemlichkeiten bis zu zynischer Unordnung entsagen, wie der Ärmste, ohne eines von beiden zu sein; die Kleidung aufs sorgloseste vernachlässigen, oder mit zierkünstlerischer Aufmerksamkeit eigentümlich daran schnörkeln; eigne Sprachbildung, eigene geräuschvolle Arten, Beifall oder Tadel zu äußern, und ein vorzüglich auf diese ungestörte Mannigfaltigkeit sich beziehender, gewissermaßen öffentlich eingestandener und gestatteter Gemeingeist, dies ist unstreitig das Wesen der studentischen Freiheit, und alles, was sich sonst noch daran hängt, nur zufällig.

So die Sache angesehen, möchte man fast zuerst fragen, warum denn diese Freiheit so übel berüchtiget ist, und warum es sie denn nicht geben soll? Die kleinen Unordnungen und die Verschwendung väterlicher Güter, welche daraus in einzelnen Fällen entstehen, sind Kleinigkeit gegen das, was die Jugend der begüterten Stände, auch ohne alle Universität, in andern Verhältnissen ausübt. Die kleinen Unbequemlichkeiten, welche den Einwohnern eines Universitätsortes daraus erwachsen, müssen eben als ein lokales Übel angesehen werden, deren eines oder das andere es doch überall gibt, und nachteiligen Folgen dieser Art vorzubeugen, ist eine Aufgabe teils für die Polizei, teils für den Einfluß, welchen sich Lehrer und Vorgesetzte müssen zu erwerben su- 
chen. Wenn doch diese Freiheit sich so von selbst bildet, daß sie von dem innersten Geiste der Universität unzertrennlich zu sein scheint; wenn doch hier die Mannigfaltigkeit und Eigentümlichkeit der Sitten um so stärker heraustritt, als in anderen Ständen die Gleichförmigkeit und Charakterlosigkeit überhand nimmt: so scheint sie ja ein heilsames Gegengewicht, welches man müßte gewähren lassen, wenn nicht die wichtigsten Gründe entgegenstehn. Man nehme hinzu, daß in der Art, wie die meisten Menschen sich eingestanden ungern den lästigen Formen fügen, wie die niedern Stände den höhern schmeicheln und sich schmiegen, diese Jünglinge, welche die Wahrheit und das Wesen der Dinge und des Lebens suchen, zunächst nichts anderes sehen können, als Feigherzigkeit, Trägheit, niedrigen Eigennutz. Soll man ihnen nicht vergönnen, hiegegen den Einspruch so stark und so praktisch als möglich auszudrücken?

Doch es ist wahrlich auch sehr leicht einzusehen, warum diese Freiheit stattfinden muß, und daß sie Beziehungen von der größten Wichtigkeit hat. Im allgemeinen ist die Zeit, wo der Mensch sein besonderes Talent unterscheiden lernt, wo er sich seinen Beruf bildet und aus dem Zustande des persönlichen Unterworfenseins, des Gehorsams, in ein selbständiges Dasein übergeht, zugleich auch die, wo sein Charakter sich festsetzt, wo sein Gemüt eine bestimmte Richtung nimmt, und ein bleibendes Verhältnis von Neigungen sich entwickelt. Daß also hier der Übergang zur Selbständigkeit, daß das Werden des Lebens durch freie Wahl sich auch äußerlich ausprägt, ist natürlich, und es zeigt sich dies auch mehr oder weniger in allen Verhältnissen. Bei denenjenigen aber, die sich der Erkenntnis ergeben haben, soll ja diese Entwicklung nicht nur die eigentümlichste sein, weil sie sonst auf einer niedrigeren Stufe zurückbliebe, als ihrem Streben nach Erkenntnis ziemt; sondern sie muß auch, damit nicht das alte Abgedroschene sich bewähre, daß die Gelehrtesten am wenigsten sehen, was vor den Füßen liegt, ebenfalls eine Sache des Erkennens sein, sie 
müssen sich selbst, wie sie werden, auf das bestimmteste finden. Darum eben sorgt man sie aus der Familie zu entfernen, damit nicht das Gemeinsame derselben die persönliche Eigentümlichkeit zu überwältigen scheine; darum hält man sie noch zurück von der Verbindung mit dem Staate, damit sie dieser großen Gewalt nicht eher anheimfallen, bis sie ihr eigentümliches Dasein, so wie es einem Erkennenden geziemt, festgestellt haben. Dies alles aber würde umsonst sein, wenn sie sich nicht eine Zeitlang in einer Lage befänden, wo sie ganz ihrem eigenen sittlichen Gefühl überlassen sind, wo nichts bloß Äußeres, wie eine in der Gesellschaft, welcher sie noch nicht angehören, gebildete Schicklichkeit für sie allerdings wäre, ihre Neigungen zurückhält, wo sie jede Weise und Ordnung des Lebens versuchen und sehen können, wie mächtig jede Lust und Liebe in ihnen zu werden vermag. Dadurch allein werden sie fähig, in der Folge ihre Stellung und ihre Lebensweise richtig zu wählen, und keine anderen Verbindungen zu knüpfen, als die ihrer Natur angemessen sind. Die durch diese Freiheit hier zu weit geführt werden, die ihr eignes sittliches Gefühl nicht in solchen Schranken hält, daß sie ihrer Würde nicht verlustig gehen, das sind offenbar auch die, welche gar nicht auf die Universität gehörten, welche diese Würde, deren sie so leicht verlustig gehen, nie besessen haben, und deren, wie man meint hier erst verderbte, Sittlichkeit nichts gewesen ist als ein erzwungenes Werk äußerer Zucht und Gewöhnung. Denn wer in der Tat Wahrheit sucht, und andere sollten doch nicht sein Mitglieder dieser Anstalt, der ist auch in sich selbst sittlich und edel; bei ihm wird auch die Erkenntnis vorzüglich Eingang finden, die ihn das Niedrige als nichtseiend und leer verwerfen lehrt; und wenn ein solcher auch in mancherlei Verirrungen hineingeworfen wird, und so die Gewalt der Natur an sich selbst erfährt, so werden auch diese nicht an ihm verloren, und noch weniger von solcher Art sein, daß man aufhören müßte, ihn zu achten und zu lieben. Die aber keiner andern als einer von außen hervorgebrachten Sittlichkeit fähig sind, werden auch keiner wahren Erkenntnis fähig sein, 
ja auch nicht der Einsicht und Bildung, welche selbst in den mehr Untergeordneten auf der Universität soll hervorgebracht werden. Wenn sie also Schaden leiden durch die Art, wie sich diese Unfähigkeit offenbart, so ist er nicht den für ihre wahren Mitglieder notwendigen Einrichtungen dieser Anstalt zuzuschreiben.

Aber es lohnt wohl, daß man nicht nur das Innere, sondern auch das mehr Äußerliche dieser Freiheit betrachte, nicht nur was sie für den Charakter ist, sondern auch was für die Sitten. Die Sitten sind der Ausdruck der innern Sittlichkeit, und inwiefern sie sich als etwas Gemeinsames bilden, und als eine Norm für mehrere, sind sie der Ausdruck ihrer gemeinsamen Sittlichkeit, ein Werk des Bewußtseins, welches jede Gesellschaft und jede Abteilung derselben hat von ihren Verhältnissen. Soll nun die Sittlichkeit reiner werden, und das Bewußtsein klarer: so müssen auch die Sitten und das, was für anständig gilt, nicht unveränderlich sein, sondern bildsam, und müssen auch wirklich gebildet werden. Hier ist nun eben der Vorzug und die Eigentümlichkeit von Deutschland, daß von jeher die Bildung der Sitten nicht ausgegangen ist von den äußerlich höheren Ständen, deren Hoheit ja eben auch nur Sitte ist, und also in Frage steht, sondern von denen, welchen vermöge ihres Geschäftes die ursprünglich bildende Kraft der Erkenntnis einwohnen muß. Diese haben teils in ihrem Kreise unmittelbar den freieren Stil des Lebens eingeführt, der sich von da aus verbreitet hinauf und hinabwärts; teils prüfend entschieden, was von dem Vorhandenen oder anderwärts neu Entstehenden verworfen $\mathrm{zu}$ werden verdiene oder angenommen. Die also auf der Universität sich zur Erkenntnis bilden, sind zugleich die, welche in Zukunft auch die Sitten bilden sollen. Können wir nun von diesen verlangen, daß sie immer nur aus Gehorsam in Gehorsam gehen sollen, aus dem des väterlichen Hauses in den der Konvenienz ihrer künftigen Verhältnisse? Sollen sie von Anfang an und immer dem unterworfen sein, was sie bilden sollen? Vielmehr kann ja der Übergang von dem Gehorsam zu ihren bildenden Einflüssen 
nur der sein durch eine Periode, in welcher sie sich frei fühlen von solchem Zwang, in welcher jeder, eine große Mannigfaltigkeit vor sich habend, seine eigenen Sitten sich frei bildet, wie er sie seinen jetzigen Verhältnissen angemessen findet; nicht damit sie so bleiben, was ja auch nicht geschieht, sondern damit er lerne, auch in künftigen Verhältnissen die Sitte, die er findet, ihnen angemessener gestalten. Darum ist die Universität so notwendig zugleich ein Sammelplatz von Menschen aus den verschiedensten Gegenden; darum arbeitet diese Freiheit, wie sie sich unter uns gestaltet hat, so vorzüglich auf das hin, was uns grade am meisten fehlt, auf den liberalen Ausdruck des Eigentümlichen auch in einer gemeinsamen Form. Wer Gelegenheit gehabt hat zu beobachten, dem wird auch nicht entgangen sein, wie sich die studentische Freiheit als ein wirksames Mittel zu diesem Zwecke bewährt, wie sehr sie, zumal wenn auch die Erkenntnis der Jünglinge auf diesen Punkt gerichtet wird, hilft das Wesentliche und Wahre vom Zufälligen und Leeren unterscheiden, und finden lehrt, was auf der einen Seite notwendig geschehen muß, und was auf der andern höchstens geschehen kann unter den gegebenen Umständen.

Daß die Jünglinge sich hernach anfänglich scheu zeigen und verlegen, daß ihre ersten Versuche in der Gesellschaft oft linkisch ausfallen, ist kein Unglück, und der Fehler würde sich noch eher verlieren, wenn das Verhältnis der Studenten zur Gesellschaft auf der Universität selbst richtiger organisiert wäre. Die Studierenden bedürfen einer großen Abgeschiedenheit von den übrigen; sie dürfen in die Leerheit des gewöhnlichen geselligen Verkehrs nicht hineingezogen werden. Auf der andern Seite aber kann sich nie eine Klasse von Menschen ungestraft ganz isolieren. Das rechte Maß ist auch hier ein natürliches. Wenn der Umgang der Lehrer mit den Schülern lebendig und auf den rechten Ton gestimmt ist; wenn die Ausgezeichnetern, die allein daran teilnehmen können, auch von allen andern Seiten so qualifiziert sind, daß ihnen ein bedeutender Einfluß auf ihre Gefährten nicht entgehen kann; wenn 
die Älteren die rechte Gewalt ausüben über die Neulinge, alles ohne dem Wesen der studentischen Freiheit zu nahe zu treten: so wird auch hier das Rechte immer mehr erreicht werden, und das nach jedem vernünftigen Maßstab rohe und ungeschlachte Wesen sich immer mehr verlieren.

Wohl! wird auch dies alles zugegeben, so klagt man noch über zwei große und wesentliche Übel, welche jene Freiheit begleiten, und von welchen unrecht wäre ganz zu schweigen.

Das eine ist, daß die Studenten alles Nichtstudentische in diesen einen großen Gegensatz als Philisterwesen zusammenwerfen, und sich jede nur nicht offenbar straffällige Verhöhnung dagegen erlauben. Dieser herrschenden Stimmung liegt aber etwas sehr Wahres zum Grunde, nämlich der Gegensatz zwischen dem höchsten bildenden Prinzip, welches sie in sich zu entwickeln da sind, und der rohen, gemeinen, der Bildung widerstrebenden Masse, der sich ihnen desto stärker aufdringt, je weniger sie selbst noch in dem lebendigen bildenden Verhältnis zu dieser Masse stehn. Die Verachtung und Härte gegen die widerstrebende sittliche und geistige Roheit sollte man ihnen nur recht tief einprägen, und es ihnen zum Ehrenpunkt machen, in dieser Hinsicht immer Studenten zu bleiben. Wenn sie aber glauben, das bildende Prinzip nur unter sich, und überall sonst die verächtliche Masse zu finden: so ist das der Ausbruch des Übermutes, der zurückgedrängt werden muß, und die natürliche Folge jener zu starken Isolierung. Aber im ganzen kann man auch der Gesamtheit dieser Jünglinge Gerechtigkeitssinn nicht absprechen; das Achtungswerte, was sich ihnen als solches offenbart, wissen sie zu ehren. Man zeige ihnen nur recht viel Edles in recht freien Formen; man sorge nur dafür, daß sie nicht unter denen, die ihnen die Nächsten sind, unter ihren Lehrern, das Gemeine haufenweise erblicken: so wird auch hier der Mißbrauch leicht beseitiget werden, ohne daß das Gute verloren geht. 
Das andere ist der Zweikampf, und dieser ist eine höchst natürliche und unvermeidliche Erscheinung. Diejenigen, welche die Wissenschaft suchen und in noch nichts anderes verflochten sind, sind dem Staate mehr als sonst irgend ein einzelner fremd, und können nicht gewohnt sein, einander aus dem Gesichtspunkte des Bürgers zu betrachten. Auch insofern sie damit beschäftiget sind, ihrer Person die höchste Würde zu verschaffen und sich innerlich durch Erkenntnis über alle anderen zu erheben, müssen sie, hinzugenommen das Feuer der Jugend, am reizbarsten sein gegen Kränkungen, die ihrer Person widerfahren, und können weniger als andere in Ehrensachen Recht und Genugtuung vom Gesetz nehmen, da dies fast überall Erörterungen vorschreibt, welche das reizbare Gefühl aufs neue empören - oder Abstufungen in der äußern Würde, und demgemäß auch Verschiedenheiten in der Zurechnung und Strafe der Beleidigungen annimmt, welche sie sich nicht können gefallen lassen. Dazu kommt, daß, so wie in den Augen der der Wissenschaft Beflissenen ihre Person den höchsten Wert hat, sie auf der andern Seite noch durch keine besondere Verbindung verpflichtet sind, ihrer zu schonen, und daß also für das höchste Gut auch der höchste Preis geboten und gewagt wird. Es liegt zutage, daß die Sühne für persönliche Beleidigungen die Aufgabe ist, welche der Staat noch am wenigsten zu lösen weiß, und in allen Ständen offenbart sich die Neigung, sich selbst zu helfen. Aus dem Gesagten erhellt nun wohl, daß, so lange es noch irgend einen Stand gibt, bei welchem der Zweikampf die übliche Form dieser Selbsthilfe ist, gewiß auch auf der Universität keine andere wird gebräuchlich sein, und daß in Zukunft wie bisher alle Anstalten, ihn abzuschaffen, vergeblich sein werden, bis etwa auf einem andern Wege die Gesetzgebung und das herrschende Ehrgefühl einander näher gekommen sind. Tragische Ausgänge sind auch so selten, daß man bei weitem weniger Aufheben von der Sache machen würde, wenn nicht unter den bürgerlichen Ständen eine panische Furcht herrschte vor dem Gedanken an das Klirren der Degen. Daß jedoch großer Mißbrauch mit dem Zweikampf getrieben wird, läßt 
sich nicht leugnen, auch wenn man die Sache selbst als unvermeidlich ansieht. Aber eben gegen diese Mißbräuche ließe sich viel tun, wenn man nicht so hartnäckig darauf bestände, alle Mittel, die man in Händen hat, nur an der vorderhand unmöglichen Abstellung zu verschwenden. Vorzüglich müßten alle gymnastischen Übungen und namentlich das Fechten unter öffentlicher Autorität kunstmäßig bis zur höchsten Vollkommenheit getrieben werden. Dadurch würde der Zweikampf nicht nur minder gefährlich werden, sondern auch, indem jeder sich den Ruf der Gewandtheit, der Stärke, des Mutes schon durch die Übungen erwerben könnte, würden die Trefflichsten es am leichtesten verschmähen dürfen, für jede Kleinigkeit Genugtuung zu fordern, weil doch niemand es auslegen könnte als Feigherzigkeit, und so würde das Ehrgefühl selbst von innen heraus sich allmählich berichtigen. Ja auch viele Veranlassungen zum Schlagen würden wegfallen. Denn auch hier zeigt sich, welch eine gefährliche Sache es ist, wie ein alter Weiser sagt, die Seele zu üben ohne den Leib. Weil es auf den Universitäten so viele gibt, die dieses tun, so entsteht eben daraus auch das Entgegengesetzte, daß viele wiederum den Leib üben ohne den Geist, und in diesen bildet sich dann das äußere Ehrgefühl des Standes, welchem sie angehören, auf eine desto herbere und leidenschaftlichere Art bis zur wirklichen Schlagesucht. Ist hierin das Gleichgewicht hergestellt, so werden nur noch wenige Fälle übrig bleiben für unvermeidlichen Zweikampf. Anerkennen kann der Staat, und selbst die Korporation der Universität, insofern sie gerichtliche Funktionen ausübt, freilich auch diese nicht; aber sie wird dann die Maßregel, die Zweikämpfe so viel möglich zu ignorieren, wenigstens auf diejenigen nicht mehr anwenden dürfen, welche die gymnastischen Übungen verabsäumt und sich geschlagen haben, ohne ausgelernte Fechter zu sein, auch auf diejenigen nicht, welche den bei weitem zufälligeren Schuß dem Gefecht vorziehen. Dadurch würde, bei gehöriger Wachsamkeit, ohne dem Ehrgefühl zu nahe zu treten, dieses gefährliche Spiel bald in die möglichst engen Schranken zurückgewiesen werden. 


\section{Von Erteilung der gelehrten Würden}

Dies ist unstreitig die am meisten veraltete Partie unserer Universitäten. Die scholastische Form der Disputationen ist zu einem leeren Spielgefecht geworden: und da man es auch mit dem übrigen durchgängig nicht sonderlich genau genommen hat, so ist der Kredit fast aller auf der Universität erteilten Würden tief unter den Punkt der Satire herabgesunken. Es fehlt nur noch, daß man es als einen Maßstab der größten Schnelligkeit angäbe, wie ein Student sich in einen Doktor der Philosophie verwandelt. Der größte Beweis aber dieses allgemeinen Mißkredits ist, daß häufig der Staat diese Würden nicht einmal für zureichend hält, um den Besitzern ohne weitere Prüfung die Praxis in den Gerichtshöfen oder auch die ärztliche zu verstatten, was in der Tat eine solche Unzufriedenheit desselben mit den Universitäten voraussetzt, daß man sich nur wundern muß, wie er sie doch sonst anerkennt und unterstützt. Fast nur in den ehemaligen kleinen Reichsländern und Reichsstädten, die selbst keine Universitäten haben, gleichsam als ob dies nur bei minderer Kenntnis der Sache möglich wäre, hat sich noch die Achtung für diese Würden erhalten, welche der Idee derselben angemessen ist. Und doch geschehen diese öffentlichen Erklärungen großenteils für den Staat und in Beziehung auf ihn. So geht es, wenn ein Institut das klare Bewußtsein seines Zweckes sich nicht erhält, und also verfehlt, sich allmählich nach Maßgabe desselben umzubilden. Dann ist ihm späterhin nicht anders mehr zu helfen als durch große durchgreifende Reformen; und nur durch diese könnte auch den Graden, welche die Universität erteilt, ihr verlorenes Ansehn wieder verschafft werden.

Die wahre Bestimmung der gelehrten Würden ist leicht einzusehn, wenn man sich an das bisher Gesagte hält. Soll es einen wissenschaftlichen Verein geben als eine äußere Gesellschaft: so muß es auch eine äußere Handlung geben, durch welche der Einzelne aus der übrigen Masse abgesondert und in denselben aufgenom- 
men wird. Da nun auf der gelehrten Schule diese Sonderung nicht streng und eigentlich erfolgen kann, sondern auch zur Universität noch alle diejenigen müssen zugelassen werden, welche sich auf der Schule nur ein vorläufiges Recht erworben haben, nach dieser Aufnahme zu streben: so kann diese Handlung nur nach zurückgelegter Laufbahn auf der Universität erfolgen. Natürlich aber ist die Aufnahme selbst und die Entscheidung über die Würdigkeit auf das genaueste verbunden, und die letztere kann nur dadurch entstehen, daß durch die Tat selbst ein einstimmiges Urteil des Aufzunehmenden und derer, welche den wissenschaftlichen Verein dabei repräsentieren, sich bilde. Hieraus erklärt sich auch die Form dieser Handlungen im allgemeinen. Es muß dadurch dokumentiert werden, daß der Einzelne den Geist der Wissenschaft als Prinzip in sich aufgenommen hat; dies geschieht durch das Gespräch, durch die Disputation, wodurch er veranlaßt wird, seine Denkungsart und das Innere seiner Ansichten zu eröffnen, und zu zeigen, welcher Kombinationen er fähig ist. Dabei liegt der alte Satz zum Grunde, daß die dialektische Konsequenz bewähren müsse, ob etwas Aufgestelltes in wissenschaftlichem Geist hervorgebracht sei oder nicht. Es soll aber auch ferner dokumentiert werden die Fähigkeit des Aufzunehmenden, die Wissenschaft weiter zu bilden. Darum muß er auch bewähren, wie er in einem einzelnen Felde des realen Wissens einheimisch, und mit dessen Fortschritten sowohl als dessen Bedürfnissen bekannt ist; und dies soll eben geschehen durch die abzufassenden Dissertationen oder durch die eigentlichen mündlichen Prüfungen. So kann es nicht fehlen, daß in dem Aufzunehmenden, wenn nicht eine von beiden Parteien bösen Willen hat, ganz dasselbe Urteil entsteht wie in seinen Richtern. Denn mit dem Produkt zugleich, welches ihnen die Anschauung von seinem Zustande gibt, muß sich auch sein eigenes Selbstgefühl dem analog entwickeln. Die eigentliche Aufnahme besteht nur in symbolischen Gebräuchen, welche die Handlung beschließen. 
So erscheint die Sache ganz einfach; allein sie wird weit verwickelter, wenn man sie näher betrachtet. Auf die Universität nämlich gehen viele, die sich zwar nicht durch lebendige Vereinigung des wissenschaftlichen Geistes und des Talentes zu wahren Mitgliedern des wissenschaftlichen Vereins ausbilden, aber doch vermöge ihres Talentes eine Menge von Kenntnissen einsammeln und Fertigkeiten erlangen, und so viel Ehrfurcht und Anhänglichkeit gewinnen für das, was auf dem eigentlich wissenschaftlichen Gebiet vorgeht, daß man erwarten kann, sie werden sich in der Anwendung ihrer Talente durch die wissenschaftlichen Geister leiten lassen. Dies sind Arbeiter auf dem Gebiet der Wissenschaft. Ob nun diese als Mitglieder des Vereins sollen angesehen, und also auch, wiewohl in einem andern Sinne und auf andere Weise, darin aufgenommen werden, oder ob er sie nur durch vorteilhafte Zeugnisse seinen Mitgliedern als brauchbare Werkzeuge für bestimmte Fächer empfehlen soll, das hängt schon davon ab, in wie strengem oder weitem Sinne der Begriff dieses Vereins gefaßt wird, und kann recht sein so oder so. Aber auch unter den wahren Mitgliedern zeigt sich ein Unterschied für den wissenschaftlichen Verein. Ihr Talent nämlich kann, wie wir zu sagen pflegen, mehr praktisch sein oder mehr theoretisch, und dann auch ihre Gesinnung und Lebensweise mehr gelehrt oder mehr politisch. Die letzteren werden, wie sehr sie auch vom wissenschaftlichen Geiste durchdrungen sind, dennoch mehr darnach streben, das Erkannte auf eine reale Weise darzustellen, die Wissenschaft mit dem Leben $\mathrm{zu}$ einigen, und ihre Früchte in dasselbe überzutragen, als daß sie an ihr selbst arbeiten und bilden sollten. Nur diejenigen aber, welche sich das letzte zum Geschäft machen, werden die höchsten sein für den wissenschaftlichen Verein; nur sie werden die Stellen ausfüllen auf der Universität und in der Akademie, und wenn sie an öffentlichen Geschäften teilnehmen, dieses, eben wie jene das Lehren, nur als Nebensache ansehn. Sie allein sind also die eigentlichen Doctores, von denen aber auch in einem höheren Grade muß gefordert werden, daß sie von dem Zustande einer besonde- 
ren Wissenschaft genaue Kenntnis, und in der Handhabung derselben großes Geschick beweisen. Hier sind nun vorzüglich die Proben der Gelehrsamkeit an ihrer Stelle, und müssen eigentlich immer von der Art sein, daß sie etwas Merkwürdiges bleiben für dieses Gebiet. Ein Doktor, welcher nicht gleich bei seinem Eintritt in diese Würde eine Spur von seinem Dasein zeichnet, welche allgemeine Aufmerksamkeit erregt und während der Epoche, in der sich die Wissenschaft eben befindet, nie ganz verschwinden kann, ein solcher ist eigentlich seines Namens unwürdig. Was der zu Erhebende mit einer solchen Probe noch weiter verbinden will, zum Beweise seines Talentes für das Lehrgeschäft, welches ihm natürlich anheimfällt, das hängt am besten von ihm selbst ab, ob ein gelehrtes Gespräch oder eine kleine Anzahl von Vorlesungen über einen bestimmten Gegenstand. Oder wenn er dennoch die Form der Disputation wählen wollte, die eigentlich hieher am wenigsten gehört, und nur in den scholastischen Zeiten der Theologie, aus denen sie herübergenommen ist, alles in allem sein konnte: so müßte ihr nur der Zweck untergelegt werden, daß er als Schiedsrichter der eigentlich Streitenden die Gabe zeigte, den Gang ihrer Rede so zu leiten, daß der Gegenstand klar werden müßte, und zu verhüten, daß sie sich nicht durch Mißverständnis immer tiefer verwickelten.

Welches ist nun aber weiter das richtige Verhältnis der Fakultäten in Absicht auf die Erteilung dieser Würden? Daß jene Zeugnisse, oder wenn es als mehr angesehen werden soll: der niedrigste Grad von jeder Fakultät für sich erteilt wird, versteht sich von selbst, da es hiebei nur auf die innerhalb ihres besonderen Gebietes erworbenen Kenntnisse ankommt. Dasselbige gilt von der höchsten Würde der Doktoren, inwiefern diese von dem vorangehenden mittleren Grade sich sondert und allemal auf ihn gepfropft wird. Ohnstreitig ist dies das Richtigste, da jeder, sobald er den wissenschaftlichen Geist in sich lebendig fühlt, auch nach den äußerlichen Zeichen dieses Vorzuges streben wird, jenes andere aber, ob 
Neigung und Talent mehr auf das Praktische hingehe oder auf das Theoretische, sich gewöhnlich erst später entscheidet. Dann also hat man es wiederum nur mit dem Gebiet jeder besonderen Fakultät bei Erlangung dieser höchsten Würde zu tun, und jede kann also auch unter dieser Voraussetzung für sich verfahren. Ob aber auch jene eigentlich erste Würde, da sie zugleich die Aufnahme in den gesamten wissenschaftlichen Verein ist, und dabei alles auf den Geist und das Vermögen der Erkenntnis überhaupt ankommt, ob diese zu erteilen auch die Sache der einzelnen, mehr positiven Fakultäten sein kann, die nur durch ihre Verbindung mit der philosophischen den wissenschaftlichen Verein repräsentieren können, und sie nicht vielmehr - wo nicht ausschließlich, doch vorzüglich - von der philosophischen Fakultät ausgehn muß, dies ist gewiß sehr zu überlegen. Am nächsten scheint hier die theologische Fakultät sich an das zu halten, was die Natur der Sache erfordert. Die niedrigste Bewährung pflegt sie nur durch Zeugnisse zu beurkunden; von zwei verschiedenen Graden zeigen sich fast nur noch da Spuren, wo sie sich mehr als Spezialschule, und nicht auf eine lebendige Weise mit den andern und der philosophischen zu einer Universität vereiniget zeigt. Bei Erteilung ihrer Doktorwürde aber setzt sie in der Regel die philosophische voraus, und läßt letztere allein auch bei sich den niederen Grad vertreten, natürlich in Voraussetzung der von ihr selbst eingeholten Zeugnisse. Offenbar wenigstens müßte überall bei dieser ursprünglichen Aufnahme die philosophische Fakultät mit zugezogen werden, da keine andere als sie für sich allein die Einheit des wissenschaftlichen Vereins unmittelbar repräsentiert. Innerhalb dieser Fakultät selbst aber tritt wiederum mit wenigen Abänderungen dasselbe Verhältnis ein, welches zwischen ihr und den andern Fakultäten stattfindet, weil sie nämlich in sich selbst auch ein Zentrum hat, die Philosophie im engen Sinne, und nach außen mehrere Seiten, die realen Wissenschaften. Zeugnisse kann sie nur ausstellen über geschichtliche und naturwissenschaftliche Kenntnisse; denn wer von der höheren Philosophie nur Kenntnisse hat, ohne den wissenschaft- 
lichen Geist, abgerechnet, daß nach solchen kaum jemand fragen wird, der hat sie auch nur geschichtlich. Zwei Grade aber müßten in ihr auch unterschieden werden, indem alle, welche von der Universität aus entweder in die Staatsverwaltung oder in die Naturbearbeitung für den Staat in einem großen Sinne eingreifen wollen, billig den wissenschaftlichen Geist in sich müssen ausgebildet haben, dennoch aber manches entbehren können, was dem, der den Beruf des Lehrers fühlt, nicht fehlen darf. In beiden Graden wird jeder immer einen bestimmten Zweig des realen Wissens angeben können, von dem er vorzüglich ausgehn will; weshalb denn außer den Philosophen im engeren Sinne auch diejenigen vorzüglich seine Richter sein mögen, welche diesen Zweig bearbeiten, wiewohl auch das nicht das Ratsamste sein möchte, da doch in der Folge kein Gebiet dem Aufgenommenen verschlossen ist; auf jeden Fall aber werde, wer die Würde eines Doktors erhält, zum Doktor der Philosophie schlechthin ernannt, ohne einen Beisatz, der auf eine einzelne Disziplin hinweiset. Denn die Fakultät, welche vorzugsweise die Einheit aller Wissenschaften repräsentiert, die ohnedies von allen Seiten her genugsam verdunkelt wird, muß auch in ihren feierlichen Handlungen diese Einheit bestimmt aussprechen. Doktoren der Geschichte oder der Ästhetik zu ernennen, ist fremd und lächerlich, und wird gewiß, wenn man es auch willkürlich einführt, nicht bleibend sein und geschichtlich werden.

Was aber nicht wesentlich zu sein scheint bei diesen Handlungen, sondern nur dem früheren Zustande der Roheit und Unwissenschaftlichkeit unserer Sprache angemessen, das ist der durchgängige Gebrauch der lateinischen in allen diesen Geschäften. Gewiß hat diese Einrichtung, weil die größere Menge sich dabei zu mancherlei Verfälschungen versucht fühlen mußte, nicht wenig beigetragen, die gelehrten Würden selbst um ihren guten Ruf zu bringen. Je mehr wir auch Fortschritte machen, um desto mehr muß gewiß jene schon längst abgeschlossene Sprache sich zur wissenschaftlichen Darstellung für uns, außer auf dem philolo- 
gischen und vielleicht mathematischen Gebiet, unbrauchbar zeigen. Was für Gewinn soll auch entstehn, wenn, was deutsch vortrefflich gesagt werden konnte, in römischer Sprache mittelmäßig auftritt? Es ist genug, wenn außer jenen Gebieten die römische Sprache rein und zierlich bei solchen öffentlichen Gelegenheiten erscheint, welche mehr eine populäre und schöne, als eine wissenschaftliche und gründliche Darstellung fordern, und wo sich der Redner nach Belieben in dem Gebiet antiker Gesinnung und Ansicht halten darf.

So ohngefähr gestalten sich die gelehrten Würden, rein aus dem Gesichtspunkt des wissenschaftlichen Vereins angesehen; was für Rücksichten aber hat wohl der Staat darauf zu nehmen, oder überhaupt gar keine? Er gesellt sich doch zu der wissenschaftlichen Vereinigung und nimmt sich ihrer an, oder untergibt ihr die von ihm selbst gestifteten Unterrichtsanstalten, um gewiß für die Geschäfte, wozu es deren bedarf, Männer von Kenntnissen und von höherer Bildung zu finden. Stimmt dies wohl zusammen damit, daß er doch hernach dem Urteil dieses Vereins nicht traut, und sich nicht darnach richtet? Es läßt sich unterscheiden für den Staat ein niederer Dienst und ein höherer. Wie wohl es getan ist, auch diejenigen, welche eigentlich für den höheren bestimmt sind, sich dennoch zunächst eine lange Zeit im niedern Gebiet herumtreiben $\mathrm{zu}$ lassen; oder wie richtig die Meinung sein mag, daß, wer nur lange genug den niedern Dienst verrichtet hat, auch wohl geschickt sein werde für den höheren: dies gehört nicht hieher zu untersuchen; die Verschiedenheit in der Sache aber ist einleuchtend und bekannt. Im niedern Staatsdienst gibt es ein ansehnliches Gebiet, welches Kenntnisse wissenschaftlicher Art erfordert. Wenn die Universität im Namen des wissenschaftlichen Vereins einem Einzelnen das Zeugnis ausstellt, daß er diese besitzt: so weiß ich nicht, was für einen Sinn die Prüfung noch haben soll, welche der Staat durch Beamte über ihn verhängt; so wie, wenn er sich auf das Zeugnis der letztern verlassen will, nicht einzusehen ist, wa- 
rum er den Besuch der Universität zur Pflicht macht. Diese hinzukommende Prüfung sollte zur Qualifikation des Einzelnen gar nicht gehören; sondern nur um zu erfahren, wozu er sich besonders eignet, und wieviel er schon von den kleinen Fertigkeiten und Notizen mitbringt, welche allenfalls auch erst durch die Übung dürfen erworben werden. Für den höheren Dienst bedarf es nicht nur einer Masse wohlerworbener Kenntnisse, sondern auch Übersicht des Ganzen, richtiges Urteil über die Verhältnisse der einzelnen Teile, ein vielseitig gebildetes Kombinationsvermögen, einen Reichtum von Ideen und Hilfsmitteln. Soll dies alles zuverlässig sein und geordnet, so muß, wer sich dieser Gaben rühmt, in das Heiligtum der Wissenschaft eingedrungen sein. Darum eröffnet es auch der Staat seinen künftigen Dienern, und will sie nur aus diesem empfangen. Sollten nun nicht eben hierüber auch die Zeugnisse der wissenschaftlichen Anstalten, wenn sie zweckmäßig und streng erteilt werden, das erste sein, worauf der Staat sich verläßt? Das Vorurteil, als ob es etwa einem adlig Gebornen, oder überhaupt der Klasse, welche auf die höheren Geschäfte Anspruch macht, kaum anstehe, einen gelehrten Grad anzunehmen, und ein solcher sich dadurch schon selbst von den Geschäften ausschließe und zum Schulstaube verdamme, kann wohl kaum gerechtfertigt werden, sondern muß verschwinden, wenn Staat und Universität sich selbst und gegenseitig verstehen. Vielmehr sollte der höhere Staatsdienst gerade nur solchen eröffnet sein; diejenigen, welche sich mit dieser Würde ausschließlich in die politische Laufbahn begeben, sollten überall an die Spitze der Geschäfte gestellt zu werden Hoffnung haben, und auch die, welche mit der Würde der Lehrer bekleidet sich vorzüglich den Wissenschaften widmen, sollte doch der Staat als Aufseher, als Ratgeber bei allem, was in ihr besonderes Fach einschlägt, zu gebrauchen wissen. Doch diese Änderung in der gegenwärtigen Praxis müßten die Universitäten selbst vorbereiten; sie müssen ihre gotischen Formen beleben, sie müssen mit den Würden, die sie erteilen, nicht länger ein Spiel treiben und sie mißbrauchen lassen zu leeren Namen. 


\section{Anhang über eine neu zu errichtende Universität}

Man sagt, der preußische Staat fühle das Bedürfnis, auch für seinen verminderten Umfang die verlorene ehemalige FriedrichsUniversität durch eine andere, neu $\mathrm{zu}$ errichtende $\mathrm{zu}$ ersetzen, und man sagt, es sei beschlossen, in Berlin solle sie errichtet werden. Großenteils in dieser Hinsicht sind die vorstehenden Gedanken gerade jetzt niedergeschrieben und bekannt gemacht worden, und sie würden ihren Zweck verfehlen, wenn nicht von einigem wenigstens die Anwendung auf den vorliegenden Fall hinzugefügt würde.

Das Gefühl, welches diesen Entwurf erzeugt hat, ist gewiß sehr richtig und achtungswert. Es beweiset, daß Preußen den Beruf, den es lange geübt hat, auf die höhere Geistesbildung vorzüglich $\mathrm{zu}$ wirken und in dieser seine Macht zu suchen, nicht aufgeben, sondern vielmehr von vorne anfangen will; es beweiset ferner ganz bestimmt, was wohl ebenso viel wert ist, daß Preußen sich nicht isolieren will; sondern auch in dieser Hinsicht mit dem gesamten natürlichen Deutschland in lebendiger Verbindung zu bleiben wünscht. Zwei Provinzialuniversitäten hat es bereits. Königsberg für die außerdeutschen, oder vielmehr, da es ja jetzt keine Beziehung mehr gibt, in welcher das eigentliche Preußen weniger deutsch wäre als Brandenburg, für die nördlichen, Frankfurt für die südlichen Provinzen. Aber mehr können auch diese beiden Anstalten ihrer Natur nach nicht werden; auch Frankfurt ist $\mathrm{zu}$ abgelegen, um irgend Ausländer an sich zu ziehn, die für eine große Universität von der höchsten Wichtigkeit sind, um die Anlage zu einer hart manierierten intellektuellen Existenz, wie sie im eigentlichen Preußen so sehr auffällt, und wie man sie auch auf den königlich sächsischen Universitäten findet, in Schranken $\mathrm{zu}$ halten. Frankfurt war nur gut zu einer Missionsanstalt für die Polen, um welche sich Preußen hoffentlich jetzt weniger beküm- 
mern wird. Auch müßte diese Universität, um sie bedeutend zu machen, durchaus neu geschaffen werden, und warum sollte der Staat die Kräfte, welche dazu gehören, an einem übel gelegenen Ort und an der Umbildung einer durchaus untergeordneten und in vieler Hinsicht schlechten Anstalt, was immer eine ebenso undankbare als schwierige Arbeit ist, verschwenden, da er mit fast gleicher Anstrengung Neues erbauen kann?

Aber warum gerade in Berlin? Potsdam freilich kann wohl kaum einem Sachkundigen einfallen, da eine Universität in einer kleinen Stadt mit dem privilegiertesten Militär und dem Hofe dicht zusammen, der alle Kleinigkeiten notwendig erfahren müßte, in der Nähe der Hauptstadt eigentlich der wunderlichste Gedanke ist, den man haben kann. Allein Brandenburg, Havelberg, mittlere Städte nahe an der Grenze, also gelegen für die Ausländer, und wo man zum Besten der Universität allmählich große Fonds einziehn könnte, dergleichen sollten einem jeden weit eher in den Sinn kommen, als Berlin. Sollte also bei einer so auffallenden Wahl eine Hinsicht auf Vorteile entschieden haben, welche Berlin allein darbietet? Diese sind freilich leicht zu sehn, insofern es in den preußischen Staaten der reichste Sammelplatz ist von Gelehrsamkeit, von Talenten, von Kunstübungen aller Art, insofern es viele Institute in sich faßt, welche die Universität unterstützen und wiederum durch die Verbindung mit ihr neuen Glanz oder einen höhern Charakter bekommen könnten, insofern es zugleich die gebildetsten Formen des Lebens darstellt, und die höchsten Würden, zu denen sich der anstrebende Jüngling in jedem Fache emporschwingen kann, ihm dicht unter die Augen bringt. Allein dies sind Vorteile, deren alle Universitäten, welche für die Wissenschaft und den Staat den meisten Nutzen gestiftet haben, immer entbehrten. Dagegen hat Berlin für eine solche Anstalt eigne, nicht zu verkennende Nachteile, die aus der Weitläuftigkeit der Stadt, der Teurung der Bedürfnisse, der Leichtigkeit der Zerstreuungen, der Mannigfaltigkeit andringender Versuchungen, der Ofensitze- 
rei vieler Jünglinge, die hier schon auf Schulen erzogen, hier auch studieren, und hier gleich in die Verwaltung treten würden, und eigentlich von allen Seiten, könnte man wohl sagen, unausbleiblich entstehen müssen, Nachteile, welche dem großen Publikum am meisten in die Augen leuchten, und welche es der neuen Anstalt, die ohnehin mit mannigfaltiger Eifersucht zu kämpfen hätte, schwer machen würden, Vertrauen zu gewinnen. Sollte also jetzt wohl der Zeitpunkt sein, um jener mehr glänzenden als wesentlichen Vorteile willen einen mißlichen Kampf zu wagen mit diesen Nachteilen? Wer einen so bedeutenden Verlust gemacht hat, der darf nicht leichtsinnig spekulieren, sondern muß mit sichern Unternehmungen von neuem anfangen, um seinen Kredit zu heben.

Schon unter der vorigen Regierung, zu einer Zeit, wo der preußische Staat durchaus kein Bedürfnis hatte, eine neue Universität zu errichten, wurde ein Plan gemacht zu einer großen Lehranstalt in Berlin, welche eigentlich keine Universität sein, aber doch die Dienste der Universitäten leisten sollte, von einem sehr gebildeten Schriftsteller, der Prinzenlehrer gewesen war und zugleich das Schauspiel dirigierte. An Feinheit und an Pracht, wie an höfischer Vornehmigkeit wird es also dem Entwurf nicht gefehlt haben. Zur Ausführung ist er indes nicht gekommen, wenn man nicht eine und die andere, um diese Zeit entstandene Spezialschule ansehn will als Versuche, mit solchen einzelnen Teilen dieses Ganzen, denn auf einen Mittelpunkt und dessen lebendige Kraft mag wohl wenig gerechnet worden sein - den Anfang zu machen, bei denen man am wenigsten in Grenzstreitigkeiten käme mit den bestehenden Universitäten. Die Hauptabsicht war ohnstreitig, die gotische Form und das Zunftwesen der alten Universitäten allmählich zu untergraben, vorzüglich aber den sogenannten Studentengeist zu tilgen, der von Furchtsamen für höchst furchtbar und verderblich gehalten wurde. Mit solchen Bildungsversuchen aus heiler Haut, ohne daß ein bestimmtes Bedürfnis bestimmte Maßregeln natür- 
lich erzeugte, und ohne daß man von dem Umzubildenden eine vollständige Ansicht genommen hätte, um sich zu überzeugen, wie das wesentliche Gute und die dermaligen Mißbräuche sich gegeneinander verhalten und worin beide gegründet sind, ist es immer eine bedenkliche Sache. Wer Zeit und Kraft übrig hat und es nicht scheut, mit wichtigen Dingen auch zu spielen, der mag dergleichen wagen. Soll man aber wohl glauben, daß eine weise Regierung unter den gegenwärtigen Umständen einen so entstandenen Plan hervorsuchen werde, dessen Erfinder gewiß durch reife Einsicht in das streng wissenschaftliche Gebiet nicht vorzüglich glänzte, sondern vielmehr durch einseitiges Popularisieren für diesen Gegenstand sich mißempfiehlt, und dessen Hauptabsicht war, einen Geist zu untergraben, den man, mit möglichster Beseitigung seiner Auswüchse und verkehrten Äußerungen, jetzt mehr als je suchen sollte sorgfältig zu bewahren als Einigungsmittel für den besten Teil des künftigen Geschlechtes und als Gewahrsam für echt vaterländischen Sinn? Gewiß, das wollen wir nicht denken, um so weniger, da auch jene ganze Methode, die realen Wissenschaften aus dem Zusammenhang mit der Philosophie herauszureißen, und entweder auf willkürliche Theorien zu bauen, oder in bloße Empirie verwandeln zu wollen, sich unter uns wohl längst überlebt hat.

Es scheint also nichts übrig zu bleiben, um eine solche Wahl für das Lokale einer neuen Universität zu erklären, wenn sie sich doch in Berlin nicht eben wesentlich besser befinden wird als anderswo, als daß irgend eine Notwendigkeit vorhanden ist, weshalb sie nur in Berlin überhaupt bestehen kann; und diese ist leicht aufzuzeigen. Denn wenn sie sogleich gestiftet und in Tätigkeit gesetzt werden soll, und wenn ihre Lage allerdings eine solche ist, daß sie sich bei einem kränklichen Anfang kein langes Leben versprechen darf: woher soll sie anderswo alle die Hilfsmittel nehmen, welche einer blühenden Universität notwendig sind? Hätte sie auch Geldkräfte in Überfluß, so sind doch Bibliotheken, Sammlungen von 
alten Denkmälern, botanische Gärten, anatomische, mineralogische und zoologische Kabinette unmöglich im Augenblicke herbeigeschafft; und wie könnte in unsern Tagen eine Universität mit Auszeichnung in die Schranken treten wollen, der es an diesen wesentlichen Attributen fehlte? Dies ist gewiß eine so einleuchtende Ursache, daß nach keiner andern weiter gesucht werden darf.

Wenn also nicht um irgend einer besondern Pracht und Herrlichkeit willen, sondern nur damit sie unmittelbar leben und rasch gedeihen könne, die Universität in Berlin wohnen soll: so scheinen die Maßregeln, die zu ergreifen sind, einander so untergeordnet werden zu müssen, daß man zunächst für alles dasjenige sorge, was der Universität zum selbständigen Dasein notwendig ist; dann darauf denke, wie die besondern Nachteile zu vermeiden sind, mit denen eben Berlin ihr vorzüglich droht, und nur erst nach diesem, und insofern dieses Nötigere nicht darunter leidet, dürfte man in Betrachtung ziehen, wie nun auch wiederum die besondern Vorteile, welche Berlin darbietet, recht zu benutzen wären.

Was das erste betrifft: so scheint zunächst schon die Art, wie die gesuchten notwendigen Hilfsmittel in Berlin vorhanden sind, der Unabhängigkeit der Universität nicht günstig zu sein, wenn man nicht durch Machtsprüche eingreifen will in die Ordnungen anderer Anstalten, und das würde ihr wiederum Haß zuziehen. Wo die Universität keinen andern Gebrauch zu machen hat, als der dem qualifizierten Publikum überhaupt verstattet ist, da ist sie in der Tat auch nur als eine Vermehrung desselben anzusehn, und die Sache hat keine Schwierigkeit. So müßten, was die Bibliothek betrifft, die Studierenden besondere Lesezimmer haben in dem Universitätsgebäude, und die Bücher von der Bibliothek allemal auf den Namen eines Professors oder der Universität überhaupt dorthin geholt werden. Nur müßte man freilich allmählich auf eine eigne Handbibliothek aus solchen Werken denken, nach denen die Nachfrage besonders häufig sein muß, und die doch auf der König- 
lichen Bibliothek für das übrige Publikum nicht fortdauernd können entbehrt werden. Bei andern Instituten könnte man es für die beste Auskunft halten, die gegenwärtigen Aufseher derselben zu Professoren ihrer Wissenschaft bei der Universität zu ernennen, und was könnte man in der Tat dieser Besseres wünschen, als einen Willdenow zu besitzen für die Botanik, und einen Karsten für die Mineralogie? Allein teils ist damit nicht für immer geholfen, wenn neben der Universität noch die Bergakademie bestehen soll, und das medizinisch-chirurgische Collegium; und es wären dadurch entweder der Universität oder diesen beiden Korporationen, die unter ganz anderer Aufsicht stehen und eine ganz andere Bestimmung haben, die Hände gebunden für die Zukunft; teils ist es dem echten Geist einer Universität zuwider, daß nur einer ausschließend befugt oder instand gesetzt sein soll, eine Wissenschaft zu lehren. Hier entsteht also die freilich schwierige, aber doch auch nicht unauflösliche Aufgabe, solche Instruktionen zu entwerfen und solche Garantien zu geben, daß die Universität nichts aufgeben müsse, was ihre Natur wesentlich erfordert, und doch auch in frühere bestimmte Rechte so wenig als möglich eingegriffen würde. Ähnliches würde vielleicht geschehen müssen in Absicht des anatomischen Kabinetts und der Tierarzneischule, wiewohl letztere sich wohl am leichtesten und vorteilhaftesten auf gewisse Weise mit der Universität vereinigen ließe.

Doch nicht nur in Beziehung auf die Hilfsmittel, sondern auch auf die Personen der Lehrer und Schüler, ist es eine Aufgabe, die leicht verfehlt werden kann, der Universität ihre Unabhängigkeit gleich anfangs zu sichern. Wenn man nämlich etwa das Personal der Lehrer, ich will nicht sagen ausschließend, aber doch größtenteils aus solchen Gelehrten zusammensetzen wollte, die bereits in andern Verhältnissen in Berlin leben: so würde es, wie vortrefflich auch die Männer sein mögen, mit dem freien Dasein der Universität nur schlecht bestellt sein. Es ist bekannt, wie gefangennehmend das Geschäftsleben ist, zumal ein genau ausgear- 
beitetes und spitzfindig eingerichtetes, und Gelehrte, die einmal in dieses eingelebt sind, werden immer ihre Anstellung bei der Universität nur als eine Nebensache ansehn, nicht viel anders als die Vorlesungen, welche sie schon jetzt $\mathrm{zu}$ halten gewohnt sind. Hiezu kommt, daß sie durch ihre andern Geschäfte mit der Zeit beschränkt sind auf eine Weise, die mit der natürlichen Ordnung der studierenden Jünglinge nicht wohl vereinbar ist. Dasselbe gilt von denen, welche auf höheren oder besonderen Schulen als Lehrer angesetzt sind, und diese müßten sich überdies noch zwei ganz verschiedene Methoden des Lehrens aneignen, was schwerer sein mag, als man glaubt. Von solchen Kollisionen darf die Universität nicht abhängen; und überhaupt, wäre sie für die meisten Lehrer nur eine Nebensache, so würde sie es bald auch für die Schüler sein; sie würde trotz alles Vortrefflichen, was sie in sich vereinigte, nur wenig Vertrauen finden und auch wenig verdienen, weil sie bald gewissen administrativen Kollegien gleichen würde, in denen es auch nie an vortrefflichen Männern gefehlt, über die man doch aber immer geklagt hat, eben weil sie für alle diese Männer nur eine Nebensache waren. Gewiß ist es durchaus notwendig, Lehrer anzusetzen, welche kein anderes als gelehrtes Geschäft treiben, und auch nicht nötig haben, sich um ein anderes, am wenigsten administratives, $\mathrm{zu}$ bewerben, und welche zugleich schon als Universitätslehrer Übung und Ansehn haben, und zwar in solcher Anzahl, daß das Wesentliche in jeder Fakultät durch sie allein könnte gedeckt werden; und nur in diesem Fall wird man sagen können, daß die Universität auf festen Füßen steht. Endlich darf die Universität auch nicht, und zwar unter den gegenwärtigen Umständen am wenigsten, abhängen von der Wohlhabenheit der Eltern, welche glauben, ihre Söhne für einen Aufenthalt in Berlin hinreichend versorgen zu können. Auf diesem Wege würde man nur eine kleine Anzahl zierlicher und vornehmer, oder üppigreicher und lockerer Studierenden bekommen, deren größter Teil den Lehrern, welche es mit der Wissenschaft redlich meinten, eben nicht viel Lust und Liebe einflößen würden. Noch keine Uni- 
versität hat ohne einen Unterstützungsfonds bestanden, und ein solcher müßte vorzüglich für Berlin herbeigeschafft werden. Würde er nach den oben aufgestellten Grundsätzen verwaltet: so würde die Besorgnis wegfallen, daß durch Unterstützungen nur ungeschickte und unerzogene Arme herbeigelockt würden. Besonders zweckmäßig aber wäre es für Berlin, wenn alle Unterstützungen nicht sowohl in barem Gelde beständen, als in unentgeltlicher und zugleich ehrenvoller Darreichung wesentlicher Bedürfnisse, Wohnung, Speisung, Heizung. Dadurch würde auch am leichtesten der Privatreichtum angelockt werden, zu diesen Unterstützungen beizutragen. Allein nicht nur für das wahre Bedürfnis muß gesorgt werden, sondern auch für die großenteils ungegründete Furcht der Auswärtigen vor einer unmäßigen Teurung in Berlin muß etwas geschehen. Viel tut freilich schon die Hoffnung, daß jeder Fleißigste und nicht nur der Ärmste an den öffentlichen Unterstützungen Anteil nehmen kann. Dann sorge man dafür, daß unter öffentlicher Autorität wenigstens für den Anfang einige Personen die Vermittlung zwischen den Studierenden und den Hausbesitzern und Speisewirten übernehmen, billige Kontrakte abschließen, und die verschiedenen Preise, welche sie halten können, gehörig bekannt machen, damit jeder die Sicherheit habe, bald und leicht zu finden, was seinen Vermögensumständen angemessen ist. Auch dieses muß man noch verhüten, daß nicht zu sehr überhandnehme das Unterrichterteilen der Studierenden, um sich Erleichterung zu verschaffen. Dies ist freilich in Berlin verderblicher als anderswo. Am besten aber geschähe dies durch Vorkehrungen, die nicht von der Universität ausgehen müßten, sondern von der Behörde, welcher die Aufsicht über den Unterricht überhaupt obliegt.

Wie dieses schon eine Zerstreuung ist: so möchte man im allgemeinen die mannigfaltigen Gelegenheiten zu Zerstreuungen aller Art obenanstellen unter den Nachteilen, die in Berlin vorzüglich $\mathrm{zu}$ befürchten sind. Auch hiemit möchte es aber so arg nicht sein, 
als man glauben will. Das Sehenswürdige der Stadt selbst und ihrer Umgebungen, und alles, was man unter dem Namen der Merkwürdigkeiten begreift, ist nur gefährlich durch die Neuheit, also nur für die erste Zeit, und es gibt gewiß keine Universität, wo nicht den meisten über solchen Neuigkeiten ein Teil von dieser verloren ginge. Natürlich wird sich auch die Universität in einem Teile, und wahrscheinlich nicht in der glänzendsten Mitte der Stadt zusammendrängen, und der Fleißige leichter, was in den übrigen vorgeht, ignorieren können. Von allen Ergötzungen aber und Lustbarkeiten, welche ebenso viel Aufwand fordern, als sie Zeit kosten, die theatralischen und musikalischen Darstellungen an der Spitze von diesen, ist eben des Aufwandes wegen wenig zu besorgen. Wenn nur der Studierende außer stand gesetzt ist, seine notwendigen Bedürfnisse fortdauernd unbezahlt zu lassen und den größten Teil seiner Zuschüsse an dergleichen Vergnügungen zu verwenden, so wird er bald auf ein für seine Zeit gar leidliches Maß gebracht sein. Und dies ist gewiß zu erreichen, wenn nur die Gesetze über das Kreditwesen der Minderjährigen wirklich in Anwendung gebracht werden. Dies ist in der Tat in Berlin leichter als anderswo, weil keine Klasse von Bürgern genötigt sein wird, fast ganz von den Studierenden zu leben und also um ihre Gunst zu buhlen. Auch werden schon alle diejenigen jungen Leute sich mehr vor nicht ganz ehrenvollen Schulden hüten, die nun beim Abgang von der Universität ihren Gläubigern nicht entgehen, sondern in Berlin bleiben, um dort ihre erste Anstellung zu suchen, und dadurch wird bald eine ernstere Ansicht von dieser Sache herrschend werden. Nur daß man ja nicht auf den unseligen Gedanken einer Zahlungskommission komme! Doch man hat ja wohl gesehn, wie wenig Eingang, allen eingezogenen Nachrichten zufolge, sie anderwärts gefunden und wie noch viel weniger sie ausgerichtet hat. Auch ist nichts in der Welt dem Wesen einer Universität mehr zuwider. Soll die Bildung des Charakters mit der des wissenschaftlichen Geistes gleichmäßig fortschreiten; soll der Jüngling sich in dem Maß und Verhältnis seiner Neigungen 
kennen lernen: so muß er Freiheit haben, auch in seinen Ausgaben jetzt dieses, jetzt ein ganz entgegengesetztes Verhältnis einzuführen; er muß die Bequemlichkeiten sowohl, als die Gefahren der Ordnung wie der Unordnung und was sonst hierher gehört, kennen lernen, damit, wenn er ins tätige Leben tritt, er nicht erfahrungslos erscheine, sondern als ein gemachter Mann, der auch über seine eigene Lebensweise sicher ist. Diese Freiheit ist notwendig, Mißbrauch im einzelnen wird immer stattfinden; aber den gibt es ja auch in den späteren Perioden des Lebens, und übel wäre uns geraten, und schlecht wäre es um die Regierung jeder Angelegenheit bestellt, wenn uns nichts übrig bliebe, als um des Mißbrauchs willen dem unentbehrlichsten Gut zu entsagen. Sollte unsre Gesetzgebung und Polizei noch nirgends so weit gediehen sein, daß man ihr die reine Aufgabe vorlegen dürfte, den Mißbrauch möglichst einzuschränken ohne die Aufopferung wesentlicher Vorteile?

Dasselbige gilt auch wohl von den Ausschweifungen vorzüglich des Geschlechtstriebes und der Spielsucht, von welchen man unsägliches Unheil fürchtet für eine Universität, die in Berlin wäre. Freilich gefährliche Klippen! allein wohl nicht viel gefährlicher in Berlin als an jedem andern Orte. Es werden immer, solange Berlin eine Hauptstadt bleibt und seinen ehemaligen Charakter nicht ganz verleugnet, viele junge Leute sich dort aufhalten, die reicher sind und mehr üppige Verwöhnungen haben als die Studierenden, und daher werden auch diejenigen Klassen, welche von der Sittenlosigkeit der Jugend leben, ihre Nachstellungen mehr auf jene richten, als auf diese. Dagegen in kleineren Städten die Studenten fast die einzige Jugend sind, welche in Betracht kommt, und alle Künste der Verführung ausschließend gegen sie gerichtet werden; ein Umstand, durch welchen jener Unterschied reichlich aufgewogen wird; wie denn in einer Residenz freilich alles Böse glänzender und verführerischer ist als an andern Orten, aber auch zumal, was von dieser Art das Ausgesuchteste ist und das Glän- 
zendste, die Geldkräfte eines Studenten, der seiner Natur nach überall Liberalität übt, gar bald übersteigt. Daher scheint in dieser Hinsicht nur zweierlei notwendig zu sein. Einmal, daß die Wachsamkeit der Polizei gegen alle Anstalten der Verführung geschärft werde, daß sie sich es z. B. zum Gesetz mache, welches gar nicht ausgesprochen werden darf, ihr sonst so oft vernachlässigtes Recht gegen Spielhäuser mit der größten Strenge auszuüben, sobald Studenten darin angetroffen werden; daß ferner bekannt gemacht würde, Klagen in Unzuchtssachen sollten gegen eine gewisse Klasse junger Leute, unter welche sich die Studenten ganz natürlich subsumieren müßten, gar nicht angenommen werden, und was für ähnliche gute Maßregeln sich sonst nehmen ließen. Dann aber auch müßte alles mögliche geschehen, um die Studenten vor niedrigen Arten des Umganges und der Vergnügungen zu bewahren, und strenge Ehrbegriffe auch in dieser Hinsicht unter ihnen aufrecht zu erhalten. Denn freilich in dem Maß, als sie sich mit dem Niedrigen auf dem Gebiete des Umganges und der Vergnügungen behelfen müßten, würden sie auch den niedrigsten Arten der Verführung preisgegeben und dann sicher verloren sein.

Beide Vorschläge hängen zusammen mit zwei wichtigen Fragen, die wir nicht ganz unerörtert lassen können; die eine ist die: unter welcher Obrigkeit sollen die Studenten stehen? die andre die: wie sollen sie in der Gesellschaft angesehen werden? Was die erste betrifft: so ist wohl jetzt niemand, der nicht die Unzweckmäßigkeit der eigenen Universitätsgerichte einsähe, und man kann sagen, daß sie auf preußischen Universitäten schon seit langer Zeit vorzüglich ist gefühlt worden. Es würde hier zu weit führen, die Sache historisch zu beleuchten, und zu zeigen, wie weit die gegenwärtigen Umstände von denen unterschieden sind, unter welchen diese Einrichtung ursprünglich ist getroffen worden. Auf der andern Seite muß es allerdings ein Mittel geben, gefährliche Subjekte zu warnen und sogar zu entfernen, wenn sie auch noch nichts begangen haben, was eine so strenge Ahn- 
dung von seiten gewöhnlicher Gerichtshöfe veranlassen könnte. Daher scheint man beides verbinden zu müssen. Die Studenten seien in allem, was sich zu einer gerichtlichen Klage qualifiziert, der gewöhnlichen Obrigkeit unterworfen; aber es gebe zugleich eine disziplinarische Kommission, aus den Vorstehern der Universität zusammengesetzt, welche nicht nur als Polizeimaßregel mancherlei Strafen, nicht ausgeschlossen die Entfernung der Studenten von der Universität, ausschließend verfügen könne, sondern an welche auch die Obrigkeit angewiesen sein muß, Klagesachen gewisser Art, nachdem sie sie gehörig eingeleitet, immer zurückzuweisen, und dann unter ihre Autorität die Entscheidung der Kommission zu publizieren und auszuführen. Wer diese Maßregel genauer durchdenkt, wird sehn, wie durch sie eine Menge von Schwierigkeiten bei weitem am leichtesten gehoben werden. Nur solange noch ein mehrfacher Gerichtsstand besteht, darf die Obrigkeit der Studenten keine andere sein als die der sogenannten Eximierten. Sie ist die Obrigkeit ihrer Lehrer, und größtenteils das Forum des Standes, dem sie entgegengehn. Ja schon deshalb kann es nicht anders sein, weil man doch den Adligen unter ihnen dies Vorrecht nicht streitig machen könnte, und unter den Studenten selbst alle Spuren von Unterschied des Standes soviel möglich müssen vertilgt werden.

Was aber die zweite Frage betrifft über die Gesellschaftsverhältnisse der Studierenden: so kann freilich weniger die Rede davon sein, was geschehen solle, als was wahrscheinlich geschehen werde, und nach welcher Seite hin man demgemäß die öffentliche Meinung müsse zu lenken suchen. Viele besorgen, der Student werde sich sehr zurückgesetzt fühlen in Berlin, und als ein armseliges, ganz unbedeutendes Wesen erscheinen, und das wäre allerdings ein großer Nachteil. Allein wird nicht jeder bessere Lehrer es sich zur Pflicht machen, seine ausgezeichneteren Schüler in seinen gesellschaftlichen Kreis zu ziehen und ihnen auch dadurch seine Achtung und seine nähere Teilnahme zu beweisen? 
Werden nicht sehr viele empfohlen sein an Bekannte des väterlichen Hauses? Für alle diese wäre gesorgt genug in dieser Hinsicht, und vielmehr bei der großen gesellschaftlichen Leichtigkeit Berlins nur zu befürchten, daß sich hieran schon zuviel gesellschaftliche Zerstreuungen anknüpfen möchten, und daß durch $\mathrm{zu}$ vielfaches und frühes Schmiegen in die gesellschaftlichen Verhältnisse und die eingeführten Sitten der Charakter der studentischen Freiheit verschwinden und die wohltätigen Einflüsse derselben verloren gehen möchten. Auf der andern Seite wäre dies gesellschaftliche Verkehr freilich nicht allgemein; die so Vorgezogenen würden leicht von ihren Genossen zu weit entfernt, und die Zurückgesetzten eben dadurch genötigt, sich entweder ganz zu isolieren, oder sich Gesellschaften von untergeordneter, niedriger Art aufzusuchen. Darum wäre es in Berlin ganz notwendig, auch wieder das Untersichsein der Studenten, wo der eigene und freie Stil des Lebens seinen Platz hat, und ihren eigenen Gemeingeist zu befördern, notwendig, sie fühlen zu lassen, daß sie schon als Studenten, als diejenigen, auf denen die wichtigsten Hoffnungen des Vaterlandes ruhen, eines Grades von öffentlicher Achtung und Aufmerksamkeit genießen, deren sie sich nicht unwürdig machen dürfen, und deshalb zweckmäßig, daß man die landschaftlichen Verbindungen, welche sich um so zuverlässiger bilden werden, als das Ganze den Charakter der Universität trägt und als die gymnastischen Übungen an der Tagesordnung sind, mit Klugheit dulde und leite, daß man nicht jede Art, sich äußerlich auszuzeichnen, verbiete, und daß man erlaube, daß bei gewissen Gelegenheiten die Studenten als Korporation öffentlich auf eine ehrenvolle Art erscheinen und repräsentieren dürfen. Auf solche Weise wird man am besten ihr ganzes Verhältnis zur übrigen Gesellschaft in die rechte Temperatur setzen.

Indem auf diese Weise der eigentümliche Geist der Universität und die notwendige Freiheit der Studierenden beschützt und erhalten werden, verschwinden zugleich zum Teil wenigstens die üb- 
len Folgen davon, daß immer ein ansehnlicher Teil der Jünglinge seinen Aufenthalt nicht verändert und auf der Universität wie auf der Schule dem elterlichen Hause einverleibt bleibt. Denn um an der Achtung, welche die Korporation genießt, teilzunehmen, werden sie sich zu dieser halten müssen, indem der leichte Spott über diejenigen, die sich ausschließend auch in der Universitätsperiode an die Familie halten wollen, von dem echten Studentensinn, wenn er sich frei entwickeln darf, unzertrennlich ist. Auch die Verwandlung der öffentlichen Unterstützungen in Speisung und Behausung wird einiges beitragen, um Einzelne aus dem beschränkten Familienleben herauszureißen, und darum sollte man vorzüglich auch allen für Berliner bestimmten Benefizien diese Einrichtung geben.

Sind nun im allgemeinen die ursprünglichen Einrichtungen in dem Sinne festgesetzt, um das unabhängige Bestehen der Universität zu sichern und die nachteiligen Verhältnisse, die in Berlin für sie eintreten, möglichst zu beschränken: dann erst und wenn sich das Wesentliche so bewährt hat, kann man fragen, wie nun auch die besondern Vorteile, welche Berlin darbietet, möglichst können benutzt werden.

Zuerst ist unstreitig Berlin der Ort, an welchem sich auch in $\mathrm{Zu}$ kunft die Universität am vortrefflichsten mit Dozenten versorgen kann, mit Ausnahme des eigentlich spekulativen Faches, für welches man wahrscheinlich immer am besten tun wird, sie von auswärts zu holen. Was aber die übrigen Zweige betrifft, so ist oben auseinandergesetzt worden, wie bei manchem, der seine erste wissenschaftliche Bildung vollendet hat, unentschieden sein kann, ob er mehr Talent und Neigung habe, seine Einsicht und Gesinnung in der Verwaltung des Staates geltend zu machen, oder auf dem Lehrstuhl. Anderwärts muß dies oft übereilt oder nach bloß äußeren Beziehungen entschieden werden; und ist die Wahl einmal gemacht, so ist sie meistenteils unwiderruflich. An einem Orte 
hingegen, welcher beides, das Zentrum der Verwaltung und die Universität, in sich faßt, hat jeder Gelegenheit, sich hinreichend zu prüfen; er kann sich beide Schranken öffnen lassen, und sich so lange in beiden versuchen, bis der innere Zwiespalt ihm selbst überzeugend entschieden ist, und sich das eine Talent bedeutend über das andere herausgehoben hat. Ja auch die kürzesten Blüten der Lehrgabe dürfen an einem solchen Ort nicht verloren gehen; sondern in wem sich, wenn er einmal wissenschaftlich durchdrungen ist, vielleicht mitten in den Geschäften der Verwaltung irgend eine eigentümliche Ansicht so weit entwickelt hat, daß er fühlt, er könne eine klare, durchgreifende, aufregende Darstellung davon geben; oder wer in seinen wissenschaftlichen Nebenstunden irgend einen einzelnen Zweig einer Wissenschaft mit Gründlichkeit und mit solchem Erfolg getrieben hat, daß er glaubt durch seine Entdeckungen oder seine eigentümliche Methode auf dem Katheder nützlich zu werden, der kann es besteigen. Ebenso haben wir gesehen, wie gar oft, besonders bei denen, die als Lehrer auf der geschichtlichen Seite der Wissenschaft stehen, wenn das vergängliche Talent des eigentlichen, für die Universität gehörigen Lehrens zu verblühen anfängt, die Neigung zur praktischen und politischen Anwendung der Wissenschaft wieder die Oberhand gewinnt. Nirgends läßt sich nun dieser natürlichen Umwandlung milder und leichter entgegenkommen durch einen allmählichen Übergang, als in der Hauptstadt, so daß auf der einen Seite auch noch die letzten Äußerungen der Lehrgabe genutzt werden können, und auf der andern keiner, dessen Lust und Kraft nicht mehr der Universität gehört, ihr, weil er seine rechte Stelle nicht finden kann, eine unnütze Last sei. Aber freilich wird dieser Vorteil nur in dem Maß erreicht werden können, als der Staat das Vertrauen hat, daß, wer in der Wissenschaft gelebt hat und von Ideen durchdrungen ist, auch die notwendigen empirischen Einzelheiten schnell auffassen, sich leicht in die Kenntnis der Sachen versetzen, und durch ein höheres Talent die Länge der Dienstzeit ersetzen kann; nur in dem Maß, als er in der Organisation seiner ganzen Verwal- 
tung den wesentlichen Unterschied zwischen dem kleinen Dienst und dem großen stärker hervortreten läßt als bisher; und nur in dem Maß, als gleich die Erteilung der gelehrten Würden, als der unentbehrlichen Qualifikation sowohl für einen angehenden Universitätslehrer, als für einen, der in den großen Staatsdienst treten will, auf einen solchen Fuß gesetzt wird, daß sie wieder allgemeinen Kredit gewinnen, und das Vorurteil keine Nahrung findet, daß, wer sich mit ihnen befasse, dadurch zugleich seine Unfähigkeit und Unlust zu Geschäften bekunde. Dann könnte eine Universität in Berlin vor allen andern den Vorzug haben, immer lauter frische, kräftige, lehrlustige und in dem rechten Verhältnis zur studierenden Jugend stehende Lehrer zu besitzen.

Nächstdem kann sie sich auch auszeichnen durch einen Reichtum an Lehrern auch für das Besonderste und für die vom Mittelpunkt der Erkenntnis am weitesten entfernten technischen Disziplinen. Man denke hiebei zunächst an die schon in Berlin bestehenden Spezialschulen, die chirurgische Schule, die Bauschule, die Bergwerksschule; denn Akademien wünschten wir sie nicht nennen zu müssen, wo Unterricht bis ins kleinste des äußern Apparats und der Hilfsfertigkeiten für einzelne Wissenschaften erteilt wird, Unterricht, welcher eigentlich auch dem Studierenden offen stehn muß, damit er selbst seine äußerlichsten Talente versuchen und verhältnismäßig ausbilden kann, und auch die äußerliche Seite des wissenschaftlichen Gebietes kennen lernt. Auf eine mehr zufällige und unsichere Weise könnten diese Anstalten der Universität nützlich werden, wenn nur die bei ihnen angesetzten Lehrer Erlaubnis erhielten, die wesentlichen Disziplinen ihrer Anstalt auch bei der Universität vorzutragen. Vielleicht aber könnte noch etwas Größeres ausgerichtet werden, wenn man die Anstalten selbst auf eine gewisse Weise mit der Universität vereinigte. Jetzt haben sie ein gar besonderes Ansehn. Neben dem Fach, welchem sie zunächst gewidmet sind, haben sie noch Lehrer in allgemeinen Wissenschaften, die mit jenem zunächst zusammenhängen, was 
sich in der Nähe der Universität hernach wunderlich ausnehmen wird. Man sollte sie vielleicht in zwei Teile teilen; der eine wäre die Schule, und bearbeitete diejenigen, welche sich diesem Fach gewidmet haben, ohne nach wissenschaftlicher Bildung zu streben. Der andere, höhere würde mit der Universität vereinigt; die Zöglinge wären Studenten in vollem Sinn, die Lehrer Professoren, und der Unterricht ganz in den der Universität aufgenommen. Die niedere Klasse könnte ebenso mit den gelehrten Schulen in Verbindung gesetzt werden, und diese mit der Universität selbst durch solche Mittelglieder in eine nähere Gemeinschaft treten, so daß beide, ohne von ihrer Eigentümlichkeit etwas aufzugeben, doch auch wieder als ein Ganzes anzusehn wären, und die Hauptstadt auch hierin das bestimmteste sinnliche Bild von dem Einssein aller Teile im Ganzen aufstellte.

Dasselbige könnte endlich auf der andern Seite auch geschehen in Beziehung auf die Akademie der Wissenschaften. Zwischen dieser und der Universität gibt es, wie wir schon gesehen haben, eine natürliche Gemeinschaft; der Universitätslehrer arbeitet sich allmählich in die Akademie hinüber, und ein großer Teil der Akademiker hat immer noch Zeiten, wo es ihn drängt, im Einzelnen die Funktionen eines Universitätslehrers zu versehen. Diese Gemeinschaft könnte hier auf eine höchst wünschenswürdige Weise organisiert werden, ebenfalls ohne daß beide Anstalten äußerlich eins würden und aufhörten, das Eigentümliche ihres Zweckes und Wesens auf das bestimmteste auszusprechen, sondern nur so, daß durch die Einzelnen, welche mit Recht beiden angehören, für das Leben ein allmählicher Übergang stattfände und eine freundschaftliche Verbindung beider Anstalten, in welcher sich wiederum die Einheit der ganzen wissenschaftlichen Organisation sinnlich darstellte. Die Einflüsse, welche wir der Akademie und den Akademikern auch auf die Universität zugeschrieben haben, und ihre überall unbeschränkt zu erhaltende Freiheit, sich selbst zu erneuern, sichert hinlänglich gegen die wunderliche Ansicht, als würde dann 
die Akademie nur eine Versorgungsanstalt sein für abgelebte Professoren; vielmehr wird sie durchaus in der wissenschaftlichen Republik erscheinen als die ehrwürdige Versammlung der Ältesten. Nur muß auch die Universität, indem sie diese wie die vorige Verbindung sucht, nicht erscheinen, als täte sie es aus einseitigem Bedürfnis, als würde sie ohne diese Stützen ärmlich und unscheinbar sein, und als sollten zu ihrem Besten andere Anstalten von ihrer Selbständigkeit aufopfern. Vielmehr muß auch sie unabhängig auftreten und selbständig, und die Verbindung muß eine von beiden Teilen gewünschte Annäherung sein. Denn was abgerungen wird auf diesem Gebiet, ist sicher als unrechtes Gut nie gedeihlich. Darum, wenn man nicht alles verderben will, denke man doch ja anfänglich auf nichts anders, als nur eine Universität zu stiften, die soviel möglich für sich bestehe. Ja, um recht deutlich zu machen, daß es zunächst nicht die Hinsicht auf diese künftigen Vorteile ist, was die Universität nach Berlin bringt, sondern der Drang des Augenblickes: so erkläre man doch am liebsten, sie solle nur provisorisch in Berlin sein, und denke darauf, ihr Kräfte zu sammeln, damit sie alles, was ihr notwendig ist, eigen habe. Sieht man dann, daß die eigentümlichen Nachteile von Berlin sich nicht besiegen lassen: so werde man ja nicht geblendet durch die etwaigen Vorteile, sondern die Universität wandere, so bald sie kann. Es wird ja wohl nicht nötig sein, steht zu hoffen. Aber durch die Kundmachung dieses Entschlusses und die Anstalten, um ihn nötigenfalls zu realisieren, wird die Universität Vertrauen auf ihre Moralität gewinnen, und nach Maßgabe ihrer Unabhängigkeit wird sich auch die Stimmung bilden, durch welche sie sich in Besitz der letzt erwähnten Vorteile setzen kann. Und dann ist eine wissenschaftliche Organisation gegründet, die ihresgleichen nicht hat, und durch ihre innere Kraft sich ein weiteres Gebiet unterwerfen wird, als die jetzigen Grenzen des preußischen Staates bezeichnen, so daß Berlin der Mittelpunkt werden muß für alle wissenschaftlichen Tätigkeiten des nördlichen Deutschlandes, so weit es protestantisch ist, und die Bestimmung des preußischen 
Staates für die Zukunft von dieser Seite einen sichern und festen Grund gewinnet. Bei einer solchen Aussicht müssen ja wohl kleinliche Rücksichten und Besorgnisse verschwinden, und es bleibt nur zu wünschen, daß die Regierung, welche diesen Entwurf gefaßt hat, sich bald imstande fühle, ernstlich zur Ausführung zu schreiten. 